
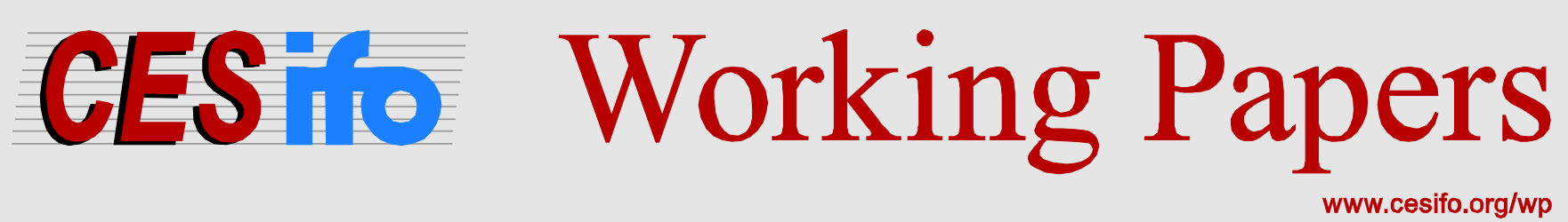

\title{
General Equilibrium Trade Policy Analysis with Structural Gravity
}

\author{
Mario Larch \\ Yoto V. Yotov \\ CESIFO WORKING PAPER NO. 6020 \\ CATEgory 8: TRADE POLICY \\ JULY 2016 \\ An electronic version of the paper may be downloaded \\ - from the SSRN website: \\ - from the RePEc website: \\ - from the CESifo website: \\ www.SSRN.com \\ Www.RePEc.org \\ www.CESifo-group.org/wp
}




\title{
General Equilibrium Trade Policy Analysis with Structural Gravity
}

\begin{abstract}
The objective of this manuscript is to serve as a practical guide for evaluation of the general equilibrium (GE) effects of trade policy using the structural gravity model. We try to achieve this objective in four steps. First, we focus on the original Armington-CES gravity model, as a representative framework for a large class of GE models, to offer a deep analysis of the structural relationships underlying the general equilibrium gravity system, and how they can be exploited to make trade policy inferences. Second, we present and discuss a series of indexes that can be used to summarize the GE effects of trade policy. Third, we summarize the standard procedures to perform counterfactual analysis with the gravity model, and we outline recent methods to obtain theory-consistent GE effects of trade policy with a simple estimation procedure that can be performed in any statistical software package capable of estimating a poisson model (e.g. Stata). Finally, we demonstrate how gravity can be integrated with a broader class of general equilibrium models by nesting the Armington-CES model within a dynamic production superstructure with capital accumulation.
\end{abstract}

JEL-Codes: F130, F140, F160.

Keywords: structural gravity, trade policy, general equilibrium analysis.

Mario Larch

Department of Law and Economics

University of Bayreuth

Universitätsstraße 30

Germany - 95447 Bayreuth

mario.larch@uni-bayreuth.de
Yoto V. Yotov

School of Economics

Drexel University

USA - Philadelphia, PA 19104

yotov@drexel.edu

July 14, 2016 
Disclaimer and Acknowledgements

This manuscript, along with a companion paper titled "Estimating Trade Policy Effects with Structural Gravity", are written in preparation to contribute to an extension of the "A Practical Guide to Trade Policy Analysis”, co-published by the World Trade Organization (WTO) and the United Nations Conference on Trade and Development (UNCTAD). As this is a working paper, it is still subject to changes and we welcome and will try to accommodate any useful comments and suggestions. We are indebted to Delina Agnosteva, Benedikt Heid, Joschka Wanner, and Thomas Zylkin for their careful reading and excellent comments on earlier versions of this document. We also thank James Anderson, Richard Barnett, Davin Chor, Gabriel Felbermayr, Russell Hillberry, Lou Jing, Ma Lin, Roberta Piermartini, Serge Shikher, Costas Syropoulos, Robert Teh, Mykyta Vesselovsky, and seminar and workshop participants at the ifo Institute, the World Trade Organization, the World Bank, the U.S. International Trade Commission, Global Affairs Canada, the University of Ottawa and the National University of Singapore for helpful suggestions and discussions. We also benefitted from the suggestions of the participants in the 2015 WTO Thematic Trade Policy Analysis course, and from the feedback of the graduate students who took the Gravity course module at Princeton University and at Drexel University in 2015 and 2016. Yotov thanks the researchers at the Economic Research and Statistics Division of the WTO and at the ifo Institute for their hospitality during his visits in 2014 and 2015, respectively, when parts of this work were completed. The views and opinions expressed in this document are solely those of the authors and do not necessarily reflect the official policy or position of any unit of WTO and/or UNCTAD. All errors are our own. 


\section{Contents}

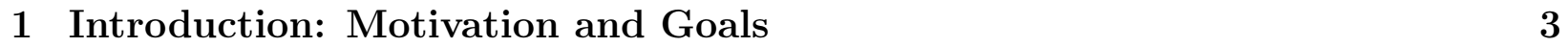

1.1 Why is Gravity so Popular? . . . . . . . . . . . . . . . . . . . . . . . . 3

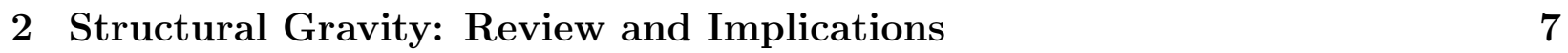

$2.1 \quad$ Evolution of Gravity Theory Over Time . . . . . . . . . . . . . . . . . . . . 7

2.2 Review of the Structural Gravity Model $\ldots . . . . . . . .8$

2.3 On the Beauty of the Multilateral Resistances . . . . . . . . . . . . . . . . . 12

2.4 On the GE Effects of Trade Policy: A Discussion . . . . . . . . . . . . . . . 15

2.5 Some Useful General Equilibrium Trade Cost Indexes . . . . . . . . . . . . 20

3 General Equilibrium Analysis with Structural Gravity 26

3.1 Performing Counterfactuals with the Gravity Model . . . . . . . . . . . . . 26

3.2 GE Trade Policy Analysis with Stata: GE PPML . . . . . . . . . . . . . . . 31

3.3 Estimating GE Trade Policy Effects: Applications . . . . . . . . . . . . . . . 35

3.3 .1 Trade Without Borders . . . . . . . . . . . . . . . . . . 36

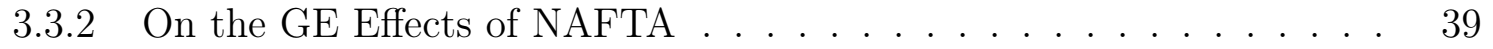

\begin{tabular}{|lll}
4 & Nested Gravity & 44
\end{tabular}

4.1 Growth and Trade: A Dynamic Gravity Framework . . . . . . . . . . . . . . 44

4.2 Growth and Trade: From Theory to Empirics . . . . . . . . . . . . . . . . . 48

4.3 Dynamic GE Trade Policy Analysis with Stata . . . . . . . . . . . . . . . . . 50

4.4 Dynamic Gravity with Intermediates . . . . . . . . . . . . . . . . . . 51

5 Boundless Gravity: Extensions and Conclusion 53

\begin{tabular}{ll}
\hline References & 55
\end{tabular}

\begin{tabular}{|cc}
\hline Tables and Figures & 63
\end{tabular}

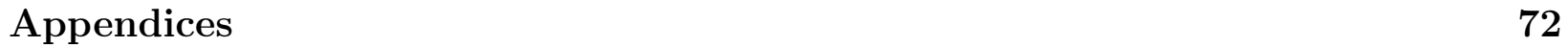




\section{Introduction: Motivation and Goals}

"Modelers must know general-equilibrium theory so that their models have a sound theoretical basis; they must know how to solve their models; they need to be able to program (or at least communicate with programmers); they must understand the policy issues on which they work; they have to know about data sources and all their associated problems; and they have to be conversant with relevant literature, especially that on elasticities." (p. 1047)

Shoven and Whalley (1984)

Often referred to as the workhorse in international trade, the gravity model is one of the most popular and successful frameworks in economics. Hundreds of papers have used the gravity equation to study and quantify the effects of various determinants of international trade 1 There are at least five compelling arguments that, in combination, may explain the remarkable success and popularity of the gravity model.

- First, the gravity model of trade is very intuitive. Using the metaphor of Newton's Law of Universal Gravitation, the gravity model of trade predicts that international trade (the gravitational force) between two countries (objects) is directly proportional to the product of their sizes (masses) and inversely proportional to the trade frictions (the square of distance) between them.

- Second, the gravity model of trade is a structural model with solid theoretical foundations. This makes the gravity framework particularly appropriate for counterfactual analysis, e.g. to quantify the effects of trade policy.

- Third, the gravity model represents a realistic general equilibrium environment that simultaneously accommodates multiple countries and multiple sectors. As such, the gravity framework can be used to capture the possibility that markets (sectors, countries, etc.) are linked and that trade policy changes in one market will trigger ripple effects in the rest of the world.

- Fourth, the gravity setting is a very flexible structure that can be integrated within a wide class of broader general equilibrium models in order to study the links between trade and labor markets, investment, the environment, etc.

- Finally, one of the most attractive properties of the gravity model is its predictive power. Empirical gravity equations of trade flows consistently deliver a remarkable fit of between 60 and 90 percent with aggregate data as well as with sectoral data for both goods and services.

\footnotetext{
${ }^{1}$ For example, the gravity model has been used to estimate the effects of Geography, Demographics, Regional Trade Agreements (RTAs), Tariffs, Exports Subsidies, Embargoes, Trade Sanctions, World Trade Organization membership, Currency Unions, Foreign Aid, Immigration, Foreign Direct Investment, Cultural Ties, Trust, Reputation, Mega Sporting Events (Olympic Games and World Cup), Melting Ice Caps, etc. on international trade.
} 
Capitalizing on the appealing properties of economic gravity, this paper and a companion complementary manuscript (Piermartini and Yotov, 2015) offer a comprehensive and balanced (between theory and empirics) approach to quantify the partial equilibrium and the general equilibrium effects of trade policy with the structural gravity model. The focus of Piermartini and Yotov (2015) is on the estimation of structural gravity equations and on the evaluation of the partial equilibrium effects of trade policy. The objective of the current manuscript is to serve as a practical guide for evaluation of the general equilibrium impact of trade policy. While we attempt to give credit to a large number of related studies and to offer general implications and analysis whenever possible, this monograph is not intended to be a survey of the related contemporary literature ${ }^{2}$ neither is it intended to be a review of the wide literature devoted to applied and computable general equilibrium (CGE) analysis $\mathrm{H}^{3}$

Instead, our main focus will be on the original Armington-CES gravity model, its evolution in the literature, and its practical use for general equilibrium (GE) analysis of trade policy. To the extent however, that the simple Armington-CES gravity structure represents a wider class of trade models (Arkolakis, Costinot and Rodríguez-Clare, 2012; Costinot and Rodríguez-Clare, 2014) many of the recommendations made here are quite general. In combination with the theory-consistent estimation recommendations from Piermartini and Yotov (2015), the tractable Armington-CES theory and the novel empirical developments presented here will help applied economists and practitioners to overcome the challenges to GE modeling from the introductory quote by Shoven and Whalley (1984) and will enable them to perform rigorous evaluation of the general equilibrium effects of various trade policies. Specifically, by focusing on the Armington gravity model, we aim to achieve five major objectives:

1. Offer deep analyses of the structural interpretations of the relationships underlying the general equilibrium (GE) gravity system, and how they can be exploited to make trade policy inferences.

2. Capitalize on the structural foundation of the gravity model to present and discuss a series of theory-consistent indexes that can be used to summarize, decompose, and aggregate the general equilibrium effects of trade policy.

3. Review the standard procedure to perform general equilibrium counterfactual analysis and adapt this procedures to perform GE experiments with the Armington-CES gravity model.

4. Review recent developments in the empirical gravity literature and describe novel econometric procedures that can be used to estimate theory-consistent general equi-

\footnotetext{
${ }^{2}$ The analysis in this manuscript complements the two excellent recent papers by Anderson (2011) and Costinot and Rodríguez-Clare (2014), which review the developments in the theoretical trade gravity literature from a broader perspective.

${ }^{3}$ We refer the interested reader to the following publications, which capture and are representative of the evolution of the CGE literature: Jones (1965), Dervis, de Melo and Robinson (1982), Shoven and Whalley (1984), Deardorff and Stern (1986), Shoven and Whalley|(1992), Amman, Kendrick and Rust|(1996), Dixon and Parmenter (1996), Hertel (1997), Francois and Reinert (1998), Ginsburgh and Keyzer (2002), and Gilbert and Tower (2012).
} 
librium effects of trade policy with the Armington-CES model, as a representative of a wider class of GE trade models, directly in standard software packages such as Stata $f^{4}$

5. Demonstrate how gravity can be integrated with a broader class of general equilibrium models and discuss opportunities for further developments and extensions.

In order to set the foundation for the analysis in subsequent sections, Section 2 starts with a review of the original Armington-CES gravity model as introduced by Anderson (1979) and popularized by Anderson and van Wincoop (2003) 5 After deriving structural gravity, we discuss six appealing properties of the multilateral resistances as the key vehicle to translate the partial equilibrium changes in trade costs into GE trade policy effects. Specifically, we present the multilateral resistances as: (i) intuitive, structural trade cost terms; (ii) theoryconsistent aggregates of bilateral trade costs; (iii) general equilibrium trade costs indexes, which (iv) decompose the incidence of trade costs on consumers and producers in the world, and (v) are straight-forward to construct. Finally, we note the (vi) the multilateral resistance indexes are appealing for practical purposes and we point to some of their uses. Then, we complement the theoretical developments in Section 2 with a discussion of the effects of a hypothetical trade liberalization scenario that demonstrates how a bilateral trade liberalization shock is transmitted via the multilateral resistances throughout the whole economic system. The section concludes with a presentation and discussion of several GE indexes that summarize the effects of trade policy and decompose their incidence on producers and consumers in the world. Later on, in Section 3, we demonstrate that all of the GE trade policy indexes that we discuss here can be recovered directly from the estimates of the fixed effects in structural gravity estimations.

Stimulated by the seminal work of Eaton and Kortum (2002) and Anderson and van Wincoop (2003), a series of recent papers offer counterfactual trade policy analysis that are based on models with solid microfoundations and tight connection to the data (Costinot and Rodríguez-Clare, 2014). The new generation of quantitative trade models take advantage of more and more readily available data (e.g. data on production and trade) for the economic system under investigation and they calibrate and/or estimate certain model components in order to recover behavioral parameters (e.g. various elasticities), which govern the system's response to shocks (e.g. the formation of a regional trade agreement). Similar to the standard approach in the macro literature and consistent with the traditional methods from the CGE literature, many studies rely on parameters obtained from previous work. Others follow a more structural approach and obtain own estimates of the key model parameters within the same theory-consistent framework. This approach allows for actual tests of the underlying theories, e.g. whether RTAs really promote bilateral trade, and delivers structural parameters from the same data that are used in the counterfactual experiments. Stimulated by

\footnotetext{
${ }^{4}$ All analysis presented in this paper can be replicated directly in Stata. Datasets and Stata codes are available upon request from the authors at mario.larch@uni-bayreuth.de and yotov@drexel.edu.

${ }^{5}$ In the Appendix, we follow Eaton and Kortum (2002) to also offer a derivation of structural gravity from the supply side, and we demonstrate that the demand-side and the supply-side approaches deliver the same structural gravity system. In addition, in the Appendix we also follow some recent efforts to accommodate sectors in the structural gravity framework (e.g. Egger, Larch and Staub, 2012, Larch and Wanner, 2014 Caliendo and Parro, 2015, Anderson and Yotov, 2016), and we derive and compare the sectoral structural gravity models on the demand side and on the supply side.
} 
the great predictive power of the gravity model, we will pursue the structural estimation approach whenever possible. In addition, however, we will discuss the hybrid approach of Anderson, Larch and Yotov (2015a) who estimate trade costs and trade costs elasticities, to which they add information contained in the gravity error term in order to construct a 'calibrated' trade cost matrix that matches the data perfectly.

Our goal in Section 3 is to outline a standard sequence of steps to perform general equilibrium counterfactual analysis and to adapt these procedures to perform experiments with the Armington-CES gravity model. In addition, we review the analysis from Anderson, Larch and Yotov $(2015 a)$ who capitalize on the properties of the Poisson Pseudo-MaximumLikelihood (PPML) estimator and develop a simple estimation procedure to perform theoryconsistent GE analysis in any statistical software package capable of estimating a poisson model (e.g. using the 'glm' or 'ppml' command in Stata). Two counterfactual experiments complement the theoretical developments in Section 3 and establish the empirical equivalence between the GE estimates that we obtain with the methods from Anderson, Larch and Yotov (2015a) and those from a standard, but computationally intensive, procedure that requires setting and solving the structural non-linear gravity system explicitly. In the first application, we follow Anderson, Larch and Yotov $(2015 a)$ and simulate the removal of existing international borders in the world. In the second counterfactual experiment we use NAFTA, as one of the most-studied trade agreements, in order to demonstrate how our procedures can be applied in a panel framework.

The objective of Section 4 is threefold. The first goal is instructional. Specifically, we want to demonstrate how the Armington gravity model can be integrated within a wider class of GE production models. Costinot and Rodríguez-Clare (2014) offer an excellent review of a large body of recent trade papers offering counterfactual analysis of the effects of various trade policies that are based on a variety of solid microfoundations and maintain tight connection to the data. In Section 4 we want to show how the key structural properties of the Armington model can be used to endogenize production and to conveniently switch the additional general equilibrium channels on and off in order to study the impact of trade policy. The second goal is methodological: We present and discuss dynamic gravity modeling. ${ }^{6}$ To do this, we review a recent contribution by Anderson, Larch and Yotov (2015b) who integrate Armington gravity with a dynamic production model that allows for capital accumulation within a tractable nested general equilibrium framework. The third goal is practical: We complement the theoretical developments in Section 3 and extend the general counterfactual procedures from Head and Mayer (2014) to accommodate dynamics. Importantly, we also discuss how the dynamic GE analysis presented here can be performed with standard statistical software packages such as Stata.

The remainder of this manuscript is organized as follows. Section 2 reviews the original gravity model, offers a discussion of the general equilibrium relationships that are captured by the model, and presents a series of GE indexes. Section 3 reviews the standard procedures to perform GE counterfactual experiments and demonstrates how to estimate the GE effects

${ }_{6}^{6}$ Head and Mayer (2014) identify dynamic gravity modeling as a key area for future work by noting that all existing micro-foundations of empirical models of trade flows (e.g. gravity) are static and pointing to the "econometric problem of how to handle the evolution of trade over time in response to changes in trade costs." (Head and Mayer 2014, p. 189). Similarly, the large body of trade models that are covered by Costinot and Rodríguez-Clare (2014) are also static. 
of trade policy (in Stata). Section 4 shows how gravity can be integrated with a broader class of general equilibrium models by nesting the Armington-CES model within a dynamic production superstructure with capital accumulation. Section 5 offers concluding remarks and discusses further extensions. Finally, the Appendix offers some complementary theoretical derivations and analysis including a derivation of structural gravity on the supply side, and an extension of the gravity system to the sectoral level.

\section{Structural Gravity: Review and Implications}

This section starts with a brief overview of the evolution of gravity theory over time. Next, we review the original (Armington-CES) version of the structural gravity model in order to set the foundation for the analysis in subsequent sections. After deriving structural gravity, we establish and discuss three properties of the multilateral resistances as a vehicle to translate the partial equilibrium changes in trade costs into GE trade policy effects. We then complement our theoretical developments with a discussion of the effects of hypothetical bilateral trade liberalization scenarios. The section concludes with a presentation of several GE indexes that summarize the effects of trade policy and decompose their incidence on the producers and on the consumers in the world.

\subsection{Evolution of Gravity Theory Over Time}

The initial applications of Newton's Law of Gravitation to economics are a-theoretical. Prominent examples include Ravenstein (1889), who used gravity to study immigration, and Tinbergen (1962) who applied gravity to study trade flows. Anderson (1979) is the first to offer a theoretical economic foundation for the gravity equation under the assumptions of product differentiation by place of origin (Armington, 1969) and Constant Elasticity of Substitution (CES) expenditures. Another early contribution to gravity theory is Bergstrand (1985). Despite these theoretical developments and its solid empirical performance, the gravity model of trade struggled to make much impact in the profession until the late 90s and early 2000s (Leamer and Levinsohn, 1995, Deardorff, 1998). Arguably, the most influential structural gravity theories in economics are those of Eaton and Kortum (2002), who derive gravity on the supply side as a Ricardian structure with intermediate goods, and Anderson and van Wincoop (2003), who popularize the Armington-CES model of Anderson (1979) and emphasize the importance of the general equilibrium effects of trade costs. The academic interest in the gravity model was recently stimulated by the influential work of Arkolakis, Costinot and Rodríguez-Clare (2012) who demonstrate that a large class of models generate isomorphic gravity equations and who argue that the gains from trade are invariant to a series of alternative microfoundations including perfect competition, e.g. Eaton and Kortum (2002), monopolistic competition, e.g. Krugman (1980), entry of heterogeneous firms and selection into markets, e.g. Chaney (2008) and Helpman, Melitz and Rubinstein (2008). Most recently, Allen, Arkolakis and Takahashi (2014) establish the universal power of gravity by deriving sufficient conditions for the existence and uniqueness of the trade equilibrium for a 
wide class of general equilibrium trade models.7

\subsection{Review of the Structural Gravity Model}

One of the main advantages of the structural gravity model is that it delivers a tractable framework for trade policy analysis in a multi-country environment. Accordingly, we will consider a world that consists of $N$ countries, where each economy produces a variety of goods, i.e. goods are differentiated by place of origin (Armington, 1969), that is traded with the rest of the world. The supply of each good is fixed to $\left.Q_{i}\right]^{8}$ and the factory-gate price for each variety is $p_{i}$. Thus, the value of domestic production in a representative economy is defined as $Y_{i}=p_{i} Q_{i}$. $Y_{i}$ is also the nominal income in country $i$. Country $i$ 's aggregate expenditure is denoted by $E_{i}$. Aggregate expenditure can be expressed in terms of nominal income by $E_{i}=\phi_{i} Y_{i}$, where $\phi_{i}>1$ shows that country $i$ runs a trade deficit, while $1>\phi_{i}>0$ reflects that country $i$ runs a trade surplus. Similar to Dekle, Eaton and Kortum (2007, 2008), we treat trade deficits and surpluses as exogenous.

On the demand side, consumer preferences are assumed to be homothetic, identical across countries, and approximated by a Constant Elasticity of Substitution (CES) utility function for country $j: 9$

$$
\left\{\sum_{i} \beta_{i} \frac{1-\sigma}{\sigma} c_{i j}\right\}^{\frac{\sigma-1}{\sigma}},
$$

where $\sigma>1$ is the elasticity of substitution among different varieties, i.e. goods from different countries ${ }^{10} \beta_{i}>0$ is the CES preference parameter, ${ }^{11}$ and $c_{i j}$ denotes consumption of varieties from country $i$ in country $j$.

\footnotetext{
${ }^{7}$ We refer the reader to Anderson (2011), Arkolakis, Costinot and Rodríguez-Clare (2012) and Costinot and Rodríguez-Clare (2014) for excellent surveys of the evolution of the theoretical gravity literature and the alternative microfoundations of structural gravity. Baldwin and Taglioni (2006), Head and Mayer (2014), and Piermartini and Yotov (2015) offer informative discussions of the data and econometric challenges with gravity estimations.

${ }^{8}$ We relax the endowment economy assumption in Section 4 , where we demonstrate how the gravity model can be nested into a dynamic general equilibrium production structure with capital accumulation and we discuss further extensions. In addition, as noted earlier, in the Appendix, we follow Eaton and Kortum (2002) to obtain gravity from the supply side. We also derive sectoral structural gravity models on the demand side and on the supply side.

${ }^{9}$ The CES utility function assumption is widely used in the existing gravity literature. Anderson and Neary (2005) discuss the implications of more general, non-homothetic preferences. Recent attempts to depart from CES, while preserving the key properties of the structural gravity model, include Novy $(2013 b)$, Behrens et al. (2014), and Arkolakis et al. (2015), who also provide an informative review of the main alternatives to CES utility functions that have been used in the trade literature.

${ }^{10}$ As emphasized by Costinot and Rodríguez-Clare (2014), the trade elasticity is "the single most important structural parameter in gravity models" (Costinot and Rodríguez-Clare, 2014, p. 39). The relationship between the elasticity of substitution $\sigma$ from the Armington-CES framework and the trade elasticity from Costinot and Rodríguez-Clare (2014) is that the latter is equal to $1-\sigma$. Thus, in principle, one can use the terms "elasticity of substitution" and "trade elasticity" interchangeably. However, the formal difference should be clear and we attempt to use proper terminology in this manuscript by referring to $\sigma$ exclusively as the 'elasticity of substitution'.

${ }^{11}$ Throughout our analysis, $\beta_{i}$ will remain treated as an exogenous taste parameter. However, $\beta_{i}$ can bear different interpretations depending on the underlying microfoundations of the structural gravity setting. For example, it can be thought of as an embedded country-specific technology in production that enables some
} 
Consumers maximize (1) subject to the following standard budget constraint:

$$
\sum_{i} p_{i j} c_{i j}=E_{j} .
$$

Equation (2) ensures that the total expenditure in country $j, E_{j}$, is equal to the total spending on varieties from all countries, including $j$, at delivered prices $p_{i j}=p_{i} t_{i j}$, which are defined conveniently as a function of factory-gate prices in the country of origin, $p_{i}$, marked up by bilateral trade costs, $t_{i j} \geq 1$, between trading partners $i$ and $j$. Throughout the analysis in this paper, we retain the standard (due to Samuelson, 1952) treatment of bilateral trade costs in the trade literature as iceberg costs: In order to deliver one unit of its variety to country $j$, country $i$ must ship $t_{i j} \geq 1$ units, i.e. $1 / t_{i j}$ of the initial shipment melts en route. While the Armington model presumes that all bilateral trade costs are variable, in principle, structural gravity can also accommodate fixed trade costs, à la Melitz (2003) as well. See for example Arkolakis et al. (2008) and Egger and Larch (2011). The iceberg trade costs metaphor can also be extended to accommodate fixed costs with the interpretation that "a chunk of the iceberg breaks off as it parts from the mother glacier", (Anderson, 2011).

Solving the consumer's optimization problem yields the expenditures on goods shipped from origin $i$ to destination $j$ as:

$$
X_{i j}=\left(\frac{\beta_{i} p_{i} t_{i j}}{P_{j}}\right)^{(1-\sigma)} E_{j},
$$

where, for now,

$$
P_{j}=\left[\sum_{i}\left(\beta_{i} p_{i} t_{i j}\right)^{1-\sigma}\right]^{1 /(1-\sigma)}
$$

has the standard interpretation as a CES consumer price index. Given that the elasticity of substitution is greater than one, $\sigma>1$, Equation (3) captures several intuitive relationships. First, expenditure in country $j$ on goods from source $i, X_{i j}$, are proportional to total expenditure, $E_{j}$, in destination $j$. The simple intuition is that, all else equal, larger/richer markets consume more of all varieties, including goods from $i$. Second, $X_{i j}$ is inversely related to the (delivered) prices of varieties from $i$ to $j, p_{i j}=p_{i} t_{i j}$. This is a direct reflection of the law of demand. Note however, that a low factory-gate price $p_{i}$ plays only a partial role in this relationship. The other important component is the bilateral trade cost $t_{i j}$ between partners $i$ and $j$. The ideal combination that favors bilateral trade is an efficient producer, i.e. low factory-gate price, and a low bilateral trade cost between $i$ and $j{ }^{12}$ Third, expenditure on varieties from $i$ in $j$ is directly related to the CES price aggregator $P_{j}$. This relationship reflects the substitution effects across varieties from different countries. All else equal, the

countries to produce more desirable varieties than others. We refer the reader to Hillberry et al. (2005) for an insightful discussion and analysis of the importance of the preference parameters for calibration results in the Armington gravity model.

${ }^{12}$ We will exploit the fact that the delivered price is a combination of the factory-gate price and bilateral trade costs in the general equilibrium analysis and indexes that we present below. Specifically, we will define and identify general equilibrium effects of changes in trade costs at constant factory gate prices. 
relatively more expensive the rest of the varieties in the world are, the more consumers in $j$ will substitute away from them and toward the goods from $i$. Finally, the magnitude of the response of bilateral expenditure to changes in the factory-gate prices or in the aggregate CES prices (or in the combination of those as a relative price), also depends on the elasticity of substitution. All else equal, a higher elasticity of substitution will magnify the trade diversion effects from the more expensive commodities to the cheaper ones.

The final step in the derivation of the structural gravity model is to impose market clearance for goods from each origin:

$$
Y_{i}=\sum_{j}\left(\frac{\beta_{i} p_{i} t_{i j}}{P_{j}}\right)^{1-\sigma} E_{j} .
$$

Equation (5) tells us that, at delivered prices (because part of the shipments melt en route), the value of output in country $i, Y_{i}$, should be equal to the total expenditure on this country's variety in all countries in the world, including $i$ itself. To see this intuition more clearly, note that the right-hand-side expression in Equation (5) can be replaced with the sum of all bilateral shipments from $i$ as defined in Equation (3), so that $Y_{i}=\sum_{j} X_{i j}$.

Define $Y \equiv \sum_{i} Y_{i}$, divide the preceding equation by $Y$, and rearrange terms to obtain:

$$
\left(\beta_{i} p_{i}\right)^{1-\sigma}=\frac{Y_{i} / Y}{\sum_{j}\left(\frac{t_{i j}}{P_{j}}\right)^{1-\sigma} \frac{E_{j}}{Y}} .
$$

Define the term in the denominator of 60 as $\Pi_{i}^{1-\sigma} \equiv \sum_{j}\left(\frac{t_{i j}}{P_{j}}\right)^{1-\sigma} \frac{E_{j}}{Y}$, and substitute this definition into Equation (6):13

$$
\left(\beta_{i} p_{i}\right)^{1-\sigma}=\frac{Y_{i} / Y}{\Pi_{i}^{1-\sigma}}
$$

Use (6) to substitute for the power transform $\left(\beta_{i} p_{i}\right)^{1-\sigma}$ in the bilateral allocations Equation (3) and in the CES price index Equation (4). Combine the definition of $\Pi_{i}^{1-\sigma}$ with the resulting expressions that correspond to Equation (3) and Equation (4) to obtain the structural gravity system: 14

$$
\begin{aligned}
X_{i j} & =\frac{Y_{i} E_{j}}{Y}\left(\frac{t_{i j}}{\Pi_{i} P_{j}}\right)^{1-\sigma}, \\
\Pi_{i}^{1-\sigma} & =\sum_{j}\left(\frac{t_{i j}}{P_{j}}\right)^{1-\sigma} \frac{E_{j}}{Y}, \\
P_{j}^{1-\sigma} & =\sum_{i}\left(\frac{t_{i j}}{\Pi_{i}}\right)^{1-\sigma} \frac{Y_{i}}{Y} .
\end{aligned}
$$

\footnotetext{
${ }^{13}$ In our opinion, this simple step is one of the most important contribution of Anderson and van Wincoop (2003), because, as demonstrated next, this is the step that leads to the elegant structural gravity system, which gave a new face to the original gravity theory of Anderson (1979), which otherwise is identical to the theory from Anderson and van Wincoop (2003).

${ }^{14}$ In the Appendix, we follow Eaton and Kortum (2002) and we demonstrate that the same gravity system can be derived on the supply side.
} 
Here, (8) is the theoretical gravity equation that governs bilateral trade flows. To see the remarkable resemblance between the trade gravity equation and the corresponding equation from physics, define $T_{i j}^{\theta} \equiv\left(\frac{t_{i j}}{\Pi_{i} P_{j}}\right)^{\sigma-1}$, and introduce a trade gravity constant $\tilde{G} \equiv 1 / Y$ in 8 to obtain $X_{i j}=\tilde{G} \frac{Y_{i} E_{j}}{T_{i j}{ }^{\theta}}$. Compare with Newton's Law of Universal Gravitation, $F_{i j}=G \frac{M_{i} M_{j}}{D_{i j}^{2}}$, where $F_{i j}$ is the gravitational force between the objects, $G$ is the gravitational constant, $M$ denotes the object's mass, and $D_{i j}$ is the distance between the two objects.

The gravity equation can be conveniently decomposed into two terms: a size term, $Y_{i} E_{j} / Y$, and a trade cost term, $\left(t_{i j} /\left(\Pi_{i} P_{j}\right)\right)^{1-\sigma}$. The intuitive interpretation of the size term, $Y_{i} E_{j} / Y, \sqrt{15}$ is as the hypothetical level of frictionless trade between partners $i$ and $j$ if there were no trade costs. ${ }^{16}$ This term already carries some very useful information regarding the relationship between country size and bilateral trade flows: (i) Large producers will export more to all destinations; (ii) Big/rich markets will import more from all sources; (iii) Trade flows between $i$ and $j$ will be larger the more similar in size the trading partners are. 17

The second term in the gravity equation $(8)$ is $\left(t_{i j} /\left(\Pi_{i} P_{j}\right)\right)^{1-\sigma}$ and, as noted earlier, it disappears in the absence of bilateral trade frictions. Thus, the natural interpretation of this term is as capturing the total effects of trade costs that drive a wedge between realized and frictionless trade ${ }^{18}$ The trade cost term consists of three components. The first element is the bilateral trade cost $t_{i j}$ between partners $i$ and $j$. This term is typically approximated in the literature by various geographic and trade policy variables such as bilateral distance, tariffs, the presence of regional trade agreements, etc., between partners $i$ and $j$. Proper treatment of bilateral trade costs is crucial for sound analysis of the partial equilibrium as well as of the general equilibrium effects of trade policy. Anderson and van Wincoop (2004) offer a very informative survey of bilateral trade costs. In the companion estimation paper, Piermartini and Yotov (2015) build on the recommendations from Anderson and van Wincoop (2004) to accommodate the latest developments and considerations in the treatment of bilateral trade costs with special focus on the effects of trade policy. For expositional simplicity, we will preserve the general notation of bilateral trade costs as $t_{i j}$ (with possible intuitive interpretation as reflecting the effects of trade policy) for most of the current analysis. Next, we focus on the two components from the denominator of the trade cost term.

\footnotetext{
${ }^{15}$ World output, $Y$, does not appear explicitly in the general discussions of the structural gravity model as presented in some recent surveys and academic articles that adjust the definitions of Equations (9) and (10) to account for $Y$. We find our current treatment and presentation of the structural gravity system instructive because it allows for the intuitive interpretation of the first term from Equation (8) as frictionless trade and of the second structural component as a general equilibrium trade cost term.

${ }^{16}$ Mechanically, this can be shown by eliminating bilateral trade frictions, i.e. setting $t_{i j}=1$, and rederiving the gravity system. Intuitively, a frictionless world implies that consumers will face the same price for a given variety regardless of their physical location and that their expenditure share on goods from a particular country will be equal to the share of production in the source country in the global economy, i.e. $X_{i j} / E_{j}=Y_{i} / Y$.

17 Anderson (2011) offers an insightful discussion and formal proofs of these and other, less obvious, properties based on the relationship between trade flows and country size in a frictionless world.

18 Agnosteva, Anderson and Yotov (2014) label the estimated version of this term Constructed Trade Bias $(C T B)$ and define it as the ratio between realized trade and hypothetical frictionless trade. In Section 2.5 . we discuss some useful properties of CTB and we demonstrate how this index can be aggregated consistently to obtain a series of policy-relevant general equilibrium trade costs statistics.
} 


\subsection{On the Beauty of the Multilateral Resistances}

Coined by Anderson and van Wincoop (2003) as the multilateral resistances $(\mathrm{MRs}), \Pi_{i}$ (the outward multilateral resistance, or OMR) and $P_{j}$ (the inward multilateral resistance, or IMR) are structural gravity terms that are at the heart of the general equilibrium analysis of trade policy that we are about to present in this paper. Therefore, we find it instructive to define and discuss in more detail what we believe are the six main (and interrelated) properties of the MR terms.

1. The MRs are Intuitive Structural Trade Cost Terms. The multilateral resistances bear the intuitive interpretation that, all else equal, two countries will trade more with each other the more remote they are from the rest of the world. Proper account for the multilateral resistances is the key difference between the naive vs. theory-founded applications of the trade gravity model Anderson and van Wincoop, 2003). While the multilateral resistances of Anderson and van Wincoop (2003) offer elegant structure behind the remoteness, Krugman (1995) offers a great intuition for it by comparing the hypothetical levels of trade between two economies that are always on the same distance from each other but once they are on Mars and once they are in the middle of Europe. Following this intuition, the MR terms are often referred to as 'remoteness indexes' and some researchers have constructed proxies for the MRs as GDP-weighted distance averages. While easy to construct, such a-theoretical remoteness indexes are not perfectly consistent with the GE analysis presented here and this is one of the reasons why Head and Mayer (2014) advice against their use. We refer the reader to Head and Mayer (2014) and to Piermartini and Yotov (2015) for related discussions.

2. The MRs are Theory Consistent Aggregates of Bilateral Trade Costs. As is evident from the definitions of the MR terms from Equations (9) and (10), the multilateral resistances are theory consistent aggregates of all possible bilateral trade costs to the country level. In combination with the other properties of the MRs, this property is very convenient and important because, by construction, the multilateral resistance terms are vehicles that translate the $N \times N$-dimensional system of bilateral links in the gravity model into a $2 \times N$-dimensional series of country-specific indexes. Anderson, Larch and Yotov (2015b) capitalize on the reduced-dimensionality property of the MR terms to build a tractable theory of dynamic gravity, where the Armington gravity model is nested within a dynamic production superstructure. In addition, in combination with the other MR properties that we discuss here, the consistent-aggregation property of the MRs makes these indexes particularly appealing for structural estimation purposes and for policy analysis. We emphasize the convenience of using the MR terms and the practical importance of these indexes in the last main MR property that we discuss below.

3. The MRs are General Equilibrium Indexes. Third, and probably most important for the purposes of this paper, the multilateral resistances are general equilibrium trade cost terms. As such, the MRs will capture the fact that a change in bilateral trade 
costs, e.g. a formation of a free trade agreement (FTA) 19 between any two partners will result in (i) additional effects (in addition to the direct partial effects) for the FTA members and (ii) also will affect all other countries in the world with (iii) possible feedback effects on the original liberalizing partners.

Anderson and van Wincoop (2003) emphasize the importance of the general equilibrium effects of the MR terms for proper account for the total impact of trade costs on trade between two countries. Specifically, they demonstrate that the effects of the Canadian border on trade with the US were much smaller than the corresponding partial equilibrium estimates obtained by McCallum (1995), thus resolving McCallum's famous border puzzle. As mentioned earlier, the intuition is that trade between two countries depends not only on the direct trade costs between these countries but also on how remote they are from the rest of their trading partners. The multilateral resistances do exactly that; they account for the general remoteness of the two countries from the rest of the world.

In the case of trade liberalization between two countries, the general equilibrium forces will translate into lower multilateral resistances for the FTA members and into higher multilateral resistances for all other countries in the world. The intuition for this result is that when two countries become more integrated with each other, all else equal, they also become more isolated from the rest of the world. The importance of this channel is reflected in the concerns of some policy makers and popular observers who are alarmed that trade mega deals such as the Trans-Pacific Partnership (TPP) and the Transatlantic Trade and Investment Partnership (TTIP) will trigger significant negative effects on non-members. We offer further discussion of the possibility for such effects in Section 2.4 .

4. The MRs Decompose the Incidence of Trade Costs. Fourth, the multilateral resistances decompose the aggregate incidence of trade costs and their changes on consumers and producers in each country. Equation (9) shows that outward multilateral resistance is a weighted-average aggregate of all bilateral trade costs for the producers of goods in each country. It is as if each country $i$ shipped its product to a single world market facing supply side incidence of trade costs $\Pi_{i}{ }^{20}$ Similarly, Equation (10) defines the inward multilateral resistance as a weighted average of all bilateral trade costs that fall on the consumers in each region. It is as if each country $j$ bought its goods from a single world market facing demand side incidence of $P_{j}{ }^{21}$ Anderson and

\begin{tabular}{l}
\hline${ }^{19}$ Throughout this manuscript we will refer to 'free trade agreements (FTAs)' for illustrative purposes. \\
More generally, we will refer to trade agreements as 'regional trade agreements (RTAs)'. The terms RTA \\
and FTA are not used consistently in the literature. Whenever possible, we follow the WTO definition \\
(http://rtais.wto.org/UserGuide/RTAIS_USER_GUIDE_EN.html\#_Toc201649637), where RTA refers to \\
all agreements, and FTA is a RTA as defined in Paragraph $8(\mathrm{~b})$ of Article XXIV of GATT 1994. \\
\hline${ }^{20}$ If the actual set of bilateral trade costs is replaced by $t_{i j}=\Pi_{i} P_{j}$, all budget constraints and market \\
clearance conditions continue to hold, and factory gate prices and supply and expenditure shares remain \\
constant. Thus, the multilateral resistances can be thought of as the general equilibrium analog to a tax \\
incidence decomposition from an introductory principles of microeconomics course. We refer the reader to \\
Anderson and van Wincoop (2004) for a related discussion. \\
\hline \hline${ }^{21}$ As indicated in the theoretical derivation of the structural gravity model, an alternative interpretation \\
\hline of IMR is as a buyers price index. We discuss implications below.
\end{tabular}


Yotov (2010a) emphasize the incidence property of the MR terms and reveal significant differences in how producers and consumers in different regions are affected by trade costs. Importantly, in combination with the previous two items, this property of the MRs will enable us to quantify and decompose the effects of trade policy changes between any two countries into separate effects on producers and consumers in every country in the world.

5. The MRs are Straightforward to Construct. With data on output and expenditure, and for given values of the elasticity of substitution $(\sigma)$ and the vector of bilateral trade costs $\left(t_{i j}\right)$, system (9)-(10) delivers estimates of the multilateral resistances. Two properties of the MR system deserve deeper discussions. First, as noted by Anderson and Yotov (2010a), system (9)-(10) solves for $\left\{\Pi_{i}, P_{j}\right\}$ only up to a scalar; If

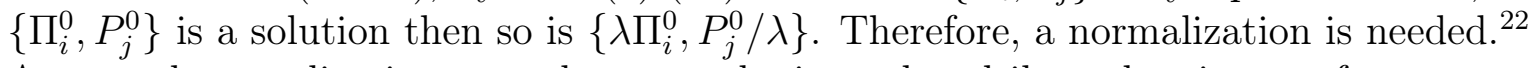
A natural normalization procedure sets the inward multilateral resistance for a country of choice (usually the country with the most reliable data) to be equal to one, e.g. $P_{D E U}=1$. Thus, the values of all MR terms (both inward and outward) are relative to the inward multilateral resistance for Germany (DEU). An alternative normalization strategy when counterfactual experiments are performed, is to choose a country that presumably will not be affected much by the counterfactual shock. The idea is that if the reference group is not affected than the 'relative' counterfactual changes in the MR indexes will be much closer to their 'absolute' counterparts. Second, note also that while system (9)-10) is highly non-linear in the multilateral resistance terms, $\Pi_{i}$ and $P_{j}$, it becomes a quadratic system when expressed in terms of the power transforms of the MRs, $\Pi_{i}^{1-\sigma}$ and $P_{j}^{1-\sigma}$. The simple quadratic system (9)-(10) can be solved easily with any software supporting non-linear solvers (e.g. using Matlab or the matrix capabilities of Mata in Stata). Finally, as we demonstrate in Section 3.2, the MR terms can actually be recovered directly from a canned estimation command in any statistical software package capable of estimating a poisson model (e.g. using the 'glm' or 'ppml' command in Stata).

6. The MRs are Appealing for Practical Purposes. In combination, the above properties make the MR indexes very appealing for practical purposes both from a policy perspective and from a structural estimation perspective. Specifically, from a policy perspective, the MR terms should be viewed as informative indexes that summarize the GE effects of trade costs and that can be used to aggregate and decompose the impact of trade policy on the consumers and the producers in liberalizing and outside countries. In addition, the multilateral resistances combine to form a series of other summary measures of the effects of trade costs and trade policy. The benefits of this property will become clear in Section 2.5, where we present and discuss such general equilibrium trade costs indexes. In addition, from a structural estimation perspective, the solid theoretical foundation of the MR terms makes them an appealing alternative to reduced-form specifications. Two benefits of the structural use of the MR terms in

\footnotetext{
${ }^{22}$ No explicit normalization is needed in the less realistic case with symmetric trade costs and balanced trade. In this case the MR system collapses to a system of $\mathrm{N}$ equations under the implicit normalization $P_{j} \equiv \Pi_{j}$.
} 
estimations include (i) the ability to recover and to interpret structurally the estimates of the coefficients on the MR terms; and (ii) the advantage of using theory to address potential endogeneity concerns. Anderson, Larch and Yotov (2015b) capitalize on this property to demonstrate how the outward multilateral resistance (OMR) term replaces the reduced-form trade openness measure in the famous income regressions of Frankel and Romer (1999). The significant estimate of the coefficient on the OMR term is used to establish a causal relationship between trade liberalization and income (growth) and also to recover an estimate of the elasticity of substitution $(\sigma)$. We discuss the practical use and benefits of the MRs in more detail in Section 4.

In sum, the beauty of the multilateral resistances is that these terms consistently aggregate the effects of all bilateral trade costs and their changes into country-specific general equilibrium indexes that also decompose the incidence of trade costs on the producers and on the consumers in each country. Combined with their intuitive appeal and the straightforward procedures to construct the multilateral resistances, these properties make the MR indexes very appealing for various practical purposes including, for example, policy analysis as well as structural estimation. We capitalize on some of these properties in the next section, where we discuss the general equilibrium effects of trade policy in a hypothetical trade liberalization scenario.

\subsection{On the GE Effects of Trade Policy: A Discussion}

This section offers an intuitive discussion of the general equilibrium effects of trade policy. The goal is a deep and thorough understanding of the underlying links and causal mechanisms between trade policy and economic outcomes within the CES-Armington gravity model 23 For clarity and tractability, we consider a hypothetical bilateral trade liberalization scenario (e.g. a bilateral free trade agreement between partners $i$ and $j$ ). In order to facilitate exposition and to offer a more thorough analysis of the general equilibrium links within the gravity framework, we combine system (8)-(10) with the market clearing condition (6) and we add the definition of the value of output, $Y_{i}$, and its relation to aggregate

\footnotetext{
${ }^{23}$ We remind the reader that the CES-Armington is a representative framework for a large class of GE trade models. As demonstrated in the appendix, for example, the Eaton and Kortum (2002) framework and the Anderson and van Wincoop (2003) model deliver identical gravity systems. See Arkolakis, Costinot and Rodríguez-Clare (2012) and Costinot and Rodríguez-Clare (2014) for alternative general representations of the gravity model.
} 
expenditures, $E_{i}$, to obtain 24

$$
\begin{aligned}
& X_{i j}=\frac{Y_{i} E_{j}}{Y}\left(\frac{t_{i j}}{\Pi_{i} P_{j}}\right)^{1-\sigma}, \\
& \Pi_{i}^{1-\sigma}=\sum_{j}\left(\frac{t_{i j}}{P_{j}}\right)^{1-\sigma} \frac{E_{j}}{Y}
\end{aligned}
$$

Conditional GE :

$$
\begin{aligned}
& P_{j}^{1-\sigma}=\sum_{i}\left(\frac{t_{i j}}{\Pi_{i}}\right)^{1-\sigma} \frac{Y_{i}}{Y} \\
& p_{i}=\left(\frac{Y_{i}}{Y}\right)^{\frac{1}{1-\sigma}} \frac{1}{\beta_{i} \Pi_{i}}
\end{aligned}
$$

Full Endowment GE :

$$
E_{i}=\phi_{i} Y_{i}=\phi_{i} p_{i} Q_{i}
$$

Similar to Head and Mayer (2014), we present the effects of trade policy in three stages including: (i) Direct or Partial Equilibrium (PE) Effects, which are captured by Equation (11); (ii) Conditional General Equilibrium (GE) Effects, which operate via the MR channels, captured by Equations (12) and (13), in addition to the partial equilibrium effects; and (iii) Full Endowment General Equilibrium (GE) Effects, which also allow for endogenous response in income and expenditures via Equations (14) and (15). The goal is to decompose the different channels through which trade policy affects trade and to evaluate the relative importance of these channels in the overall impact of trade policy. We discuss each of the three scenarios in turn. Then, in Section 3.3.2, we complement the current discussion with empirical estimates from a counterfactual experiment that evaluates the effects of the North American Free Trade Agreement (NAFTA).

Partial Equilibrium Effects. The Direct (Partial Equilibrium, PE) effect of a decrease in bilateral trade costs is the initial and, most likely, the strongest effect of trade liberalization on bilateral trade between the two liberalizing countries. This effect is captured by adjusting $t_{i j}$ in Equation (11), while holding output, expenditure, and multilateral resistances constant. By definition, the direct effects of trade policy changes are limited to liberalizing members only, and have no implications for trade and welfare of other countries. For example, a 10 percent decrease in bilateral trade costs between partners $i$ and $j$ will translate into a $\left(0.9^{1-\sigma}-1\right) \times 100$ percent increase in bilateral trade between the two countries, with zero effects on the rest of the countries in the world. ${ }^{25}$ The structural gravity model also allows for a convenient conversion of any partial equilibrium decrease in trade costs into

\footnotetext{
${ }^{24}$ Alvarez and Lucas, Jr. (2007) and Allen, Arkolakis and Takahashi (2014) establish the uniqueness of the equilibria in the structural gravity system presented here.

${ }^{25}$ Note the importance of the elasticity of substitution $\sigma$ in quantifying the effects of trade cost changes.
} 
a corresponding tariff equivalent ${ }^{26}$ We demonstrate this in Section 3.3.2, where we model bilateral trade costs explicitly and we estimate the effects of the regional trade agreements (RTAs) from the 90s with the structural gravity model.

Conditional GE Effects. An important limitation of the partial equilibrium analysis of the effects of trade policy is that, by construction, the PE scenario implies no effects for outsiders. At the same time, much of the policy debate around the impact of trade policy is based on fears that countries that are left out of the integration efforts may be hurt and that, at the extreme, the benefits from trade liberalization for member countries may be outweighed by the losses for outsiders, leading to a decrease in global efficiency (Anderson and Yotov, 2016). In order to capture such possibilities, the structural gravity model allows for a tractable general equilibrium analysis via the multilateral resistances, even at constant output and expenditures. We label this scenario a 'Conditional General Equilibrium'. We use the term 'Conditional', because output and expenditure remain unchanged in this scenario. However, we also label this scenario as a 'General Equilibrium', because it allows for the effects of trade liberalization between two countries in the world to ripple through the rest of the world via the general equilibrium MR terms.

The 'Conditional General Equilibrium' step may seem redundant to some, because the 'Partial Equilibrium' effects of trade policy can be translated into 'Full Endowment GE' effects directly, without the need to perform this intermediate step ${ }^{27}$ However, we see at least four benefits from analyzing the Conditional GE scenario as a standalone intermediate step between the partial equilibrium analysis and the Full Endowment GE scenario. First, from an instructional perspective, we believe that it is important to understand that a change in bilateral trade costs between any two countries will trigger GE effects that affect any other country in the world, even if everything else stayed the same. This is one of the main points of Anderson and van Wincoop (2003). Second, from a policy perspective, the Conditional GE scenario will deliver the total trade cost indexes that correspond to the partial trade cost gravity estimates, at given output and expenditure levels. Third, from a theoretical perspective, the construction of the Conditional trade costs indexes allows for a consistent mapping between the decomposition of the structural gravity equation into a 'size' vs. a pure 'trade cost' term. For given sizes, captured by the first term in the structural gravity equation (8), $Y_{i} E_{j} / Y$, the second structural term in $(8),\left(t_{i j} /\left(\Pi_{i} P_{j}\right)\right)^{1-\sigma}$, captures the conditional GE effects of trade policy on trade costs. Furthermore, in combination with the Full Endowment analysis, the Conditional indexes will enable policy makers to decompose the effects of trade liberalization into those on trade costs vs. economic size. Finally, from a practical perspective, the Conditional GE indexes can be recovered directly

\footnotetext{
${ }^{26}$ Piermartini and Yotov (2015) offer a detailed discussion on the interpretation and aggregation of the estimates of bilateral trade costs within the structural gravity framework.

${ }^{27}$ To see this, note that one can apply the definitions of the multilateral resistances and express system (12)-14 only in terms of factory gate prices as the only endogenous variable. Thus, the MR system collapses to a system of $N$ equations in $N$ unknowns, which can translate any change in bilateral trade costs directly into a change in factory-gate prices. See Balistreri and Hillberry $(2007,2008)$ for excellent examples of studies that have applied this approach to structural gravity analysis. Note also that, in combination with the (exogenous) change in bilateral trade costs, the change in factory gate price is sufficient to construct a unique corresponding set of changes in inward and outward multilateral resistances.
} 
from the estimates of the fixed effects that are typically employed in gravity estimations for a perfect and consistent mapping between theory and empirical analysis. We demonstrate the latter point in Section 3.2.

For expositional reasons, we discuss separately the effects on the liberalizing countries and on the outsiders. Consider the additional effects on the liberalizing (or member) countries first. We label these effects first-order general equilibrium effects because, by construction, they are the strongest in magnitude. Part of these effects are channeled through the inward multilateral resistance, $P_{j}$. Equation (13) suggests that (i) the inward multilateral resistances (IMR) will decrease for both countries as a result of trade liberalization between them, and (ii) the effects for each country will be stronger the larger is the size of the liberalizing partner. All else equal, Equation (11) reveals that the fall in the inward multilateral resistance will work in the opposite direction of the direct effect of trade liberalization, i.e. a fall in IMR will cause $j$ to import less from all source countries, ceteris paribus. This is an example of the trade diversion effects that are often feared by policy makers and popular observers. The intuition for this result is that the more integrated country $j$ is with a particular trading partner $i$ the more remote it becomes relative to all other countries. When the variety from source $i$ becomes cheaper, consumers in country $j$ will substitute away from all other varieties. Alternatively, using the price index interpretation of $P_{j}$, the partner country $i$ gains market share in $j$ (because of the direct/partial effect of trade liberalization), whereas $j$ 's import market becomes more competitive for outside countries. It should also be noted that the decrease in IMR for each liberalizing country will always be smaller in magnitude than the decrease in bilateral trade costs between the two countries. The reason is that, by construction, the change in IMR is obtained as a weighted average of the changes in all bilateral trade costs, where the change in trade costs between the liberalizing countries plays only a small role (which of course depends on their size). Thus, the trade diversion effects due to the fall in IMR will never be strong enough to offset the direct trade creation effect of the decrease in bilateral trade costs between the liberalizing countries.

The other first-order GE effect on member countries is channeled via the outward multilateral resistances. Equation (12) suggests that the OMRs will fall for each liberalizing country. Similar to the effect of falling IMRs, the general equilibrium impact of falling OMRs will lead to less exports from each liberalizing member to all countries in the world. The intuition for this result is that, for given total output, when faced with lower export costs to a particular partner $j$, country $i$ will export more to this partner and less to every other country, i.e. the more integrated country $i$ is with a particular trading partner $j$, the more remote it becomes relative to all other countries. This is again the trade-diversion channel. Once again, we note that, by construction, the GE trade diversion effects that are channeled through the OMRs will not be strong enough to offset the direct trade creation effects due to trade liberalization between the two countries. However, as we demonstrate later, the trade diversion effects can be sizable.

An important implication of the Conditional GE scenario is that it translates the effects of trade liberalization between countries $i$ and $j$ to changes in trade (and welfare) for all other countries in the world. These effects are also channeled through the multilateral resistances but we label them second-order GE effects because the impact on outside countries is triggered by changes in the MR terms for the liberalizing countries, i.e. by the first-order GE effects that we described earlier. Specifically, Equations $(12)$ and (13) imply that the 
fall in the outward and inward resistances for the liberalizing countries will result in higher outward and inward resistances for the outside economies, which, all else equal (via Equation (11)), will result in more exports and more imports, i.e. trade creation, for the outsiders.

In order to determine the net impact on trade for outside countries, however, we need to distinguish between how trade among outsider countries will be affected versus how trade between outsiders and liberalizing countries will be affected. The first-order trade diversion effects, described earlier, dictate that the effect on trade between outsiders and liberalizing countries will be negative. The effect on trade among the outsider countries is unambiguously positive. The intuition is that, at constant output levels, once trade (imports and exports) for the outsiders is diverted from the liberalizing members it will be directed to other outsiders. Since part of the diverted trade will translate into intra-national trade, the net effect on international trade for the outside countries will most likely be negative. ${ }^{28}$ Finally, we acknowledge that the changes in the MRs for the outside countries will have third-order feedback GE effects on the liberalizing countries as well as on the outside countries themselves. However, these effects will be dominated by the first- and second-order GE effects.

Full Endowment GE Effects. We label the third general equilibrium channel through which trade liberalization between two countries will affect trade among all economies in the world 'Full Endowment GE Effect'. We call this scenario Full, because it allows for endogenous response in the value of output and expenditure, and Endowment, in order to distinguish it from the GE effects in a Dynamic scenario that we introduce in Section 4 . which also allows for changes in production (as opposed to the value of production) through accumulation of physical capital. The Full Endowment GE effects are captured by Equations (14) and (15), which translate the changes in trade costs into changes in factory-gate prices $p_{i}$ via Equation (14), and then into changes in the value of domestic production $Y_{i}$ and aggregate expenditure $E_{i}$ via Equation (15). In effect, this channel endogenizes the value of output, $Y_{i}=p_{i} Q_{i}$, and expenditure by allowing factory-gate prices to respond to trade cost changes $\sqrt{29}$

Equations (14) and (15) capture how the decreases in the outward multilateral resistance, which we marked as a first-order GE effect for member countries, formally translate into higher factory gate prices and, in turn, higher output values and expenditure. Intuitively, the producers in the liberalizing member countries will internalize the favorable change in their OMR by increasing their prices. The opposite will happen in non-member countries, where producers will suffer higher outward resistance and will decrease their factory-gate

\footnotetext{
${ }^{28}$ Note however, that there exists a theoretical possibility that the net impact on some outside countries' trade is positive. The intuition for such a result is that an outsider (outsider 1) may be facing very large (prohibitive at the extreme) trade costs with the liberalizing countries, i.e. outsider 1 may trade very little (if at all) with the liberalizing countries. Thus, outsider 1 will not suffer much trade diversion due to the formation of the FTA. However, outsider 1 may be a good trading partner of another outside country (outsider 2 ) that actually suffers significant trade diversion due to the formation of the FTA. Thus, in principle, it is possible that part of outsider's 2 exports, which have been diverted from the FTA members, will now go to outsider 1. Given the current levels of integration and interdependence in the world trading system, such a scenario is not very likely in practice but it is possible nevertheless.

${ }^{29}$ Note that one can (and probably should) further endogenize production $Q_{i}$ in order to capture the full trade policy effects. We demonstrate how this can be done with the Armington model in Section 4
} 
prices. The effect on factory-gate prices in outside countries will be smaller as compared to the effect on member countries because the initial effect on the OMRs for the outsiders is a second-order effect. In sum, the Full Endowment GE effects of trade liberalization on the value of output/nominal income will be positive in the liberalizing countries and it will likely be negative in the outside countries.

It is important to note that the changes in the value of output will have additional (direct and indirect) effects on trade and on trade costs (MRs). The direct effects of output on trade are captured by Equation (11). All else equal, both exports and imports will increase via this channel when both partners are liberalizing countries and they will decrease when the trading partners are outside countries. The intuition for these results is that member countries will become effectively richer/larger, while outside countries will be poorer/smaller in terms of value of output and expenditure. Trade between members and outsiders will also likely increase via this channel because the effects on the value of output/income for members are stronger (first-order) as compared to the effects on non-members. Importantly, the trade creation size effects can be strong enough to outweigh the Conditional GE trade diversion effects for outsiders. We offer evidence for this possibility with an application below.

Finally, in addition to their direct impact on trade, the changes in the value of output will have indirect effects on trade via changes in the multilateral resistances. These effects are captured by Equations (12) and (13). Due to their increased size, the liberalizing countries will be assigned more weight in the construction of the multilateral resistances. This means that the impact on all countries of trade liberalization among the liberalizing countries will be magnified via this channel. However, by construction (because it was initially triggered by changes in the multilateral resistances), this effect will never be stronger than the firstand second-order Conditional GE effects discussed above. The changes in the MR terms will lead to additional, third-order changes in output.

\subsection{Some Useful General Equilibrium Trade Cost Indexes}

This section presents several general equilibrium trade cost indexes that can be employed to summarize and decompose various aspects of the effects of trade policy. We start by re-visiting three familiar indices that were introduced when we reviewed the theoretical foundations of the Armington gravity model:

- Inward Multilateral Resistance (IMR). As discussed earlier, the inward multilateral resistances are theory consistent general equilibrium aggregate indexes that measure the incidence of trade costs on the consumers in each country as if these consumers buy from a unified world market:

$$
P_{j}^{1-\sigma}=\sum_{i}\left(\frac{t_{i j}}{\Pi_{i}}\right)^{1-\sigma} \frac{Y_{i}}{Y} .
$$

Thus, the IMRs can be used to evaluate the effects of domestic and foreign trade policy on consumers in each country.

An alternative, and also consistent with the structural gravity model, definition of $P_{j}$ 
is as a CES price aggregator:

$$
P_{j}=\left[\sum_{i}\left(\beta_{i} p_{i} t_{i j}\right)^{1-\sigma}\right]^{1 /(1-\sigma)} .
$$

Redding and Venables (2004) use this definition to interpret $P_{j}$ as a Supplier Access index. In their role as CES aggregators, the inward multilateral resistances may, in principle, be interpreted as ideal price indexes, and their variation across countries might be expected to reflect variation in consumer price indexes (CPIs). However, Anderson and Yotov (2010a) note that the IMRs may have more variation than the corresponding CPIs and the former may only loosely track variations in consumer price indexes. The differences between IMRs and CPIs have a number of possible explanations. First, the inward incidence of trade costs probably falls on intermediate goods users in a way that does not show up in measured prices. Second, the production weighted IMRs are not really conceptually comparable to the consumer price indexes of final goods baskets. Third, the IMRs may capture home bias in preferences, which results in attributions to trade costs that cannot show up in prices. Finally, the IMR's are no doubt subject to measurement error and are based on a CES model that itself may be mis-specified. One disadvantage of the IMRs is that, as discussed in the previous section, by construction these indexes can only be obtained with a normalization, e.g. in relative form with respect to a reference group. ${ }^{30}$ This causes difficulties with IMR comparisons over time and across sectors 31

- Outward Multilateral Resistance (OMR). As defined earlier, the OMRs are theory consistent GE aggregates of the incidence of trade costs on the producers in each country, as if they ship to a unified world market. The OMR indexes are obtained together with the inward multilateral resistances:

$$
\Pi_{i}^{1-\sigma}=\sum_{j}\left(\frac{t_{i j}}{P_{j}}\right)^{1-\sigma} \frac{E_{j}}{Y} .
$$

The OMRs can be used in combination with the IMRs in order to decompose the incidence of trade costs on the consumers and the producers in each country. Anderson and Yotov (2010a) demonstrate that in the case of Canada much of the trade cost incidence falls on the producers. The outward multilateral resistances for Canada's producers are on average 5 times larger as compared to the corresponding IMRs. Redding and Venables (2004) offer an alternative interpretation of the OMRs as Market Access indexes. Anderson and Yotov (2010b) interpret the OMRs as total factor productivity (TFP) frictions in distribution. Finally, Anderson, Larch and Yotov (2015b) use the

\footnotetext{
${ }^{30}$ As noted earlier, the MR system $\sqrt{12}|-\sqrt{13}|$ solves for $\left\{\Pi_{i}, P_{j}\right\}$ only up to a scalar. If $\left\{\Pi_{i}^{0}, P_{j}^{0}\right\}$ is a solution then so is $\left\{\lambda \Pi_{i}^{0}, P_{i}^{0} / \lambda\right\}$. We discuss further implications of this normalization below.

31 Anderson and Yotov (2010a) exploit the interpretation of the multilateral resistances as consumer price indexes and offer inter-temporal IMR analysis. Also, as mentioned earlier, when counterfactual analysis are performed, it might be a good idea to choose a reference group that is expected to be affected the least form the counterfactual shock.
} 
OMRs to implement a structural, theory-founded refinement of Frankel and Romer's famous investigation of the link between trade openness and growth, cf. Frankel and Romer (1999). Similar to the IMRs, the outward multilateral resistances can only be obtained subject to a normalization. Thus, while the OMRs can be compared consistently across countries for a given sector and year, OMR comparisons over time and across sectors should always be interpreted subject to the imposed normalization.

- Factory-Gate Price. Factory-gate prices and their changes in response to trade policy can be obtained from the market-clearing conditions in the structural gravity model:

$$
p_{i}=\left(\frac{Y_{i}}{Y}\right)^{\frac{1}{1-\sigma}} \frac{1}{\beta_{i} \Pi_{i}},
$$

where, as defined earlier, $Y_{i}=p_{i} Q_{i}$ and $Y=\sum_{i} p_{i} Q_{i}$. The factory-gate prices can be used as a complementary index to the OMRs in order to evaluate the effects of trade policy and trade cost changes on producers. In addition, as we demonstrate in Section 4, the changes in factory-gate prices in response to trade cost changes serve as an important link for integrating the structural gravity model with a series of general equilibrium production models that depart from the endowment economy setting of Anderson (1979) and Anderson and van Wincoop (2003). Using manufacturing data, Anderson and Yotov (2016) find that the FTAs that entered into force during the 90s led to large gains, in terms of higher factory-gate prices, for the sellers from relatively small European countries (e.g. Poland, Romania, and Hungary) and American economies (e.g. Mexico and Canada) that signed FTAs with large trading partners in close proximity. Some producers in countries that were left out of the integration efforts and also producers from some larger economies that sign FTAs suffered a small fall in factory-gate prices. A drawback of the estimates of factory-gate prices is that, just like the multilateral resistance terms, the factory-gate prices can only be estimated under a normalization, e.g. with respect to a reference group.

We now turn to some refined indexes that draw on the standard structural terms described above and that can be used to reveal additional insights about the effects of trade policy. An important common feature of the indexes that we present next is that they all are independent of the normalizations needed to obtain the MRs and the factory-gate prices.

- Constructed Home Bias (CHB). Anderson and Yotov (2010a) use the structural gravity model to introduce $C H B$ as the ratio of predicted to hypothetical frictionless internal trade within a given country $i$ :

$$
C H B_{i}=\frac{\hat{X}_{i i}}{Y_{i} E_{i} / Y}=\left(\frac{\hat{t}_{i i}}{\hat{\Pi}_{i} \hat{P}_{i}}\right)^{1-\sigma}
$$

Intuitively, $C H B$ measures how far is the economy from a frictionless trade equilibrium where $\hat{X}_{i i}=Y_{i} E_{i} / Y$. In that sense, $C H B$ is a complementary index to the widely popular 'sufficient welfare statistic' of Arkolakis, Costinot and Rodríguez-Clare (2012), which we discuss later in this section. The middle expression in (20) is the predicted 
(fitted) value of internal trade, $\hat{X}_{i i}$, relative to the theoretical value of internal trade in a frictionless world, $Y_{i} E_{i} / Y{ }^{32}$ The rightmost expression in 20 gives the effect of all fitted trade costs acting directly and indirectly to increase each region's trade with itself above the frictionless benchmark. Note that, through the MR terms, $\mathrm{CHB}$ will respond to changes in trade policy even at constant internal trade costs $t_{i i}$. Similarly, two regions $i$ and $j$ with the same internal trade costs $t_{i i}=t_{j j}$ may have quite different $C H B$ 's due to the general equilibrium effect of trade policy and trade costs when $\Pi_{i} P_{i} \neq \Pi_{j} P_{j}$. CHB can be a useful aggregate measure of the effects of globalization on trade. For example, exploiting the $C H B$ variation at constant bilateral trade costs, Anderson and Yotov (2010b) study the effects of specialization as a globalization force and document significant $C H B$ variation across countries and over time, interpreting the inter-temporal $C H B$ variation as solution to the missing globalization puzzle in the trade literature 33

As emphasized by Anderson (2011), $C H B$ is an informative policy index since both the import and the export penetration ratios, which are traditional policy targets, can be expressed as linear functions of $C H B$ :

$$
\begin{array}{ll}
\text { Export Penetration : } & \sum_{i \neq j} \frac{X_{j i}}{Y_{j}}=1-C H B_{j} \times \frac{E_{j}}{Y}, \\
\text { Import Penetration : } & \sum_{i \neq j} \frac{X_{i j}}{E_{j}}=1-C H B_{j} \times \frac{Y_{j}}{Y} .
\end{array}
$$

Anderson, Milot and Yotov (2014) extend the CTB family by introducing the Constructed Foreign Bias (CFB), as the predicted volume of international export trade relative to the hypothetical frictionless volume of trade, and the Constructed Domestic Bias (CDB), as the ratio of fitted to frictionless intra-national trade, excluding trade within sub-regions in a country. CFBs may be particularly useful for evaluation of the effects of trade policy on international trade, while CDBs can be used to evaluate the intra-national effects of trade policy. ${ }^{34}$ Next, we discuss the most flexible GE trade cost index, the Constructed Trade Bias (CTB).

- Constructed Trade Bias (CTB). Agnosteva, Anderson and Yotov (2014) define Constructed Trade Bias as the ratio of the econometrically predicted trade flow $\widehat{X}_{i j}$ to

\footnotetext{
${ }^{32}$ Note that, in principle, the 'home bias' index can be constructed directly from data on intra-national sales, output and expenditure values, without the need to estimate the gravity model. This procedure is akin to the tetrads or other ratio methods, e.g. Romalis (2007) and Novy (2013a), used to construct bilateral trade costs in the literature. One important difference is that $C H B$ takes into account both the direct and the indirect effects of trade costs. Another difference is that by using predicted trade flows $C H B$ is free of potential measurement error concerns in the trade flows variable. Below, we discuss some important advantages and disadvantages of the calibration vs. estimation approaches.

${ }^{33}$ According to Coe et al. (2002) "the failure of declining trade-related costs to be reflected in estimates of the standard gravity model of bilateral trade might be called the missing globalization puzzle," (p. 1). The same authors conclude that "globalization is everywhere but in estimated gravity models" (p. 3). Yotov (2012) demonstrates that the effects of globalization are indeed present in the empirical, partial equilibrium gravity model.

${ }^{34}$ Note that CDBs are different from $C H B$ s. For example, in the case of Canada, $C H B$ s can be obtained for each province or territory's intra-regional trade, while the CDBs will be based on intra-provincial trade.
} 
the hypothetical frictionless trade flow between origin $i$ and destination $j$ :

$$
C T B_{i j} \equiv \frac{\hat{X}_{i j}}{Y_{i} E_{j} / Y}=\left(\frac{\hat{t}_{i j}}{\hat{\Pi}_{i} \hat{P}_{j}}\right)^{1-\sigma}
$$

Note that the right-hand side of $(23)$ is the predicted/constructed value of the composite trade cost term from the structural gravity equation. Thus, by definition, CTB is a measure of the combined (direct, via $t_{i j}$, and indirect, via the MR terms) effects of trade policy, or other trade costs changes, on bilateral trade. CTB can be constructed for given output and expenditure, i.e. in a Conditional GE environment, and also in a Full GE scenario that accounts for the effects of trade policy on country size. Agnosteva, Anderson and Yotov (2014) discuss four other appealing properties of CTB. First, as noted earlier, CTB is independent of the normalization needed to solve system (12)-13 for the multilateral resistances. Thus, CTB is comparable not only across countries but also over time and, in principle, across sectors as well. Second, CTB is independent of the elasticity of substitution $\sigma$, because it is constructed using the inferred volume effects that are due to power transforms of the bilateral trade costs $t_{i j}^{1-\sigma}$ 's, and the multilateral resistances $\Pi_{i}^{1-\sigma}$ s $\mathrm{s}$ and $P_{j}^{1-\sigma}$ 's. Third, CTB shares the good fit properties of gravity to infer central tendency out of the random errors that beset notoriously mis-measured bilateral trade flow data, i.e. CTB is a conditional expectation. Finally, the constructed bias idea can be extended and consistently aggregated to yield the family of general equilibrium indexes, some of which we discussed earlier, that capture the effects of trade policy on trade costs at various levels of regional aggregation.

- Terms of Trade (ToT). It is well known that terms of trade (ToT) and their changes in response to trade policy are notoriously hard to measure, especially if the goal is consistent measurement and comparison across countries and sectors. Anderson and Yotov (2016) recognize that the structural gravity model offers a convenient solution to obtain terms of trade indexes as follows:

$$
\operatorname{ToT}_{i}=\frac{\hat{p}_{i}}{\hat{P}_{i}}
$$

where $\hat{p}_{i}$ is the estimate of the factory-gate price, i.e. the producer price in country $i$, and $\hat{P}_{i}$ is the estimate of the inward multilateral resistance, i.e. the corresponding consumer price in country $i$. Importantly, the ToT index of Anderson and Yotov (2016) is independent of the normalization needed to solve system (12)-(13) for the multilateral resistances. This means that ToTs can be used for inter-temporal comparisons as well as for comparisons across sectors. Note also that under the endowment economy assumption of the Armington gravity model, the ToT index can be interpreted as a welfare/real income measure because the numerator in (24) can be interpreted as the change in nominal income $\hat{p}_{i}={\widehat{p_{i} Q_{i}}}_{i}$ in country $i$ in response to trade cost changes, while the denominator in (24) can be interpreted as the change in consumer prices in $i$ in response to the same trade cost changes. Using manufacturing data for 40 countries and an aggregate rest of the world region, Anderson and Yotov (2016) estimate that 
the FTAs improved the terms of trade for all but one of the countries that signed FTAs during the 90s. The regions that did not sign FTAs suffered small ToT losses. Based on these estimates, Anderson and Yotov (2016) conclude that the integration of the 90's benefited FTA members while hurting ToT/welfare in the outsiders by an amount too small to be noticeable 35

- Sufficient Welfare Statistics. In a recent and very influential paper, Arkolakis, Costinot and Rodríguez-Clare (2012) demonstrate that the welfare (real consumption) gains from trade liberalization obtained from a wide class of trade models with alternative micro foundations ${ }^{36}$ can all be expressed as a combination of two sufficient statistics including the change in intra-national trade as share of total expenditure and the trade elasticity. Applied to the Armington gravity model, which is the focus of this work, the analysis from Arkolakis, Costinot and Rodríguez-Clare (2012) implies that the welfare gains from trade are equal to:

$$
\frac{W_{i}^{C F L}}{W_{i}^{B L N}}=\left(\frac{\lambda_{i i}^{C F L}}{\lambda_{i i}^{B L N}}\right)^{\frac{1}{1-\sigma}}
$$

where: $W_{i}=E_{i} / P_{i}$ denotes welfare/real consumption in country $i, \lambda_{i i}=X_{i i} / E_{i}$ is the share of expenditure on home goods, $\sigma$ is the elasticity of substitution, and superscripts $C F L$ and $B L N$ denote values in the counterfactual and baseline scenario, respectively. E.g. $W^{C F L}$ is the counterfactual welfare value obtained in response to a change in trade costs. Importantly, similar to the ToT index above, the ACR index is independent of the normalizations needed to obtain the IMRs and the factory gate prices. We also note that the ACR index and the ToT index are equivalent in the ArmingtonCES setting. Costinot and Rodríguez-Clare (2014) demonstrate how one can take advantage of exact hat algebra methods from Dekle, Eaton and Kortum (2007, 2008) to obtain the desired gains from trade indexes. In Section 3, we employ the methods from Anderson, Larch and Yotov (2015a) to show how the ACR index, as well as all other general equilibrium indexes presented in this section, can be obtained from an estimating procedure (directly in Stata).

\footnotetext{
${ }^{35}$ While perfectly consistent with the structural gravity model, the ToT index of Anderson and Yotov (2016) departs from the conventional definition of terms of trade as the ratio of export prices over import prices because, by construction, the factory-gate prices and the inward multilateral resistances take into account intra-national trade flows. An easy solution is to solve the multilateral resistance system without the intra-national links: $P_{j}^{1-\sigma}=\sum_{i \neq j}\left(\frac{t_{i j}}{\Pi_{i}}\right)^{1-\sigma} \frac{Y_{i}}{Y}$ and $\Pi_{i}^{1-\sigma}=\sum_{j \neq i}\left(\frac{t_{i j}}{P_{j}}\right)^{1-\sigma} \frac{E_{j}}{Y}$. The OMRs from system (12)-(13) can then be used to construct corresponding factory-gate prices.

${ }^{30}$ The models considered by Arkolakis, Costinot and Rodríguez-Clare (2012) share four main assumptions including (i) Dixit-Stiglitz preferences; (ii) One factor of production; (iii) Linear cost functions; and (iv) Perfect or monopolistic competition. In addition, the following macro-level conditions must be satisfied: (i) Balanced trade; (ii) Aggregate profits are a constant share of aggregate revenues; and (iii) The import demand system is CES.
} 


\section{General Equilibrium Analysis with Structural Gravity}

We start this section with an outline and discussion of the standard steps that need to be taken in order to perform general equilibrium counterfactual experiments with the gravity model. Then, we summarize the analysis from Anderson, Larch and Yotov $(2015 a)$ who capitalize on the properties of the Poisson Pseudo-Maximum-Likelihood (PPML) estimator to offer a simple estimation procedure to perform GE analysis with the structural gravity model in standard statistical software packages such as Stata. We finish with two counterfactual experiments that complement the theoretical developments in this section and also establishes the empirical equivalence between the GE estimates that we obtain with the methods from Anderson, Larch and Yotov (2015a) and those from a standard, but computationally intensive, procedure that requires setting and solving the structural non-linear gravity system explicitly.

\subsection{Performing Counterfactuals with the Gravity Model}

Stimulated by the seminal papers of Eaton and Kortum (2002) and Anderson and van Wincoop (2003), a series of recent studies offer counterfactual analysis of the effects of various trade policies ${ }^{37}$ In addition to solid microfoundations (both on the supply side, as in Eaton and Kortum, 2002, and on the demand side, following Anderson and van Wincoop, 2003) and tight connection to the data, (Costinot and Rodríguez-Clare, 2014), these models share a similar approach to performing counterfactual experiments. Our goal in this section is to outline a general step-by-step process to perform GE counterfactual results with the gravity model. In order to facilitate exposition, we focus on the structural Armington-CES gravity system as our departing point:

$$
\begin{aligned}
X_{i j} & =\frac{Y_{i} E_{j}}{Y}\left(\frac{t_{i j}}{\Pi_{i} P_{j}}\right)^{1-\sigma}, \\
\Pi_{i}^{1-\sigma} & =\sum_{j}\left(\frac{t_{i j}}{P_{j}}\right)^{1-\sigma} \frac{E_{j}}{Y}, \\
P_{j}^{1-\sigma} & =\sum_{i}\left(\frac{t_{i j}}{\Pi_{i}}\right)^{1-\sigma} \frac{Y_{i}}{Y}, \\
p_{i} & =\left(\frac{Y_{i}}{Y}\right)^{\frac{1}{1-\sigma}} \frac{1}{\beta_{i} \Pi_{i}}, \\
E_{i} & =\phi_{i} Y_{i}=\phi_{i} p_{i} Q_{i} .
\end{aligned}
$$

- Step 1: Obtain Trade Costs and Trade Cost Elasticities Estimates. The goal at this stage is to obtain estimates of bilateral trade costs including estimates of the

\footnotetext{
${ }^{37}$ Among a universe of GE models that calibrate and simulate trade, the following are notable examples that all feature actual gravity estimations that accompany their counterfactual analysis: Anderson and Yotov (2010a), Egger et al. (2011), Egger and Larch (2011), Ossa (2011), Fieler (2011), Costinot, Donaldson and Komunjer (2012), Behrens et al. (2014), Eaton, Kortum and Sotelo (2013), Arkolakis et al. (2013), Allen, Arkolakis and Takahashi (2014), Felbermayr et al. (2015), Heid (2015) Caliendo and Parro (2015), and Heid and Larch (2016).
} 
elasticities of bilateral trade with respect to bilateral trade policy. Ideally, the analysis in this step will deliver estimates of all relevant trade costs and elasticity parameters that capture the response of bilateral trade with respect to bilateral trade policies, e.g. RTAs and bilateral tariffs, non-discriminatory export-promotion policies, e.g. export subsidies, and non-discriminatory import-protection policies, e.g. MFN tariffs or sanitary and phytosanitary standards.

Instead of estimating trade costs, some recent and influential academic papers calibrate bilateral trade costs by using combinations of ratios of bilateral trade. ${ }^{38}$ The idea is to net out all country-specific determinants of bilateral trade in order to isolate only the effects of bilateral trade costs (or even their time-varying components). The advantage of this approach is that, by construction, it delivers bilateral trade costs that match the trade data perfectly. One disadvantage is that this approach cannot identify the effects of specific trade policies. Thus, while elegant from a theoretical perspective, the approach of calibrating trade costs is often not very informative from a policy perspective. For example, the calibrating approach can estimate the effects of a $10 \%$ decrease in trade costs. However, it does not tell us what kind of trade policy can lead to such a decrease. Another, related, disadvantage of the calibration approach is that "no way is calibration a substitute for actual econometrics that tests [our] view about how the world works" (Krugman, 2011). In other words, applied to our analysis, a calibration approach would 'assume' an initial impact of trade policy instead of 'test', when data permit, whether a specific trade policy actually resulted in a significant desired impact. 39

In order to avoid these critiques, for most of the analysis in this chapter we will implement estimating techniques, which will overcomes the above-mentioned difficulties because: (i) it delivers all needed trade cost estimates, including estimates of the effects of specific trade policies of interest, within the same theory-consistent specification; (ii) it enables us to test for and to establish the presence of causal relationships between any specific trade policies of interest and bilateral trade flows; and (iii) it consistently delivers a remarkably good fit. It is possible, however, that despite our best efforts to capture all possible drivers of trade frictions, the error term in our gravity estimations may still contain some systematic information about trade costs. In order to account for such possibility, below we discuss the hybrid approach of Anderson, Larch and Yotov (2015a), who estimate trade costs and trade elasticities but also, in addition, treat the gravity error term as a component of trade costs, thus ensuring that their bilateral trade cost matrix matches the data perfectly.

In order to obtain the estimates of trade costs at this step, we recommend estimation of the generic econometric gravity model with PPML, panel data with intervals including intra-national trade flows, exporter-time fixed effects, importer-time fixed effects, and

\footnotetext{
${ }^{38}$ See for example Head and Ries (2001), Romalis (2007), Novy (2013b), and Caliendo and Parro (2015).

${ }^{39}$ We refer the reader to Dawkins, Srinivasan and Whalley (2001) and Krugman (2011) for general discussions on the advantages and disadvantages of calibration vs. estimation, and to Balistreri and Hillberry (2007, 2008) on the relation between calibration and estimation of the structural gravity model, which is the focus of our analysis.
} 
pair fixed effects:40

$$
\begin{aligned}
X_{i j, t}= & \exp \left[\pi_{i, t}+\chi_{j, t}+\mu_{i j}+\eta_{1} R T A_{i j, t}+\eta_{2} E S_{i, t} \times I N T L_{i j}\right] \times \\
& \exp \left[\eta_{3} M F N_{j, t} \times I N T L_{i j}\right]+\epsilon_{i j, t} .
\end{aligned}
$$

Here, for expositional simplicity: we use (i) an indicator for the presence of regional trade agreements between countries $i$ and $j$ at time $t, R T A_{i j, t}$, as a representative bilateral trade policy; (ii) a continuous variable for export subsidies, $E S_{i, t}$, as a representative unilateral export-promotion policy; and (iii) a continuous variable for MFN tariffs, $M F N_{j, t}$, as a representative non-uniform trade-protection policy. $I N T L_{i j}$ is a dummy variable that is equal to one for international trade and is equal to zero for intra-national trade. The idea is to capture the fact that export-promotion policies and import-protection policies apply only to international trade. Finally, as noted earlier, we assume that $\epsilon_{i j, t}$ is a stochastic error term that does not carry any systematic information about trade costs 41

Equipped with the estimates from Equation (31), in combination with data on the corresponding covariates, we can construct the matrix of baseline trade costs as:

$$
\left(\widehat{t}_{i j, t}^{B L N}\right)^{1-\sigma}=\exp \left[\hat{\mu}_{i j}+\hat{\eta}_{1} R T A_{i j, t}+\hat{\eta}_{2} E S_{i, t} \times I N T L_{i j}+\hat{\eta}_{3} M F N_{j, t} \times I N T L_{i j}\right] .
$$

Here, the three trade policy variables are exactly the same as the corresponding covariates from Equation (31), and the superscript $B L N$ stands for 'baseline'.

- Step 2: Define Counterfactual Scenario and Construct Corresponding Trade Costs. This step defines the counterfactual experiment of interest. Given our focus on trade policy, the counterfactual scenario will be the introduction or the removal of trade barriers. This will result in a change in bilateral trade costs. The definition of the trade policy variables for the counterfactual trade costs will depend on the policy question under investigation. For example, if we were interested in simulating the effects of a new bilateral trade agreement (e.g. between Mongolia and Japan), we would re-define the RTA dummy variable from Equation (31) to include this agreement by replacing the zeros in the observations involving the pair Mongolia-Japan with ones. Note that in the case of a trade agreement between Mongolia and Japan, we should also consider adjusting/shutting off the corresponding MFN tariffs and/or other barriers that are applied to Mongolian imports from Japan and vice versa, and which have been negotiated in the agreement. In principle, the policy maker has the flexibility to adjust all counterfactual policy variables as needed. This will result in a new matrix

\footnotetext{
${ }^{40}$ We refer the reader to the companion paper, Piermartini and Yotov (2015), for a detailed discussion of the data, challenges, solutions, and best practices for structural gravity estimations. See also Bergstrand, Larch and Yotov (2015) investigating the consequences of not controlling for time-varying exogenous unobservable country-pair-specific changes in bilateral export costs for the (partial) effects on trade of trade agreements, international borders, and bilateral distance.

${ }^{41}$ We think that such an assumption is not too strong in structural gravity estimations, especially in the presence of such a rich structure of fixed effects.
} 
of counterfactual bilateral trade costs:

$$
\left(\widehat{t}_{i j, t}^{C F L}\right)^{1-\sigma}=\exp \left[\hat{\mu}_{i j}+\hat{\eta}_{1} R T A_{i j, t}^{C F L}+\hat{\eta}_{2} E S_{i, t}^{C F L} \times I N T L_{i j}+\hat{\eta}_{3} M F N_{j, t}^{C F L} \times I N T L_{i j}\right],
$$

where the superscript $C F L$ stands for 'counterfactual'. The differences between the baseline trade costs defined in Equation (32) and the counterfactual trade costs from Equation (33) is the initial trade policy shock that we will introduce in our system. As we demonstrate below, this shock will translate into differences/changes in the key economic indicators of interest to the policy maker, e.g. trade, real consumption, physical capital accumulation, etc.

- Step 3 (Optional): Recover Additional Parameters and Exogenous Variables. This step will deliver values for all remaining parameters and exogenous unobservable variables in order to ensure that the model is perfectly consistent with the data, not only at the level of bilateral trade, which we have ensured in Step 1, but at all levels in the baseline scenario. Applied to gravity system (26)-(30), this step employs the system of market-clearing conditions (29) to construct the set of CES preference parameters $\beta_{i}$ at the initial factory-gate prices, which are all normalized. Alternatively, this step may be omitted (this is why we refer to it as optional) because, as demonstrated by Dekle, Eaton and Kortum (2008), exact hat algebra can be used to solve system (26)-(30) in changes. This will eliminate the preference parameters all together ${ }^{42}$ The disadvantage of solving the system in levels is that this requires this additional intermediate step, which obtains some additional parameters. The advantage of solving the system in levels is that the parameters obtained in this step can be compared with corresponding values from the literature or, even better, directly with corresponding moments from actual data in order to validate the model (Krugman, 2011; Ottaviano, 2014).

- Step 4: Solve the Baseline and the Counterfactual Model. Using the values obtained in Steps 1, 2, and 3, solve the structural gravity system (27)-(30) in the baseline and in the counterfactual scenario. As mentioned earlier, system (27)-(30) can be solved in levels or in changes, producing identical results. Regardless of the method of choice, this step can be performed in two stages, which are useful in decomposing the general equilibrium effects of trade policy and correspond to the Conditional GE scenario and to the Full Endowment GE scenario that were presented earlier:

- Step 4.a: Obtain Conditional GE Effects. This step will deliver indexes that capture the total (direct plus indirect) effects of changes in trade policy on trade costs, for given output and expenditure. For given parameter values and

\footnotetext{
${ }^{42}$ Note that the calibration or the elimination of the additional variables and parameters at this stage has different implications as compared to the calibration of trade costs that we discussed earlier. Whether we calibrate or eliminate the additional variables and the additional parameters in this step will not make any difference for the analysis in changes as those variables and parameters are exogenous to the model and they remain constant between the baseline and the counterfactual scenario. In the appendix, we solve the structural gravity system in changes and we discuss implications.
} 
trade cost matrices, as obtained in Steps 1, 2, and 3, system (27)-(28) translates any changes in bilateral and/or non-discriminatory trade policy (i.e. any changes in $t_{i j}$ ) into Conditional (for given output and expenditure) general equilibrium effects for all countries in the world. These effects are captured by the changes in the multilateral resistances. See Section 2.4 for further discussion.

- Step 4.b: Obtain Full Endowment GE Effects. System (27)-30 delivers the indexes that describe the Full Endowment GE response to trade policy changes. As discussed earlier (see Section 2.4), the market clearing conditions (29) translate the OMR changes into changes in factory-gate prices, which lead to changes in the value of output and aggregate expenditures via Equations (30), with additional direct implications for trade and indirect implications for the multilateral resistances. System (27)-30 consists of $5 \times N$ equations that need to be solved simultaneously and deliver values for the inward multilateral resistances, for the outward multilateral resistances, the factory-gate prices, and the value of output and aggregate expenditure. Unlike the MR system, system (27)-(30) is highly non-linear (even when the MRs are re-defined as power transforms) owing to the functional form for the factory-gate prices in the market clearing conditions. System (27)-(30) can be handled easily in Matlab. It can also be solved using the matrix capabilities of Mata in Stata. Finally, below we offer an easy implementation that obtains Full Endowment GE effects directly in Stata with an iterative procedure that only calls a standard Stata estimation command.

- Step 5: Collect and Report Indexes of Interest. Collect indexes of interest, e.g. MR terms, factory gate prices, etc. that are delivered directly from the gravity system, and/or use those indexes to construct other series, e.g. the terms of trade, real consumption, etc., that were presented in Section 2.5. With respect to reporting, we recommend the standard presentation in terms of percentage changes:

$$
\Delta \% \widehat{I N D}_{i, t}=\frac{\left(\widehat{I N D}_{i, t}^{C F L}-\widehat{I N D}_{i, t}^{B L N}\right)}{\widehat{I N D}_{i, t}^{B L N}} \times 100
$$

where: $\widehat{I N D}$ can be any index of interest and, as noted above, BLN and $C F L$ stand for 'baseline' and 'counterfactual', respectively.

- Step 6: Construct Confidence Intervals. The idea behind this step is that since the direct effects of trade policy from Step 1 may be estimated imprecisely, the estimation error should translate (and be accounted for) in the general equilibrium indexes from Step 5. Despite its intuitive appeal and economic and policy significance, constructing confidence intervals for the GE effects of trade policy is not as popular procedure as it should be in the trade literature. ${ }^{43}$ However, we believe that constructing

\footnotetext{
${ }^{43}$ See Anderson and Yotov (2010a), followed by Aichele, Felbermayr and Heiland (2014), Larch and Wanner (2014) and Anderson and Yotov (2016) for some efforts in that direction. Furthermore, in principle, the approach from Anderson, Larch and Yotov (2015a) may be used to deliver standard errors for GE effects
} 
confidence intervals is a good practice for at least two reasons. First, the confidence intervals will enable the researcher to gauge the significance of the GE effects of the trade policy in question. Second, the confidence intervals can serve as uncertainty bounds offering a more conservative and a more liberal estimate of the expected trade policy effects. Finally, while we recognize that constructing confidence intervals may be computationally intensive, we also note that implementing the procedure is straightforward. For example, in order to construct confidence intervals for the GE effects of various trade policies in their study, Anderson and Yotov (2016) first generate 200 sets of bootstrapped gravity estimates according to Step 1. Next, they use the gravity estimates to construct 200 sets of bilateral trade costs as described in Step 2. Following Steps 4 and 5, they then obtain 200 estimates for each of the indexes of interest, which are used to calculate $95 \%$ centered bootstrap confidence intervals as follows:

$$
\left[2 \widehat{I N D}-\widehat{I N D}_{(195)}^{B} ; 2 \widehat{I N D}-\widehat{I N D}_{(5)}^{B}\right]
$$

where: $\widehat{I N D}$ can be any index of interest obtained with the original estimates; and $\widehat{I N D}_{(5)}^{B}$ and $\widehat{I N D}_{(195)}^{B}$ are, respectively, the $5 t h$ and the $195 t h$ indexes from the ranked (from bottom to top) bootstrap sample $\left(\widehat{I N D}_{(1)}^{B}, \widehat{I N D}_{(2)}^{B}, \ldots, \widehat{I N D}_{(200)}^{B}\right)$.

\subsection{GE Trade Policy Analysis with Stata: GE PPML}

This section reviews the methods from Anderson, Larch and Yotov (2015a) who propose a simple econometric procedure that can be used to estimate general equilibrium effects of trade policy directly in standard software packages such as Stata. As we demonstrate with two applications in Section 3.3.2, the proposed procedure delivers results that are identical to those obtained from more complicated non-linear solvers, e.g. the ones employed in Matlab. At the same time, the greatest advantage of the estimation methods presented here is that they tremendously increase access to GE analysis for applied economists and for policy makers. In order to develop these methods, Anderson, Larch and Yotov (2015a) capitalize on a special property of the PPML estimator, documented by Arvis and Shepherd (2013) and Fally (2015), which ensures a perfect match between the structural gravity terms and the corresponding directional fixed effects:

$$
\exp \left(\hat{\pi}_{i, t}\right)=\frac{Y_{i, t}}{\hat{\Pi}_{i, t}^{1-\sigma}} \quad \text { and } \quad \exp \left(\hat{\chi}_{j, t}\right)=\frac{E_{j, t}}{\hat{P}_{j, t}^{1-\sigma}},
$$

where: $\hat{\pi}_{i, t}$ and $\hat{\chi}_{j, t}$ are estimates of the directional fixed effects from a structural gravity estimation equation, such as Equation 31 for example, and $\hat{\Pi}_{i, t}^{1-\sigma}$ and $\hat{P}_{j, t}^{1-\sigma}$ are the corresponding estimates of the multilateral resistance terms obtained by solving system (27)-(28).

Anderson, Larch and Yotov (2015a) use this property of the PPML estimator to offer a simple two-step estimation procedure that can be used to obtain Conditional GE effects of

directly from the estimates of the gravity fixed effects. As also noted by Anderson, Larch and Yotov (2015a), only recently the consistency of the model parameter estimates in nonlinear panel models with two types of fixed effects has been shown by Fernández-Valz and Weidner (2015). Hence, exploring the possibility to construct standard errors from the gravity directional fixed effects is an interesting future research area. 
trade policy directly in Stata. In addition, they exploit the full structure of the theoretical gravity model by also endogenizing the value of output and aggregate expenditure. This results in an iterative estimation procedure that can be used to obtain estimates of the Full Endowment GE effects of trade policy, once again, directly in standard estimation packages, e.g. Stata. Together with the direct/partial effects (from the PPML gravity estimates), this convenient procedure can be used to obtain and to decompose all the GE effects examined in this paper 44 The following steps summarize the methods of Anderson, Larch and Yotov $(2015 a)$ :

- Step 1': Estimate Baseline Gravity. Use the PPML estimator, panel data with intervals, exporter-time fixed effects, importer-time fixed effects, and pair fixed effects to estimate the structural gravity model:

$$
X_{i j, t}=\exp \left[\mathbf{T}_{i j, t} \boldsymbol{\beta}+\pi_{i, t}+\chi_{j, t}+\mu_{i j}\right]+\epsilon_{i j, t} .
$$

In specification (35) we use the vector $\mathbf{T}_{i j, t}$ to accommodate all possible bilateral and unilateral (either on the exporter or on the importer side) trade policy covariates. $\boldsymbol{\beta}$ is a conformable parameter vector. We chose PPML as our preferred estimator in this step for consistency with the rest of our procedure and due to its appealing properties for gravity estimations (see Santos Silva and Tenreyro, 2006, 2011). However, as emphasized by Anderson, Larch and Yotov (2015a), the proposed methods can readily accommodate three alternative and widely used approaches to treat bilateral trade costs and their elasticities in the existing literature. First, any (linear or non-linear) estimator can be employed to obtain the estimates of the trade cost elasticities $\boldsymbol{\beta}$ in a preliminary step. In fact, the whole vector of bilateral trade costs and the $\boldsymbol{\beta}$ 's and can even be borrowed from other studies as is routinely done in the literature. In case the estimates of the trade cost elasticities are obtained externally, Step 1' should be repeated with the external elasticity parameters imposed as constraints in the PPML estimation (35). Second, the whole trade cost vector is obtained externally, for example with the tetrads methods of Romalis (2007) or with any other ratio methods that are used in the literature. In case the trade cost matrix is obtained externally, Step 1' should be repeated with the given trade cost vector of choice imposed as a constraint in the PPML estimation (35). Finally, the methods of Anderson, Larch and Yotov (2015a) can be used to obtain trade costs from a hybrid procedure, which estimates the key elasticities of interest, while simultaneously matching the trade flows data perfectly, i.e. calibrating, by treating the error term, $\epsilon_{i j, t}$, from specification (35) as a component of the vector of trade costs.

Regardless of whether the gravity elasticities and the trade costs are obtained directly or if they are imposed as constraints in (35), the GE estimating procedure requires attention with respect to the estimation and interpretation of the directional fixed effects. Specifically, due to perfect collinearity, one of the directional fixed effects needs to be dropped in each year. In addition, as discussed earlier, a normalization of the set of $P$ 's and $\Pi$ 's is required to solve the structural gravity system in any case.

\footnotetext{
${ }^{44}$ The Stata toolkit that supplements this manuscript can also be extended to accommodate a wider class of GE effects and assertional GE indexes. For discussion see Anderson, Larch and Yotov $(2015 a)$.
} 
In order to maintain consistency, we follow Anderson, Larch and Yotov (2015a) and normalize the inward multilateral resistance for a representative country, $P_{0, t}=1$, and to drop the corresponding importer fixed effect, $\chi_{0, t}$. Finally, in practical terms, we recommend estimation without a constant term, which has a structural interpretation as the inverse of worldwide sales $Y_{t}$. In principle, this scaling term can be attached to either the exporter or to the importer fixed effects without any consequence. We choose to attach the constant to the exporter fixed effects, which become $\pi_{i, t}=Y_{i, t} /\left(\Pi_{i, t}^{1-\sigma} Y_{t}\right)$. Taking all of the above considerations into account, the interpretation of the dropped fixed effect in a given year is $\chi_{0, t}=E_{0, t}$, and all other fixed effects in that year are estimated (and should be interpreted) relative to $\chi_{0, t}$.

- Step 1'a: Construct Baseline Indexes. Use the estimates of the fixed effects from (35) together with data on output and expenditure to construct the multilateral resistances. To do this, employ definitions (34) while taking into account the normalization(s) imposed in Step 1':

$$
\widehat{\Pi}_{i, t}^{1-\sigma}=\frac{Y_{i, t}}{\exp \left(\hat{\pi}_{i, t}\right)} \times E_{0, t},
$$

and

$$
\widehat{P}_{j, t}^{1-\sigma}=\frac{E_{j, t}}{\exp \left(\hat{\chi}_{j, t}\right)} \times \frac{1}{E_{0, t}},
$$

where, by construction, $Y_{i, t}=\sum_{j} X_{i j, t}$ and $E_{j, t}=\sum_{i} X_{i j, t}$. Construct any other Baseline GE indexes of interest (e.g. real consumption, terms of trade, etc.).

- Step 2': Define Counterfactual Experiment. This step defines the policy experiment by changing the definition of the policy variables in vector $\mathbf{T}_{i j, t}$. For example, some popular scenarios include the introduction or the elimination of a regional trade agreement, reduction or increase in tariffs or export subsidies, etc. to obtain a new vector of trade policy covariates $\mathbf{T}_{i j, t}^{C F L}$, where $C F L$ stands for 'counterfactual'. In order to implement this one needs to re-define the policy variable(s) of interest to reflect desired trade policy changes in the counterfactual scenario. Alternatively, one may change the values for the trade cost elasticities, the $\boldsymbol{\beta}$ 's. However, for expositional simplicity, we will consider scenarios where the trade cost elasticities remain constant.

- Step 3': Estimate 'Conditional' Gravity. Use PPML to estimate the constrained gravity model:

$$
X_{i j, t}=\exp \left[\mathbf{T}_{i j, t}^{C F L} \overline{\boldsymbol{\beta}}+\pi_{i, t}^{C F L}+\chi_{j, t}^{C F L}+\bar{\mu}_{i j}\right]+\epsilon_{i j, t}^{C F L},
$$

where, the 'bar' symbol is used to capture the fact that certain coefficients are constrained to be equal to their estimated counterparts from Equation (35) in Step 1' or to their new values as defined in Step 2'.

- Step 3'a: Construct Conditional GE Effects. Repeat Step 1'a with the new fixed effects estimates from (38) and the original data on output and expenditure 
to construct the Conditional GE estimates of the multilateral resistances and construct any other GE indexes of interest. 45

- Step 4': Estimate Full Endowment Gravity. This step is performed in a loop, which delivers estimates of the the fixed effects that correspond to the Full Endowment scenario. This step is performed in three stages:

- Step 4'a: Allow for endogenous factory-gate prices. Use the market clearing conditions, $p_{i}=\left(\frac{Y_{i}}{Y}\right)^{\frac{1}{1-\sigma}} \frac{1}{\beta_{i} \Pi_{i}}$, to translate the Conditional GE effects on the MR terms to first-order changes in factory-gate prices:

$$
\frac{p_{i, t}^{C F L}}{p_{i, t}}=\left(\frac{\exp \left(\hat{\pi}_{i, t}^{C F L}\right)}{\exp \left(\hat{\pi}_{i, t}\right)}\right)^{\frac{1}{1-\sigma}}
$$

where we have applied the definition of the exporter fixed effect $\hat{\pi}_{i, t}=\frac{Y_{i, t} E_{0, t}}{\hat{\Pi}_{i, t}^{1-\sigma}} \underbrace{46}$

- Step 4'b: Allow for Endogenous Income, Expenditure and Trade. Allow for endogenous response in the value of output/income $Y_{i, t}^{C F L}=\left(p_{i, t}^{C F L} / p_{i, t}\right) Y_{i, t}$ and expenditure $E_{j, t}^{C F L}=\left(p_{j, t}^{C F L} / p_{j, t}\right) E_{j, t}$, which in turn will trigger additional changes in the MR terms and so forth. The changes in output, expenditure and the multilateral resistances, however, are controlled for by the fixed effects in gravity estimations and cannot be accounted for explicitly. Therefore, we use the structural gravity Equation (26) to translate the changes in output and expenditure, triggered by the changes in factory-gate prices, into changes in trade flows:

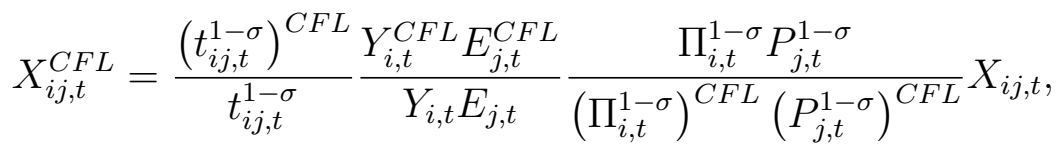

where $\left(t_{i j, t}^{1-\sigma}\right)^{C F L}=\exp \left(\mathbf{T}_{i j, t}^{C F L} \overline{\boldsymbol{\beta}}+\bar{\mu}_{i j}\right)$ and $t_{i j, t}^{1-\sigma}=\exp \left(\mathbf{T}_{i j, t} \boldsymbol{\beta}+\mu_{i j}\right)$. Note that Equation (40) accounts for the fact that a change in the factory-gate price will lead to changes in trade via several channels: via changes in output and OMRs on the exporter side, via changes in expenditure and IMRs on the importer side. Note also that the changes in trade implied by Equation 40 are not the Full Endowment GE changes. The reason is that they only reflect the Conditional OMR changes, which do not take into account the response of output and expenditures.

\footnotetext{
${ }^{45}$ Note that the counterfactual estimates of bilateral trade costs and the multilateral resistances are sufficient (in combination with the original data on output and expenditure) to construct any Conditional GE indexes. CTB and its variations can be of particular interest to policy makers because, under the Conditional GE scenario, the constructed biases capture the total (direct and indirect) effects of trade policy on trade costs at given output and expenditure.

${ }^{46}$ Note that specification (39) looks very similar to the exact hat algebra procedures from Dekle, Eaton and Kortum (2008). Note also, however, that the changes in the factory-gate prices implied by Equation (39) are not the Full Endowment GE changes. The reason is that they only reflect the Conditional OMR changes and do not allow for immediate changes in the value of output. This is why we label these initial changes in the factory-gate prices first-order.
} 
- Step 4'c: Estimate Structural Gravity. Repeat Step 3' with the new values for trade. The idea is that, using the new values of trade, the PPML estimator will translate the initial response of factory-gate prices into changes in the gravity fixed effects, which (in combination with the changes in trade) can be used to obtain additional responses in the MR terms. Repeat Step 4'a to obtain a new set of factory-gate prices. Repeat Step 4'b to obtain new values of trade (and income). Then re-estimate the model. Iterate until convergence, i.e. until the change in each of the factory-gate prices is close to zero.

- Step 4'd: Construct Full Endowment GE Effects. Construct new Full Endowment GE indexes of interest following the procedures from Step 1'a.

- Step 5': Construct Percentage Changes. The differences, in percentage, between the baseline indexes from Step 1'a and the counterfactual indexes from Step 3'a measure the Conditional GE effects of the simulated trade policy. The differences, in percentage, between the baseline indexes from Step 1'a and the counterfactual indexes from Step 4'd measure the Full Endowment GE effects of the simulated trade policy.

\subsection{Estimating GE Trade Policy Effects: Applications}

In this section, we follow the steps from Section 3.2 to estimate the general equilibrium effects of two trade policy experiments. The first hypothetical scenario removes all international borders in a cross-section setting, while the second application simulates the effects of the North American Free Trade Agreement (NAFTA). In addition to focusing on NAFTA as one of the most-widely studied regional trade agreements, the second application will enable us to obtain panel gravity estimates with the structural gravity model and to discuss certain estimation issues and challenges with the construction of bilateral trade costs. Finally, we note that the objectives of these applications are primarily instructional, however, the counterfactual experiments are performed with actual data and, therefore, each of them affords economic interpretation.

The sample that we employ in our experiments is a balanced panel that consists of 69 countries and covers aggregate manufacturing over the period 1986-2006 ${ }^{47}$ The sample combines data from several sources. Most importantly, it includes consistently constructed international and international trade flows data, which was assembled and kindly provided to us by Tom Zylkin. The original sources for the international trade data are the United Nations Statistical Division (UNSD) Commodity Trade Statistics Database (COMTRADE) database and the CEPII Trade, Production and Bilateral Protection Database (TradeProd).

\footnotetext{
${ }^{47}$ The dimensions of the data were predetermined by the availability of consistently constructed international and internal trade data. Our sample covers the following countries: Argentina, Australia, Austria, Belgium-Luxembourg, Bolivia, Brazil, Bulgaria, Cameroon, Canada, Chile, China, Colombia, Costa Rica, Cyprus, Denmark, Ecuador, Egypt, Finland, France, Germany, Greece, Hong Kong, Hungary, Iceland, India, Indonesia, Iran, Ireland, Israel, Italy, Japan, Jordan, Kenya, Kuwait, Macau, Malaysia, Malta, Mauritius, Malawi, Mexico, Morocco, Myanmar, Netherlands, Nepal, Niger, Nigeria, Norway, Panama, Philippines, Poland, Portugal, Qatar, Romania, Senegal, Singapore, South Africa, South Korea, Spain, Sri Lanka, Sweden, Switzerland, Tanzania, Thailand, Tobago, Trinidad, Tunisia, Turkey, Uruguay, United Kingdom, United States.
} 
COMTRADE is the primary data source and TradeProd is used for instances when it includes positive flows for observations when no trade flows are reported in COMTRADE. Intra-national trade for each country is constructed as the difference between total manufacturing exports and total manufacturing production. Importantly, both of these variables are reported on a 'gross' basis, which ensures consistency between intra-national and international trade. Three sources are used to construct the production data: the United Nations UNIDO Industrial Statistics (INDSTAT) database, the CEPII TradeProd database, and the World Bank Trade Production and Protection (TPP) database ${ }^{48}$ Our data on regional trade agreements are taken from Mario Larch's RTAs database ${ }^{49}$ Finally, all standard gravity variables including distance, contiguous borders, common language, and colonial ties are from the CEPII Distances database. An important advantage of the CEPII database is that the weighted-average methods that are used to construct distance ensure consistency between the measures of intra-national and international distance 50

\subsubsection{Trade Without Borders}

Many recent influential papers evaluate gains from trade in experiments that simulate a move from the observed level of trade to autarky (see for example Arkolakis, Costinot and Rodríguez-Clare, 2012, Costinot and Rodríguez-Clare, 2014). While this is an informative exercise that is suitable to demonstrate the usefulness of methods without high data demands, we believe that investigating the potential effects of removing all international borders should be equally interesting, especially from a policy perspective. In our first experiment, we follow the methods of Anderson, Larch and Yotov (2015a) to estimate the general equilibrium effects of removing the international borders for all countries in our database, while preserving the effects of geography. As noted earlier, the objective of this experiment is to demonstrate the efficiency and effectiveness of the methods that we presented thus far, however, our findings should also be interesting from an economic policy perspective. Removing all international borders, while preserving the effects of geography, gives an idea of the potential effects of full trade integration where there are no differences for consumers and producers whether to buy or sell on national or international (i.e. across national borders) markets, respectively. In other words, the results from this scenario can be interpreted as a quantification of the effects of an effective multilateral trade facilitation.

In order to obtain point estimates for the effects of international borders, the main variable of interest in this subsection, we use data for the latest year in our sample (2006) and specify a simple empirical cross-section gravity equation: 51

$$
X_{i j}=\exp \left(\beta_{1} \ln D I S T_{i j}+\beta_{2} C N T G_{i j}+\beta_{2} I N T L_{i j}+\pi_{i}+\chi_{j}\right)+\epsilon_{i j}
$$

\footnotetext{
${ }^{48}$ For further details on the construction of the trade data we refer the reader to Baier, Yotov and Zylkin (2016).

${ }^{49}$ Mario Larch's database includes all multilateral and bilateral trade agreements as notified to the World Trade Organization from 1950 onwards and it is based on information from the World Trade Organization (WTO) web site. The database can be accessed at http://www.ewf.uni-bayreuth.de/en/research/RTAdata/index.html.

${ }^{50}$ We refer the reader to Piermartini and Yotov (2015) for a detailed discussion on the most popular data sources and databases for gravity estimations.

${ }^{51}$ We note that while identification of the effects of some gravity covariates requires panel treatment, most counterfactual experiments can be performed with cross-section data.
} 
Here, the bilateral trade costs $t_{i j}^{1-\sigma}$ are approximated by the logarithm of bilateral distance, $\ln D I S T_{i j}$, an indicator variable that takes a value of one when trading partners $i$ and $j$ are contiguous, $C N T G_{i j}$, and an indicator variable for international borders, $I N T L_{i j}$, which takes a value of one for international trade and it is equal to zero otherwise. Note that the exporter and importer fixed effects, $\pi_{i}$ and $\chi_{j}$, respectively, account for the multilateral resistances as well as for outputs and expenditures. Hence, the gravity specification given in (41) is consistent with the structural gravity system as given by Equations (11)-(15).

We now follow the steps described in Section 3.2. The first step, Step 1, delivers the point estimates of the effects of distance, contiguity and international borders on international trade flows:

$$
X_{i j}=\underset{(0.050)}{\exp }\left(\mathbf{- 0 . 7 9 1} \ln D I S T_{i j}+\underset{(0.107)}{\mathbf{0 . 6 7 4} C N T G_{i j}}-\underset{(0.119)}{\mathbf{2 . 4 7 4} I N T L_{i j}}+\widehat{\pi}_{i}+\widehat{\chi}_{j}\right)+\widehat{\epsilon}_{i j} .
$$

All estimates are in accordance with prior expectations. We obtain a negative and highly statistically significant estimate of the effect of distance $\beta_{1}=-0.791$ (std.err. 0.050), which is readily comparable to the median meta-analysis estimate of -0.89 reported by Head and Mayer (2014). The impact of contiguity is also positive and highly significant as expected. The point estimate on $C N T G_{i j}, \beta_{2}=0.674$ (std.err. 0.107 ) is also close to the median summary index of 0.49 from Head and Mayer (2014). Finally, we turn to the main variable of interest in this section, $I N T L_{i j}$, to find that the effects of international borders are very large on average, even after controlling for geography. Specifically, our estimates suggest that, all else equal, international borders decrease trade by an average of 91.6 percent (std.err. 1.005), calculated as $\left(\exp \left[\widehat{\beta}_{3}\right]-1\right) \times 100$ and where we use the Delta method to construct the standard errors. Equipped with the estimates from Equation (42), we can construct all baseline indexes of interest as described in Step 1'a. We will use these baseline values to calculate their changes in response to the counterfactual shock, however, the indexes in levels are not reported here for brevity.

Next, we evaluate the 'Conditional GE' effects from the removal of international borders:

$$
X_{i j}=\exp \left(-0.791 \ln D I S T_{i j}+0.674 C N T G_{i j}+\pi_{i}^{C F L}+\chi_{j}^{C F L}\right)+\epsilon_{i j}^{C F L},
$$

where superscript $C F L$ denotes counterfactual values. Here, in accordance with Step 2 of the procedure described in Section 3.2, we have constrained the estimates on distance and contiguity to their baseline values from Equation 42 and we have removed the international border covariate. Note that removing $I N T L_{i j}$ from the trade cost specification is equivalent to keeping it with all values set to zero. Hence, this counterfactual investigates the effects of abolishing international borders, i.e., removing any trade cost specification differences between national and international trade. Using the estimates of the fixed effects and of the coefficients on the trade cost variables, we construct the multilateral resistances, total exports, and real consumption for each of the 69 countries in our sample, as described in Step 3'a.

In order to establish the validity of the proposed estimating procedure, we compare the results that we estimate in Stata with results that we obtain by solving the non-linear equation gravity system with a non-linear solver using Matlab in a series of scatter plots. ${ }^{52}$

\footnotetext{
${ }^{52}$ The Stata codes (implemented in Stata, StataCorp LP, 2013) and the Matlab codes (implemented in Matlab, Mathworks, 2013) are available upon request.
} 
Figures 1 and 2 provide scatter plots of the levels of the Conditional GE equilibrium and of the percentage changes from the Baseline to the Conditional GE scenario for the IMRs, OMRs, total exports and real GDP, respectively.

Most importantly, the scatter plots show that both methods lead to identical results, as the dots are all on the 45 degree line. In addition, from an economic perspective, we obtain large and heterogeneous conditional GE effects from the removal of international borders. We briefly analyze those effects by focusing on the percentage changes in exports and in real GDP. Our findings for exports appear in the bottom left panel of Figure 2 and we also complement them with the numerical corresponding values, which are in column (2) of Table1. Two findings are noteworthy. First, the estimated effects of abolishing international borders are quite large. The main reason is the large direct estimate of 2.474 for $I N T L_{i j}$ in specification (42). Second, the results show a wide heterogeneity, which is driven by country size, geography of countries, and initial openness of the countries. We remind the reader that the conditional GE effects on exports can also be interpreted as total impact of the removal of borders on trade costs at constant output and expenditure. Turning to the conditional GE changes in real GDP, which are reported in the bottom right panel of Figure 2, we find that abolishing international borders leads to welfare changes between about -10 percent for Singapore and 21 percent for Niger relative to our reference country Germany, where real GDP changes in the Conditional GE equilibrium are zero by construction. ${ }^{53}$

We follow Step 4 of the estimating procedure in Section 3.2 in order to obtain Full Endowment GE effects from the removal of international borders. Once again, we use plots to compare our Stata estimates with those obtained in Matlab. Figures 3 and 4 show the scatter plots of the levels of the Full Endowment GE equilibrium and the percentage changes from the Baseline to the Full Endowment GE scenario for the IMRs, OMRs, total exports and real GDP, respectively. Most importantly, and similar to our findings in the Conditional GE scenario, we find that the Full Endowment indexes that we obtain in Stata and in Matlab are identical. In addition, we find our estimates interesting and informative from an economic perspective. With respect to exports, the bottom left panel of Figure 4 and the corresponding values in column (3) of Table 1 reveal a substantial increase in total exports, which vary between 41 percentage points and 91 percentage points as compared to the conditional scenario 54 Turning to the Full GE effects on real GDP, which are plotted in the bottom right panel of Figure 4 and also appear as numerical values in column (4) of Table 1. we find that they are also large and vary significantly, with less developed and smaller economies benefitting significantly more as compared to developed and large countries. 55

In order to shed more light on the underlying forces behind our estimates for total exports

\footnotetext{
${ }^{53}$ In order to obtain the effects on real GDP, we had to chose a value for the elasticity of substitution. Following the literature, we chose $\sigma=7$. We refer the reader to Felbermayr et al. (2014) for a discussion of the sensitivity of the results in counterfactual gravity analysis to the choice of $\sigma$.

${ }^{54}$ We remind the reader that these results are obtained in an extreme scenario where all countries are positively affected by the abolishment of the international borders and the international border coefficient is large.

${ }^{55}$ As emphasized by Anderson, Larch and Yotov $(2015 a)$, the finding that more developed countries will gain less from a potential removal of international borders is in line with the undergraduate textbook intuition that the smaller of two countries gains more moving from autarky to free trade. Additionally, our findings are in line with the intuition from Arkolakis, Costinot and Rodríguez-Clare (2012) that larger countries with a larger home market share gain less.
} 
and real GDP, we report some additional results for the Full Endowment GE scenario in Table 1. Specifically, we report in column (5) the percentage changes in the IMRs, in column (6) the percentage changes of the OMRs, and in column (7) the percentage changes in producer prices. We remind the reader that the IMRs and OMRs are only determined up to a scalar due to the normalization needed to solve the MR system. We have chosen the IMR of Germany as our reference point. Hence, the IMR change in Germany is zero and the MR changes for all other countries should be interpreted relative to the effects of globalization on German consumers. We find that the OMR changes are substantially larger than the IMR changes. This result is consistent with the findings from Anderson and Yotov (2010a) who decompose the incidence of trade costs on the consumers and on the producers in Canada, and implies that most of the gains from globalization accrue on the producer side. For countries with small real GDP gains, like USA, Singapore, Korea, and China, we see an increase in the IMRs relative to Germany, while the OMRs decrease. This suggests that while the cost for producers in those countries to sell to international markets falls, consumer access to world markets is more difficult, relative to that for German consumers, after the removal of international borders. This leads to a smaller decrease of the consumer prices in those countries and, consequently, to lower gains in terms of real GDP. Countries with high increases in real GDP enjoy large decreases in both, IMRs and OMRs. Producer prices increase in all countries, but substantially more in countries with high real GDP increases, which is in line with the reported OMR effects.

Consistent with the initial motivation for our globalization experiment of abolishing international borders and in order to put our results into perspective, we compare our estimates with the corresponding indexes obtained by Costinot and Rodríguez-Clare (2014), who investigate a move from observed levels of trade to autarky. The respective results are reported in Table 4.1 in Costinot and Rodríguez-Clare (2014). The welfare gains in Costinot and Rodríguez-Clare (2014) for USA, for example (for their perfect competition framework with intermediates) are estimated to be 8.3 percent. Our estimate of potential gains from the removal of borders is very close at 10.6 percent. For Germany, Costinot and Rodríguez-Clare (2014) obtain a welfare increase of 21.3 percent, while we estimate an increase 24.3 percent. This similarity holds more or less for all comparable countries between the two studies and suggests that at this stage the world has enjoyed at most half of the possible gains from trade and trade liberalization and that there is significant scope for further gains from trade in the future 56

\subsubsection{On the GE Effects of NAFTA}

In this section, we follow the steps from Section 3.2 to estimate the general equilibrium effects of the North American Free Trade Agreement (NAFTA). We chose NAFTA because this is one of the most widely studied FTAs. Thus, despite the instructional nature of this experiment, our results can be compared to estimates from related studies. ${ }^{57}$ Similar to the

\footnotetext{
${ }^{56}$ In a one sector world and perfect competition, Costinot and Rodríguez-Clare (2014) obtain a value of 1.8 percent for the USA and 4.5 percent for Germany. With multiple sectors, but not allowing for intermediates, the values are 4.4 percent and 12.7 percent for USA and Germany, respectively.

${ }^{57}$ Recent studies that evaluate the effects of NAFTA include Shikher (2012), Rolleigh (2013), Zylkin (2014), Anderson, Larch and Yotov (2015b), and Caliendo and Parro (2015). Earlier examples include Kehoe (2003),
} 
previous application, we develop our analysis of the effects on NAFTA in two stages. First, we use Stata and we follow the step-by-step procedure described in Section 3.2 to obtain estimates of the GE effects of NAFTA . Then, after we present and analyze those estimates, we compare them with the corresponding numbers that are obtained by solving the nonlinear structural gravity system in Matlab. For this application we take advantage of the panel dimension of our data, as described in the beginning of this section.

We start by estimating a version of the empirical gravity model that will enable us to obtain estimates of bilateral trade costs including an estimate of the average effects of all RTAs in our sample:

$$
X_{i j, t}=\exp \left[\eta_{1} R T A_{i j, t}+\pi_{i, t}+\chi_{j, t}+\mu_{i j}\right]+\epsilon_{i j, t} .
$$

Here, RTA is an indicator variable that is equal to one if two countries are members of the same RTA, and it is equal to zero otherwise. Specification (44) is estimated following the six best-practice recommendations from Piermartini and Yotov (2015). Specifically, we estimate (44) with the PPML estimator, panel data with 4-year intervals ${ }^{58}$ that include consistent international and intra-national trade flows, exporter-time fixed effects $\left(\pi_{i, t}\right)$, importer-time fixed effects $\left(\chi_{j, t}\right)$, and pair fixed effects $\left(\mu_{i j}\right)^{59}$

As discussed in Piermartini and Yotov (2015), the pair fixed effects in specification (44) serve two important purposes in structural gravity estimations. First, their use will alleviate potential endogeneity concerns of the RTA dummy, which may arise due to selection of countries into RTAs (see Baier and Bergstrand, 2007). In addition, the pair fixed effects will absorb and control for all possible (observable and unobservable) time-invariant trade costs at the bilateral level. Combined with the ease in practical implementation, these properties of the pair fixed effects make them an appealing method to estimate bilateral trade costs. One potential issue that may arise with the use of pair fixed effects is that often one cannot identify the complete set of those estimates, e.g. when trade flows data is missing (or zero) for a given pair throughout the whole period under investigation 60 In this case, we follow the methods of Anderson and Yotov (2016) who propose and implement a two-stage procedure to construct trade costs. Stage 1 estimates Equation (44) and obtains estimates of the bilateral fixed effects for country-pairs with non-missing (or non-zero) trade flows. Then, stage 2 uses the estimates of the pair fixed effects as the dependent variable in a regression where the covariates include the set of standard gravity variables along with importer and exporter fixed effects ${ }^{61}$ Applied to our setting, the second stage regression to recover trade costs (not

Lederman, Maloney and Servén (2005), Trefler (2004, 2006), and Romalis (2007). Finally, NAFTA has been the object of interest of a series of papers from the computational general equilibrium literature from the 90s: See for example Brown, Deardorff and Stern (1992a b), McCleery (1992), Klein and Salvatore (1995), Fox (1999), and Krueger (1999).

${ }^{5}$ Thus, our sample includes the years 1986, 1990, 1994, 1998, 2002 and 2006.

59 We remind the reader that a normalization is needed in order to solve the structural gravity system and/or to estimate the empirical gravity model. Our choice is to set the inward multilateral resistance for Germany, $P_{D E U}=1$, a country for which reliable data is available for each variable and over the whole period of investigation, to be equal to 1 .

60 We refer the reader to Santos Silva and Tenreyro (2010) for a discussion of the existence of the maximum likelihood estimates in Poisson regression.

${ }^{61}$ As discussed in detail in Agnosteva, Anderson and Yotov (2014), the use of exporter and importer fixed 
including RTAs) takes the following form:

$$
t_{i j}^{1-\sigma}=\exp \left[\beta_{1} \ln D I S T_{i j}+\beta_{2} C N T G_{i j}+\beta_{2} L A N G_{i j}+\beta_{3} C O L O N Y_{i j}+\pi_{i}+\chi_{j}\right]+\epsilon_{i j},
$$

where $t_{i j}^{1-\sigma}=\exp \left[\hat{\mu}_{i j}\right]$, with $\hat{\mu}_{i j}$ obtained from estimating Equation (44). We take the predictions from regression (45) to fill up the missing trade cost values to obtain a final set of non-missing trade costs $t_{i j}^{1-\sigma}$.

Equation (44) delivers the estimate of the effects of the RTAs, $\hat{\eta}_{1}=.557$ (std.err. 0.056). Our estimate of $\eta_{1}$ implies that, on average, the RTAs have lead to about $\left(\exp \left[\widehat{\eta}_{1}\right]-1\right) \times$ $100=75 \%$ (std.err. 9.736) increase in trade among members, where we use the Delta method to construct the standard errors. Column (2) of Table 2 reports the increase in the total exports for each member due to NAFTA as percentage of their total exports. Our estimates reveal that all members experience a significant increase in exports. Mexico and Canada enjoy almost equal increase in total exports of about $57 \%$ and $55 \%$, respectively, while the increase for the US is smaller but still impressive 19\%. Finally, as discussed earlier, we note that countries that did not enter any RTAs during the period of investigation will not be subject to any direct/partial equilibrium effects by construction. The estimates of the directional fixed effects from Equation (44) are used to obtain Baseline GE trade cost indexes according to Step 2' from Section 3.2.

Next, we obtain Conditional GE Effects by re-defining the RTA dummy variable as if NAFTA were not in place. To do this, we estimate 62

$$
X_{i j, t}=\exp \left[\hat{\eta}_{1} R T A_{i j, t}^{C F L}+\pi_{i}^{C F L}+\chi_{j} v+\widehat{t_{i j}^{1-\sigma}}\right]+\epsilon_{i j, t}^{C F L}
$$

Here, $R T A_{i j, t}^{C F L}$ denotes the counterfactual $R T A$ dummy, which is obtained by setting the original RTA indicator variable to be equal to zero for trade between Canada, Mexico and the United states after 1993. ${ }^{63}$ The coefficient of the RT $A$ dummy as well as the bilateral fixed effects are constrained to their baseline values, $\hat{\eta}_{1}$ and $\widehat{t_{i j}^{1-\sigma}}$, respectively, ensuring that no

effects in the second-stage estimation is motivated by theory since gravity can only identify relative trade costs and, therefore, all pair fixed effects from specification (44) are estimated relative to intra-national trade costs.

${ }^{62}$ Note that in order to perform the conditional and, later on, the full GE analysis, we only need data for one appropriate year which we take as base year. In principle, it is possible to estimate phasing-in effects of NAFTA, which will vary over time, and then use the full panel dimension of our sample in order to obtain GE effects that correspond to the partial equilibrium phasing-in indexes in each year. While we view such an application as a useful exercise, given the instructional purpose of this monograph, we decided to focus here on the simpler case of a single RTA estimate for expositional simplicity.

${ }^{63}$ In this experiment we follow the top-down approach of Felbermayr et al. (2015) and make the implicit assumption that the effect of NAFTA is equal to the average effect of the RTAs from the period of investigation. This approach has the advantage that it captures additional non-tariff barriers to trade without the need of additional data and is easy to implement. However, it could potentially over- or underestimate the effects of NAFTA. If NAFTA goes deeper than the average agreement, it will underestimate the effect. However, it may also be the case that the easy barriers to trade have already been eliminated (such as huge tariffs), which will lead to an overestimation of the effects of NAFTA. An alternative approach is to obtain an RTA-specific estimate of the agreement under investigation exploiting the time variation. Applied to our setting, this means introducing an additional indicator covariate for NAFTA and then using the estimate of the NAFTA dummy to obtain the GE effects. See Zylkin (2014) and Baier, Yotov and Zylkin (2016) for recent efforts in that direction. 
part of the trade costs besides the $R T A$ dummy is changing. The estimates of the directional fixed effects from Equation (46) can be used to recover Conditional MR indexes (subject to a normalization). We will use these MR indexes at the end of the section, where we compare our Stata estimates with those obtained in Matlab. Instead, we now briefly focus on the Conditional effects of NAFTA on the exports of members and non-member countries, which are normalization-free. The ratio of the exports with and without NAFTA is:

$$
\frac{\sum_{j \neq i} X_{i j}}{\sum_{j \neq i} X_{i j}^{C F L}}=\frac{\sum_{j \neq i}\left(\hat{t}_{i j} /\left(\hat{\Pi}_{i} \hat{P}_{j}\right)\right)^{1-\sigma} \frac{E_{j}}{Y}}{\sum_{j \neq i}\left(\hat{t}_{i j}^{C F L} /\left(\hat{\Pi}_{i}^{C F L} \hat{P}_{j}^{C F L}\right)\right)^{1-\sigma} \frac{E_{j}}{Y}}=\frac{\sum_{j \neq i} C T B_{i j} \frac{E_{j}}{Y}}{\sum_{j \neq i} C T B_{i j}^{C F L} \frac{E_{j}}{Y}},
$$

where, in the rightmost equation, $C T B_{i j}=\left(\hat{t}_{i j} /\left(\hat{\Pi}_{i} \hat{P}_{j}\right)\right)^{1-\sigma}$ and $C T B_{i j}^{C F L}=$ $\left(\hat{t}_{i j}^{C F L} /\left(\hat{\Pi}_{i}^{C F L} \hat{P}_{j}^{C F L}\right)\right)^{1-\sigma}$, respectively. Note that the Conditional effects on members' and non-members' exports are captured by the change in the changes in the CTB index. Note also that, by construction, the weights used to aggregate CTB are the same in the Baseline and in the Conditional GE scenario. Since output and expenditure are not allowed to respond to changes in trade costs, the changes in exports reflect the change in total (direct and indirect) trade costs due to NAFTA.

Percentage change differences between the Baseline export levels (obtained in the presence of NAFTA) and the Conditional export levels (obtained as if NAFTA were note in place) are presented in column (3) of Table 2. Several findings stand out. First, as expected, we note that the biggest winners from NAFTA are the three member countries, which all experience significant increase in exports under this scenario. Mexico experiences the largest increase in exports of about $41.6 \%$. Canada follows with a $35.0 \%$ increase in exports. The United States is third with a $14.5 \%$ increase. Note that the increase in exports for each of the NAFTA members in the Conditional scenario is significantly smaller as compared to the direct increase that we obtained in the partial equilibrium scenario. The intuitive explanation is trade diversion. Part of the increase in trade with member countries comes at the expense of trade with non-members.

Trade diversion is also the reason for the negative estimates that we obtain for all of the outside countries. Overall, the effects on outside countries are small. The vast majority of non-NAFTA countries experience a decease in exports of less than 1\%. This is encouraging evidence in support of integration. The variation across non-members makes intuitive sense for the most part. Thus, for example, we find that the biggest losers from NAFTA are some Latin American economies. Colombia registers the largest decrease in exports of $1.8 \%$. Costa Rica and Ecuador also register losses of close to 1\%. The next countries in terms of export losses are Trinidad and Tobago, Chile, Argentina and Brazil. Other Latin American economies register losses of about $0.5 \%$ as well. The countries that were affected the least from NAFTA include some European economies (e.g. the Netherlands, Austria, Portugal, and Denmark) as well as Morocco and Tunisia. Weak trade ties with NAFTA members are a natural explanation for the small effects on those countries.

Next, we employ the iterative procedures described in Steps 4' and 5' from the previous section in order to obtain the Full Endowment GE effects of NAFTA. Percentage differences 
between the Baseline exports and their Full Endowment counterparts are reported in column (4) of Table 2. Overall, the estimates from column (4) are qualitatively identical to the corresponding numbers from column (2). However, we also notice some quantitative differences. First, we see that the effects on the exports of NAFTA members are a bit larger. The differences between the Conditional and the Full Endowment exports for NAFTA members are not very large but seem significant. For example, Mexican and Canadian exports increase by about 2 percentage points in the Full Endowment GE scenario, while US exports increase by 0.4 percentage points. The intuition for this result is that part of the decrease in bilateral trade costs due to NAFTA translates into additional gains for the producers in member countries who enjoy higher producer prices. In most cases, the increase in the size of the NAFTA members mitigates the negative effects on non-members' exports.

We also use our estimates to obtain measures of the welfare effects of NAFTA in the world. As noted earlier, the sufficient welfare statistic from Arkolakis, Costinot and RodríguezClare (2012) coincides with the ToT measure from Anderson and Yotov (2016) and both measure the effects on real GDP. Estimates of the Full Endowment welfare effects of NAFTA are reported in column (5) of Table 2. Our results suggest that the biggest winner, with an increase of $3.8 \%$ in real consumption is Mexico. ${ }^{64}$ Canada follows closely with a real consumption gain of $3.4 \%$, and we find that U.S. also experiences a gain from NAFTA, but it is only $0.33 \%$.

Next, we decompose the effects of NAFTA on the consumers and the producers in the world. Our estimates of the effects on consumers are reported in column (6) of Table 2, and the corresponding effects on producers are listed in column (7) of the same table. Several properties stand out. Focusing on the member countries, we note that both consumers and producers in Canada, Mexico and the US gain. The gains for consumers are captured by lower IMRs. The gains for producers are captured by lower OMRs and higher producer prices, reported in columns (7) and (8) of Table 2, respectively, and larger market sizes. Interestingly, but also as expected (and pushing inference to the limit), we find that most of the gains for Canada are mostly on the producer side, while consumers in Mexico and the US gain more than the respective producers. This is consistent with anecdotal evidence and complaints from US producers regarding the effects of NAFTA. Turning to outside countries, we note that the effect for many producers in the rest of the world is negative, i.e. they suffer lower producer prices. Interestingly, we see that some consumers in outside countries actually benefit from the formation of NAFTA and enjoy lower prices. This may be driven by the decrease of producer prices in many outside countries, which leads to lower import prices for consumers. It should be noted however that, due to our normalization choice, all consumer and producer effects that we obtain are relative to the effects on the consumers in Germany. Overall, despite some specification limitations, our results are comparable with findings from existing studies and serve their instructional purposes well.

We finish this section with an empirical demonstration of the equivalence between the results from the estimation GE analysis performed with the methods of Anderson, Larch and Yotov (2015a) and those from a standard, but computationally intensive, procedure that requires setting and solving the structural gravity system explicitly. In order to do

\footnotetext{
${ }^{64}$ It should be noted that our analysis does not take into account the effects of the Canada-US agreement from the late 80 s.
} 
this, we compare the Conditional and the Full Endowment estimates of the multilateral resistances (IMRs and OMRs), real GDP and total exports of countries that we obtain with the iterative estimation procedure in Stata with the corresponding numbers obtained by solving the non-linear gravity system in Matlab, both in level and changes. Figures 5 and 6 demonstrates that the Conditional indexes from the estimation in Stata and from the solution of the non-linear gravity system in Matlab are identical. Figures 7 and 8 confirm that this is also the case for the Full Endowment indexes. The equivalence between the two sets of GE indexes confirms the validity of the estimation methods from Anderson, Larch and Yotov $(2015 a)$.

\section{Nested Gravity}

The contribution of this section is threefold. The first goal is instructional. Specifically, we want to demonstrate how the Armington-CES gravity model can be integrated within a wider class of GE production models. As discussed at the beginning of Section 3.1, a large body of recent trade papers offer counterfactual analysis of the effects of various trade policies that are based on a variety of solid microfoundations and maintain tight connection to the data. For notable examples, we refer the reader to the papers in Footnote 37 and to Costinot and Rodríguez-Clare (2014) for an excellent review of the current state of the related literature. Instead, here we want to show how the key structural properties of the Armington-CES model can be used to endogenize production and to conveniently switch the additional general equilibrium channels on and off in order to study the impact of trade policy. The second goal of this section is methodological: We present and discuss dynamic gravity modeling. ${ }^{65}$ To do this, we review a recent contribution by Anderson, Larch and Yotov (2015b) who integrate Armington-CES gravity with a dynamic production model that allows for capital accumulation within a tractable nested general equilibrium framework. The third goal is practical: We complement the theoretical developments in this section and extend the general counterfactual procedures from Head and Mayer (2014) to accommodate dynamics. Importantly, we also demonstrate how the dynamic GE analysis presented here can be performed in Stata.

\subsection{Growth and Trade: A Dynamic Gravity Framework}

Policy makers and analysts on both sides of trade mega deals such as the Trans Pacific Partnership (TPP) and the Transatlantic Trade and Investment Partnership (TTIP) expect that these agreements will not only lead to more trade but also will stimulate investment.66

\footnotetext{
${ }^{65}$ Head and Mayer (2014) identify dynamic gravity modeling as a key area for future work by noting that all existing micro-foundations of empirical models of trade flows (e.g. gravity) are static and pointing to the "[E]conometric problem of how to handle the evolution of trade over time in response to changes in trade costs." (Head and Mayer, 2014, p. 189). Similarly, the large body of trade models that are covered by Costinot and Rodríguez-Clare (2014) are also static. Olivero and Yotov (2012) is an early exception that develops a dynamic gravity framework and uses theory to guide estimation and empirical analysis.

${ }^{66}$ While in this chapter we focus on the effects of regional trade agreements, a different literature investigates the questions which countries (see for example Baier and Bergstrand, 2004, Egger and Larch, 2008) and when (see for example Bergstrand, Egger and Larch 2016) regional trade agreements are concluded.
} 
At the same time, some scholars question the causal relationship between trade and growth (e.g. Frankel and Romer, 1999, Baldwin, 2000), while others point to the lack of appropriate tools to identify and quantify the endogenous links between trade and investment (e.g. Head and Mayer, 2014). Motivated by the gap between policymakers' expectations and scholars' doubts, Anderson, Larch and Yotov (2015b) (henceforth ALY) integrate the structural gravity model presented in Section 2 of this paper with a dynamic model of endogenous production and capital accumulation in the spirit of Lucas and Prescott (1971), Hercowitz and Sampson (1991) and Eckstein, Foulides and Kollintzas (1996). As a result, ALY develop a simple and tractable general equilibrium framework that establishes an intuitive, quantifiable relationship between trade liberalization and growth.

Retaining all assumptions from Section 2, ALY nest the $N$-country Armington model within a dynamic superstructure where representative households maximize the present discounted value of their lifetime utility. In addition to choosing how they source consumption (as before), consumers now also make endogenous decisions over how much to invest. The representative consumer's problem becomes:

$$
\begin{aligned}
\max _{\left\{C_{j, t}, \Omega_{j, t}\right\}} & \sum_{t=0}^{\infty} \gamma^{t} \ln \left(C_{j, t}\right), \\
Y_{j, t} & =P_{j, t} C_{j, t}+P_{j, t} \Omega_{j, t}, \\
C_{j, t} & =\left(\sum_{i} \beta_{i}^{\frac{1-\sigma}{\sigma}} c_{i j, t}^{\frac{\sigma-1}{\sigma}}\right)^{\frac{\sigma}{\sigma-1}}, \\
\Omega_{j, t} & =\left(\sum_{i} \beta_{i}^{\frac{1-\sigma}{\sigma}} I_{i j, t}^{\frac{\sigma-1}{\sigma}}\right)^{\frac{\sigma}{\sigma-1}} \\
Y_{j, t} & =p_{j, t} A_{j, t} L_{j, t}^{1-\alpha} K_{j, t}^{\alpha}, \\
E_{j, t} & =\phi_{j, t} Y_{j, t}, \\
K_{j, t+1} & =\Omega_{j, t}^{\delta} K_{j, t}^{1-\delta}, \\
K_{j, 0} & \text { given. }
\end{aligned}
$$

Equation (48) is the consumer's lifetime logarithmic utility function, which translates aggregate consumption into utility, where $\gamma<1$ is the subjective discount factor. Equation (49) is the consumer budget constraint, and it reflects the fact that, at each point of time $t$, consumers split their income between aggregate consumption $C_{j, t}$ and aggregate investment $\Omega_{j, t}$. Aggregate consumption is defined by Equation (50), which was introduced already earlier, in Section 2, as the CES utility function for the representative consumer in the original gravity model. Equation (51) is the CES investment aggregator that combines the investment varieties $I_{i j, t}$ into an aggregate investment good $\Omega_{j, t}$. Equation (52) defines the value of production. Importantly, the specification of production in 52 deviates from our original endowment economy assumption by introducing an additional channel, via capital accumulation, which endogenizes production $\left(Q_{j}\right)$ in the gravity model. Equation (53) relates aggregate expenditures to the value of production via $\phi_{j, t}$, indicating a trade deficit of country $j$ in $t$ (if $\phi_{j, t}>1$ ) and a trade surplus otherwise. The process of capital accumulation is subject to both a law of motion for the capital stock, given by (54), as well as known initial 
values, $K_{j, 0}$ in 55.67

Solving the consumer's optimization problem delivers the following dynamic system of trade and growth:

$$
\begin{aligned}
\operatorname{Direct}(P E): \quad & X_{i j, t}=\frac{Y_{i, t} E_{j, t}}{Y_{t}}\left(\frac{t_{i j, t}}{\Pi_{i, t} P_{j, t}}\right)^{1-\sigma}, \\
\Pi_{i, t}^{1-\sigma} & =\sum_{j}\left(\frac{t_{i j, t}}{P_{j, t}}\right)^{1-\sigma} \frac{E_{j, t}}{Y_{t}},
\end{aligned}
$$

Conditional GE :

$$
P_{j, t}^{1-\sigma}=\sum_{i}\left(\frac{t_{i j, t}}{\prod_{i, t}}\right)^{1-\sigma} \frac{Y_{i, t}}{Y_{t}}
$$

$$
p_{i, t}=\left(\frac{Y_{i, t}}{Y_{t}}\right)^{\frac{1}{1-\sigma}} \frac{1}{\beta_{i} \Pi_{i, t}}
$$

Full Endowment GE : $\quad Y_{i, t}=p_{i, t} A_{i, t} L_{i, t}^{1-\alpha} K_{i, t}^{\alpha}$,

$$
E_{i, t}=\phi_{i, t} Y_{i, t}
$$

$$
\text { Dynamic GE : } \quad K_{i, t+1}=\left[\gamma \delta \phi_{i, t} \frac{\alpha p_{i, t} A_{i, t} L_{i, t}^{1-\alpha} K_{i, t}^{\alpha-1}}{(1-\gamma+\delta \gamma) P_{i, t}}\right]^{\delta} K_{i, t} .
$$

System (56)- 62 looks familiar because it is very similar to the static gravity system (11)-(15) from Section 2. In fact, the first four equations of the two systems are absolutely identical, and if we shut off the capital accumulation channel of ALY, system (56)- 62 will collapse to the static system (11)-(15) from Section 2.4, i.e. the original gravity model is indeed nested in the new endogenous production superstructure with capital accumulation. This simplifies our analysis of the dynamic general equilibrium effects of trade policy tremendously, since all previous GE links that we discussed in Section 2.4 continue to hold, and all new dynamic GE linkages will be channeled through Equations (60) and (62), which are the only differences between systems (56)- 62 and (11)- 15). Accordingly, in the following discussion we focus our attention on the new production Equation (60) and on the new capital accumulation Equation (62). We start with the latter.

Equation 62 is the policy function for capital and, as expected, it captures the direct relationship between capital accumulation and the levels of technology, labor endowment, and current capital stock 68 More important for our purposes, Equation 62 reveals a di-

\footnotetext{
${ }^{67}$ As discussed in ALY, specification (54) departs from the standard linear law of motion for capital accumulation. However, this functional form delivers a closed-form solution for the transition path of capital accumulation, which is extremely convenient for analysis and decomposition of the GE effects of trade policy. ALY find small quantitative differences between the two capital accumulation specifications and offer a discussion of the advantages and disadvantages of the Cobb-Douglas approach as compared to its linear counterpart.

${ }^{68}$ ALY show that if the Cobb-Douglas specification for capital accumulation is replaced with the linear
} 
rect relationship between capital accumulation and domestic factory-gate prices, $p_{i, t}$, and an inverse relationship between capital accumulation and domestic inward multilateral resistances, $P_{i, t}$. Note that the numerator in the square brackets of Equation (62) is exactly the expression for the value of marginal product of capital. The intuition for the positive impact of factory-gate prices on capital accumulation is that, all else equal, an increase in $p_{i, t}$ translates into a higher value of marginal product of capital, which in turn stimulates investment. Importantly, as we established in Section 2.4, the factory-gate prices are general equilibrium indexes that will respond (via the market-clearing conditions) to changes in trade costs between any two countries in the world. Thus, a trade policy change in one country will not only affect investment in this country and in the partner countries, which are directly affected by the trade policy, but also in all other countries in the world.

The intuition behind the negative relationship between capital accumulation and the inward multilateral resistance, $P_{i, t}$, is twofold. Recognizing that $P_{i, t}$ is the CES price aggregator for consumption and for investment goods, an increase in $P_{i, t}$ means that consumption and investment goods are both more expensive. Thus, on the one hand, the inverse relationship between capital accumulation and the IMR reflects the law of demand for investment goods. At the same time, it also reflects the fact that when consumption becomes more expensive, investment will decrease because a higher share of income will be spent on consumption today and less will be saved and transferred for future consumption via capital accumulation. In other words, when consumption is more expensive, the opportunity cost of investment becomes higher and capital accumulation decreases. Importantly, the inward multilateral resistances are general equilibrium indexes and, as such, the IMR in one country responds to trade policy changes in any other country in the world. Equation 62 translates the GE changes in the IMRs into changes in capital accumulation. Thus, the changes in the IMRs can be viewed as embedded capital accumulation effects of trade liberalization.

The changes in capital in response to trade policy will translate into changes in the value of output/income via Equation (60). This relationship is direct, implying that more investment will lead to increase in output and, therefore, higher income. The effects on trade of the changes in income due to higher level of capital will be qualitatively identical to the effects of the changes in income in response to changes in factory-gate prices that we discussed in Section 2.4. Specifically, there will be a direct and an indirect effect on trade. The direct effect is that an increase in the size of an economy results in more exports and in more imports between this country and all of its trading partners. It is possible that the increase in size in a liberalizing country due to capital accumulation may actually stimulate exports from non-members to the extent that these effects dominate the standard trade diversion forces triggered by preferential trade liberalization.

The indirect effect of capital accumulation on trade is channeled through changes in trade costs. In particular, the changes in any country's size translate into changes in the multilateral resistances for all countries, which lead to changes in trade flows. As noted by ALY, this intuition reveals a channel through which preferential trade liberalization (e.g. a regional trade agreement) may benefit non-members. By making investment more attractive,

capital accumulation function, Equation $\sqrt{62}$ will be replaced with a standard Euler consumption equation. The difference between the two specifications in terms of quantitative implications are small, however, a closed-form solution of the dynamic gravity system can no longer be obtained. 
a regional trade agreement will stimulate growth in the member countries. This will lead to lower sellers' incidence for these countries, but also to lower buyers' incidence in nonmembers. The latter complements the direct positive size effect of member countries on non-member exports that we described above.

\subsection{Growth and Trade: From Theory to Empirics}

The objective of this section is to demonstrate how the extended gravity system can be translated into an intuitive econometric system that will serve modelers two important purposes. First, it will enable them to test the causal relationships between trade, income, and growth/capital accumulation. Second, it will deliver estimates of the structural parameters needed for counterfactual simulations. We present our analysis following the methods of Anderson, Larch and Yotov (2015b) that translates system (56)- 62 into the following econometric model:

$$
\begin{array}{ll}
\text { Trade : } & X_{i j, t}=\exp \left[\eta_{1} R T A_{i j, t}+\mu_{i j}+\pi_{i, t}+\chi_{j, t}\right]+\epsilon_{i j, t} ; \\
\text { Income }: & \ln Y_{j, t}=\kappa_{1} \ln L_{j, t}+\kappa_{2} K_{j, t}+\kappa_{3} \ln \left(\frac{1}{\Pi_{j, t}^{1-\sigma}}\right)+T F P_{j, t}+\vartheta_{j}+\nu_{t}+\varepsilon_{j, t} ; \\
\text { Capital : } & \ln K_{j, t}=\psi_{1} \ln E_{j, t-1}+\psi_{2} \ln K_{j, t-1}+\psi_{3} \ln P_{j, t-1}+\vartheta_{j}+\nu_{t}+\varsigma_{j, t} .
\end{array}
$$

Equation 63 is a version of the generic structural estimating gravity equation. It is estimated following the recommendations from Piermartini and Yotov $(2015)$ including directional fixed effects, pair fixed effects, the PPML estimator, and panel data with 4-year intervals over the period 1990-2011 ${ }^{69}$ Equation (63) delivers three important sets of estimates. First, it obtains the estimate $\left(\hat{\eta}_{1}\right)$ of the effects of regional trade agreements (RTAs), which can be used to approximate the direct effects of RTAs in a counterfactual analysis. In addition, Equation (63) delivers estimates of the pair fixed effects $\left(\hat{\mu}_{i j}\right)$, which are used to construct bilateral trade costs $\left(\hat{t}_{i j}\right){ }^{70}$ Finally, Equation $(63)$ also obtains estimates of the MR terms, which are used in the auxiliary (Income and Capital) regressions that, in turn, deliver the rest of the structural model parameters.

Equation (64) is obtained by substituting equation (59) for prices into equation (60) and log-linearizing the resulting expression. This equation delivers estimates of the elasticity of substitution $\hat{\sigma}=-1 / \hat{\kappa}_{3}$ and of the capital share $\hat{\alpha}=\hat{\kappa}_{2} \sigma /(\sigma-1)=\hat{\kappa}_{2} /\left(1+\hat{\kappa}_{3}\right) \cdot{ }^{71}$ Note also that a significant estimate of $\hat{\kappa}_{3}$ supports a causal relationship of trade on income.

\footnotetext{
${ }^{69}$ The original source for the trade data is the United Nations Statistical Division (UNSD) Commodity Trade Statistics Database (COMTRADE). Data on regional trade agreements (RTAs) are constructed based on information from the World Trade Organization's web site and are available at http://www.ewf.unibayreuth.de/en/research/RTA-data/index.html.

${ }^{\top 0}$ In principle, Equation (63) can be used directly to generate bilateral trade costs from the estimates of the pair fixed effects $\mu_{i j}$. However, due to missing (or zero) trade flows, we are not able to obtain estimates of the complete set of pair fixed effects and, instead, we adapt the procedure from Anderson and Yotov (2016), who regress the estimates of the pair fixed effects from (63) on a set of standard gravity variables and use these second-stage estimates to construct a complete set of bilateral trade costs that are used in the counterfactual experiments.

${ }^{71}$ The original source for the data on the value of output, labor, and capital stock is the latest edition of the Penn World Tables 8.0.
} 
Several econometric challenges need to be addressed in order to obtain sound estimates from Equation (64) ${ }^{72}$ First, we include country fixed effects $\vartheta_{j}$ to partially control for the unobservable technology $\left(A_{j, t}\right)$ and preference $\left(\beta_{j}\right)$ terms in our model. In addition, these fixed effects would also absorb any additional time-invariant differences between countries. We also add year fixed effects $\nu_{t}$ in order to control for any common (across countries) timevarying variables that may affect output in addition to the time-varying covariates that enter our specification explicitly. Finally, in order to account for possible additional high-frequency moves in $A_{j, t}$, which are not controlled for by the fixed effects, we also include a direct TFP covariate, a measure of research and development spending, and an index of the occurrence of natural disasters, which are summarized in the $T F P_{j, t}$ vector from Equation (64).

Endogeneity is another serious concern with the estimation of Equation (64). Most prominently, similar to the original trade-and-income regressions of Frankel and Romer (1999), our structural measure of trade openness, $\ln \left(1 / \Pi_{j, t}^{1-\sigma}\right)$, is potentially endogenous because it includes own national income. ${ }^{73}$ In addition to enabling us to recover an estimate of the elasticity of substitution from the estimate of the coefficient on $\ln \left(1 / \Pi_{j, t}^{1-\sigma}\right)$ in Equation (64), $\hat{\sigma}=-1 / \hat{\kappa}_{3}$, the structural approach presented here delivers a new instrument for the endogenous trade-openness regressor. Specifically, Anderson, Larch and Yotov (2015b) use guidance from theory to construct a trade-openness instrument that is based on international trade linkages only:

$$
\tilde{\Pi}_{i, t}^{1-\sigma}=\sum_{j \neq i}\left(\frac{t_{i j, t}}{P_{j, t}}\right)^{1-\sigma} \frac{E_{j, t}}{Y_{t}} .
$$

The explicit removal of the intra-national components, which include national income addresses "first-order" endogeneity concerns. In order to account for residual endogeneity Anderson, Larch and Yotov (2015b) employ, in addition, the original instrument from Frankel and Romer (1999), which is obtained from a first-stage gravity regression, where yearly trade flows are regressed on the vector of standard gravity variables and the logs of exporter and importer populations.

Finally, Equation (65) is obtained by using Equations (60) and (61) in Equation (62) and log-linearizing the resulting expression. This equation delivers the estimate of the capital depreciation rate $\hat{\delta}=1-\hat{\psi}_{2}$. In addition, a significant estimate of $\hat{\psi}_{3}$ would support a causal relationship of trade on capital accumulation. In order to account for potential endogeneity concerns of each of the regressors in Equation (65), Anderson, Larch and Yotov (2015b) introduce country fixed effects $\left(\vartheta_{j}\right)$ and year fixed effects $\left(\nu_{t}\right)$, which control for any unobserved and/or omitted country-specific and time-varying global effects that may affect capital accumulation, respectively. Additionally, they instrument for the endogenous regressors with their second lags, the second lag of our newly suggested instrument for openness, and the variable for occurrence of natural disasters. Finally, to account for potential endogeneity resulting from the lagged value of the dependent variable on the right-hand side Anderson, Larch and Yotov (2015b) also employ a dynamic panel estimator.

\footnotetext{
${ }^{72}$ We refer the interested reader to Anderson, Larch and Yotov $(2015 b, 2016)$ for a detailed discussion of the econometric specification and estimation of system (63)-(65).

${ }^{73}$ The rest of the main covariates in Equation (64) are potentially endogenous as well. Anderson, Larch and Yotov (2015b) use standard instruments to address this issue, and we refer the reader to their study for further details.
} 
Taking all of the above considerations into account, Anderson, Larch and Yotov (2015b) obtain the set of structural parameters that we report in Table 3. Without going into details, we note that these parameters are within the theoretical bounds and they are comparable to existing values from the literature. Specifically, the estimate of the effects of RTAs $(0.827$, std.err. 0.135) is very close to the corresponding index from Baier and Bergstrand (2007). The estimates of the bilateral trade costs are all greater than one with intuitive variation across country-pairs ${ }^{74}$ The estimates on the capital share $(\alpha)$ are also within the theoretical bounds, however they are a bit higher than expected. Sensitivity checks reveal that the variation of $\alpha$ over time and across rich vs. poor countries is intuitive. Furthermore, in their robustness experiments Anderson, Larch and Yotov (2015b) use the standard capital share value $\alpha=1 / 3$ from the literature. The estimate of the elasticity of substitution $(\sigma)$ varies between 4.084 (std.err. 0.394) and 11.282 (std.err. 3.701) across different specifications and all of the estimates of this important parameter are within the bounds that are established in the literature. Finally, Anderson, Larch and Yotov (2015b) obtain an estimate of the capital depreciation rate $\delta=0.061$ (std.err. 0.004). The estimate of the consumer discount factor is the only parameter that cannot be estimated directly from system (63)- (65), and which is borrowed from the literature and set to $\hat{\beta}=0.98$.

Armed with the parameters from Table 3 , Anderson, Larch and Yotov (2015b) employ system (56)-(62) to simulate ex post the effects of NAFTA. Anderson, Larch and Yotov (2015c) apply the same methods to study ex ante the effects of TTIP. Discussions of the results from these experiments are beyond the scope of this monograph, where the main focus is on methodological contributions. Accordingly, for further details we refer the interested reader to Anderson, Larch and Yotov $(2015 b$. c). Instead, in the next two sections we present two methodological extensions. First, we offer steps and discussion that extends the GE estimation procedures methods of Anderson, Larch and Yotov (2015a) to accommodate the dynamics. Then, we present an extension of the structural gravity system that demonstrates how the gravity framework can accommodate the important presence and trade of intermediate goods.

\subsection{Dynamic GE Trade Policy Analysis with Stata}

The goal of this section is to demonstrate how the methods of Anderson, Larch and Yotov (2015a), which we presented in Section 3.2, can be extended to accommodate the dynamic model of trade and growth that we introduced in the previous section. Capitalizing on the nested theoretical structure of the dynamic gravity model from the previous section, we extend the GE estimation procedures from Section 3.2 with two steps that capture the dynamic GE effects of trade policy due to endogenous capital accumulation within the structural gravity model:

- Step 6': Allow for Capital Accumulation. Use the policy function for capital given by Equation (62) to translate the Full Endowment GE effects of trade policy on

${ }^{74}$ These estimates constructed as $\widehat{t}_{i j}=\exp \left(\hat{\mu}_{i j}\right)^{1 /(1-\hat{\sigma})}$, where the estimate of the elasticity of substitution is $\hat{\sigma}=6$. As discussed in Anderson, Larch and Yotov (2015b), the few very large estimates, e.g. for the pair Uzbekistan-Dominican Republic (132.7), usually include as one partner one of the less developed former Soviet republics. 
the factory-gate prices and on the IMR terms to changes in capital stocks:

$$
\frac{K_{i, t+1}^{F E}}{K_{i, t+1}^{B L N}}=\left[\frac{Y_{i, t}^{F E}}{Y_{i, t}^{B L N}} \frac{P_{i, t}^{B L N}}{P_{i, t}^{F E}}\right]^{\delta}\left[\frac{K_{i, t}^{F E}}{K_{i, t}^{B L N}}\right]^{1-\delta},
$$

where: the superscript ' $F E$ ' stands for 'Full Endowment' (see for a derivation of our system in changes the Online Appendix F of Anderson, Larch and Yotov, 2015b). Note that accounting for the effects of capital accumulation requires a value for the capital depreciation rate $\delta$. The value of this parameter can be borrowed from the literature. Alternatively, as demonstrated by Anderson, Larch and Yotov (2015b, 2016), it can be obtained directly by estimating the econometric version of Equation (62) as an auxiliary regression in Stata.

- Step 7': Obtain Dynamic GE Effects. Translate the changes in capital into changes in the value of output and expenditures:

$$
\frac{Y_{i, t+1}^{F E}}{Y_{i, t+1}^{B L N}}=\frac{E_{i, t+1}^{F E}}{E_{i, t+1}^{B L N}}=\frac{p_{i, t+1}^{F E}}{p_{i, t+1}^{B L N}}\left[\frac{K_{i, t+1}^{F E}}{K_{i, t+1}^{B L N}}\right]^{\alpha},
$$

where the change in the factory-gate prices, $p_{i, t+1}^{F E} / p_{i, t+1}^{B L N}$, is calculated according to Equation (39) Then, update trade flows using Equation (40). Follow now the procedure described in Step 4'c, including Steps 6' and 7' as just described. Note that Equation (68) requires a value for the capital share $\alpha$. Similar to the value for the capital depreciation rate, $\alpha$ can be borrowed from the literature or it can be estimated directly from the econometric version of Equation (60) as an auxiliary regression in Stata. Note that the sequence of indexes between the initial Full Endowment scenario from Step 6 ' and the final indexes that are obtained upon convergence in this step describes the dynamic transition path. Construct new Dynamic GE indexes of interest following the procedures from Step 1'a. The differences, in percentage, between the Baseline indexes from Step 1'a and the counterfactual indexes from this step measure the Dynamic GE effects of the simulated trade policy. Comparison between the Full Endowment GE indexes from Step 6' and the Dynamic GE indexes from this step will measure the net dynamic effects of the trade policy in question.

\subsection{Dynamic Gravity with Intermediates}

Intermediate inputs represent more than half of the goods imported by the developed economies and close to three-quarters of the imports of some large developing countries, such as China and Brazil (Ali and Dadush, 2011). International production fragmentation and international value chains are less pronounced in some sectors, such as agriculture (Johnson and Noguera, 2012), but extreme in others, e.g. high tech products such as computers (Kraemer and Dedrick, 2002), consumer electronics such as iPods (Varian, 2007) and aircraft (Grossman and Rossi-Hansberg, 2012). Various models have recognized the important role of intermediate goods for production and trade and introduce intermediates within static 
settings. ${ }^{75}$ In this section we follow Anderson, Larch and Yotov (2015b) to demonstrate how intermediate goods can be introduced to the dynamic gravity framework from the previous section and we discuss the implications.

Following the approach of Eaton and Kortum (2002), intermediate inputs are combined with labor and capital via the following Cobb-Douglas production function:

$$
Y_{j, t}=p_{j, t} A_{j, t} K_{j, t}^{\alpha} L_{j, t}^{\xi} Q_{j, t}^{1-\alpha-\xi} \quad \alpha, \xi \in(0,1),
$$

where, $Q_{j, t}=\left(\sum_{i} \gamma_{i}^{\frac{1-\sigma}{\sigma}} q_{i j, t}^{\frac{\sigma-1}{\sigma}}\right)^{\frac{\sigma}{\sigma-1}}$ is the amount of intermediates used in country $j$ at time $t$ defined as a CES aggregator of domestic components $\left(q_{j j, t}\right)$ and imported components from all other regions $i \neq j\left(q_{i j, t}\right)$. Following the steps from our theoretical analysis in Section 4.1. we obtain the following system that describes the relationship between growth and trade in the presence of intermediate inputs: ${ }^{76}$

$$
\begin{aligned}
X_{i j, t} & =\frac{Y_{i, t} E_{j, t}}{Y_{t}}\left(\frac{t_{i j, t}}{\Pi_{i, t} P_{j, t}}\right)^{1-\sigma}, \\
\Pi_{i, t}^{1-\sigma} & =\sum_{j}\left(\frac{t_{i j, t}}{P_{j, t}}\right)^{1-\sigma} \frac{E_{j, t}}{Y_{t}}, \\
P_{j, t}^{1-\sigma} & =\sum_{i}\left(\frac{t_{i j, t}}{\Pi_{i, t}}\right)^{1-\sigma} \frac{Y_{i, t}}{Y_{t}}, \\
p_{i, t} & =\left(\frac{Y_{i, t}}{Y_{t}}\right)^{\frac{1}{1-\sigma}} \frac{1}{\beta_{i} \Pi_{i, t}}, \\
Y_{j, t} & =p_{j, t} A_{j, t} K_{j, t}^{\alpha} L_{j, t}^{\xi} Q_{j, t}^{1-\alpha-\xi}, \\
E_{j, t} & =\phi_{j, t} Y_{j, t}, \\
Q_{j, t} & =(1-\alpha-\xi) \frac{\phi_{j, t} Y_{j, t}}{P_{j, t}}, \\
K_{j, t+1} & =\left[\frac{\alpha \beta \delta \phi_{j, t} p_{j, t} A_{j, t} L_{j, t}^{\xi} Q_{j, t}^{1-\alpha-\xi}}{(1-\beta+\beta \delta) P_{j, t}}\right]^{\delta} K_{j, t}^{\alpha \delta+1-\delta} .
\end{aligned}
$$

System (70)- (77) is an extended version of the dynamic gravity system (56)- 62 from Section 4.1. Three important relationships between the two systems are worth a discussion. First, we note that the structural gravity system of Anderson (1979) and Anderson and van Wincoop (2003) appears directly and without any change in our new dynamic gravity system with intermediates. It is captured by equations $(70)-(73)$. Once again, this reinforces one of our main arguments about the power and flexibility of structural gravity, in the sense that it can be integrated within a large class of general equilibrium productions structures in its original version. The latter, of course, implies that all the nice properties of the structural gravity model that we presented and discussed earlier in this manuscript are preserved and remain to hold.

\footnotetext{
${ }^{75}$ See for example Eaton and Kortum (2002) and Caliendo and Parro $(2015)$.

${ }^{76}$ For details on the derivations we refer the reader to the online Appendix of Anderson, Larch and Yotov $(2015 b)$.
} 
Second, the introduction of intermediate goods adds a new layer of indirect and general equilibrium linkages that shape the relationship between trade and income. In combination, equations (74) and (76) introduce two additional general equilibrium links between income and trade. The first additional channel is due to the fact that own output is used as an intermediate input in production. Intuitively, this will magnify the effects of trade on income. In addition, importantly, we note that output in each country also appears as an intermediate in the production function of any other country. Thus, a trade policy that affects income anywhere in the world will have additional ripple effects in every country through this new channel. Note that the additional implications of the introduction of intermediates (in addition to the initial GE effect that is channeled via the factory-gate prices) for the relationship between trade and income can be summarized conveniently and traced more clearly by substituting the definition of intermediates from (76) into the income equation (74) and solving for $Y_{j, t}$. A new set of parameters will appear as a constant and in the power term of the new income equation, reflecting the importance of intermediates as captured by their share in production. In addition, more importantly, a new GE trade term will appear in the income equation. This is the multilateral resistance $P_{j, t}$ from Equation (76), which now appears intuitively as the price of intermediate goods.

Third, the introduction of intermediate goods adds a new layer of indirect and general equilibrium linkages that shape the relationship between trade and growth/capital accumulation. Equation (74) captures two additional effects of growth on trade, which are channeled through intermediate inputs: (i) The effect of own capital accumulation on trade is magnified because $K_{j, t}$ enters the production function (74) directly, as before, and indirectly, via the intermediates $Q_{j, t}$; (ii) More importantly, the introduction of intermediates opens a new channel through which foreign capital and foreign capital accumulation enter domestic production (via $Q_{j, t}$ ). This is an important new link because a change in domestic production will lead to changes in the demand for intermediates from all countries, which also affects trade. In addition, Equation (77) captures three new channels through which trade affects growth in the case of intermediates: (i) The effect of a change in the price of own capital on capital accumulation is magnified because own capital enters the policy function for capital directly, as before, and indirectly, via the intermediate inputs; (ii) Foreign capital and foreign capital accumulation now enter the policy function for domestic capital via the intermediate inputs; (iii) Finally, since foreign goods are used as intermediates and enter equation (77), any change in their prices will have further effects on domestic capital accumulation.

\section{Boundless Gravity: Extensions and Conclusion}

The main objective of this monograph was twofold. First, we hope that our efforts to offer a balanced and comprehensive practical guide to general equilibrium analysis of the effects of trade policy with the structural gravity model would lower the entry barriers to perform such analysis enough to open up the field to a larger number of policy makers and applied economists. We view the deep analysis of the general equilibrium links and causal mechanisms within the structural gravity model as one of our most important contributions in that direction. Another contribution that we deem valuable from a practical perspective is the focus and discussion of the counterfactual procedures which, importantly, we complement 
with a presentation of estimation GE procedures that can be performed directly with buildin estimation commands in standard statistical packages, such as Stata, and which deliver a host of GE trade cost indexes and their responses to trade policy changes.

Our second objective was to stimulate the interest of researchers to further extend the structural gravity framework. To achieve this goal, we demonstrated how the structural gravity model can be successfully nested within a larger-scale general equilibrium framework. Our focus was on a dynamic production model with capital accumulation, to which we also added intermediates. We hope that our analysis established effectively how gravity can be extended successfully in various directions and dimensions while at the same time preserving tractability and transparency. We view the following three directions as areas with significant potential for impactful contributions. First, we see some direct possibilities to extend the onesector gravity setting. Possible candidates here include modeling foreign direct investment and allowing for trade imbalances and borrowing and lending. Second, we think that the trade gravity model could be integrated with the new class of models that focus on intraregional structure, e.g. Allen and Arkolakis $(2014)$ and Redding (2016). Finally, we expect large payoffs of extending the dynamic gravity model of Anderson, Larch and Yotov (2015b) to accommodate sectoral analysis, which will enable researchers and policy makers to study the effects of trade policy on structural changes and their transition over time. 


\section{References}

Agnosteva, Delina E., James E. Anderson, and Yoto V. Yotov. 2014. "Intra-national Trade Costs: Measurement and Aggregation." NBER Working Paper No. 19872.

Aichele, Rahel, Gabriel J. Felbermayr, and Inga Heiland. 2014. "Going Deep: The Trade and Welfare Effects of TTIP." CESifo Working Paper No. 5150.

Ali, Shimelse, and Uri Dadush. 2011. "Trade in Intermediates and Economic Policy." VoxEU, 9 February 2011, available at http://www . voxeu.org/article/rise-trade -intermediates-policy-implications.

Allen, Treb, and Costas Arkolakis. 2014. "Trade and the Topography of the Spatial Economy." Quarterly Journal of Economics, 129(3): 1085-1140.

Allen, Treb, Costas Arkolakis, and Yuta Takahashi. 2014. "Universal Gravity." unpublished manuscript, available for download at http://www.econ. yale.edu/ $\sim \mathrm{ka265}$ / research. html.

Alvarez, Fernando, and Robert E. Lucas, Jr. 2007. "General Equilibrium Analysis of the Eaton-Kortum Model of International Trade." Journal of Monetary Economics, 54(6): 1726-1768.

Amman, Hans M., David A. Kendrick, and John Rust, ed. 1996. Handbook of Computational Economics. Vol. 1 of Handbook of Computational Economics, Elsevier.

Anderson, James E. 1979. "A Theoretical Foundation for the Gravity Equation." American Economic Review, 69(1): 106-116.

Anderson, James E. 2011. "The Gravity Model." Annual Review of Economics, 3: 133-160.

Anderson, James E., and Eric van Wincoop. 2003. "Gravity with Gravitas: A Solution to the Border Puzzle." American Economic Review, 93(1): 170-192.

Anderson, James E., and Eric van Wincoop. 2004. "Trade Costs." Journal of Economic Literature, 42(3): 691-751.

Anderson, James E., and J. Peter Neary. 2005. Measuring the Restrictiveness of International Trade Policy. Vol. 1 of MIT Press Books, The MIT Press.

Anderson, James E., and Yoto V. Yotov. 2010a. "The Changing Incidence of Geography." American Economic Review, 100(5): 2157-2186.

Anderson, James E., and Yoto V. Yotov. 2010b. "Specialization: Pro- and AntiGlobalizing, 1990-2002." NBER Working Paper No. 16301.

Anderson, James E., and Yoto V. Yotov. 2016. "Terms of Trade and Global Efficiency Effects of Free Trade Agreements, 1990-2002." Journal of International Economics, 99(C): 279-298. 
Anderson, James E., Catherine A. Milot, and Yoto V. Yotov. 2014. "How Much Does Geography Deflect Services Trade." International Economic Review, 55: 791-818.

Anderson, James E., Mario Larch, and Yoto V. Yotov. 2015a. "Estimating General Equilibrium Trade Policy Effects: GE PPML." CESifo Working Paper No. 5592.

Anderson, James E., Mario Larch, and Yoto V. Yotov. 2015b. "Growth and Trade with Frictions: A Structural Estimation Framework." NBER Working Paper No. $2137 \%$.

Anderson, James E., Mario Larch, and Yoto V. Yotov. 2015c. "On the Growth Effects of the Transatlantic Trade and Investment Partnership." unpublished manuscript.

Anderson, James E., Mario Larch, and Yoto V. Yotov. 2016. "Growth and Trade with Frictions: A Structural Estimation Framework." unpublished manuscript.

Arkolakis, Costas, Arnaud Costinot, and Andrés Rodríguez-Clare. 2012. "New Trade Models, Same Old Gains?" American Economic Review, 102(1): 94-130.

Arkolakis, Costas, Arnaud Costinot, Dave Donaldson, and Andrés RodríguezClare. 2015. "The Elusive Pro-Competitive Effects of Trade." NBER Working Paper No. 21370.

Arkolakis, Costas, Natalia Ramondo, Andrés Rodríguez-Clare, and Stephen Yeaple. 2013. "Innovation and Production in the Global Economy." NBER Working Paper No. 18972.

Arkolakis, Costas, Svetlana Demidova, Peter J. Klenow, and Andrés RodríguezClare. 2008. "Endogenous Variety and the Gains from Trade." American Economic Review, 98(2): 444-50.

Armington, Paul S. 1969. "A Theory of Demand for Products Distinguished by Place of Production." IMF Staff Papers, 16: 159-176.

Arvis, Jean-Francois, and Ben Shepherd. 2013. "The Poisson Quasi-Maximum Likelihood Estimator: A Solution to the "Adding Up" Problem in Gravity Models." Applied Economics Letters, 20(6): 515-519.

Baier, Scott L., and Jeffrey H. Bergstrand. 2004. "The Economic Determinants of Free Trade Agreements." Journal of International Economics, 64(1): 29-63.

Baier, Scott L., and Jeffrey H. Bergstrand. 2007. "Do Free Trade Agreements Actually Increase Members' International Trade?" Journal of International Economics, 71(1): 7295.

Baier, Scott L., Yoto V. Yotov, and Thomas Zylkin. 2016. "On the Widely Differing Effects of Free Trade Agreements: Lessons from Twenty Years of Trade Integration." unpublished manuscript.

Baldwin, Richard E. 2000. "Trade and Growth: Still Disagreement about the Relationships." OECD Economics Department Working Papers No. 264. 
Baldwin, Richard E., and Daria Taglioni. 2006. "Gravity for Dummies and Dummies for Gravity Equations." NBER Working Paper No. 12516.

Balistreri, Edward J., and Russell H. Hillberry. 2007. "Structural Estimation and the Border Puzzle." Journal of International Economics, 72(2): 451-463.

Balistreri, Edward J., and Russell H. Hillberry. 2008. "The Gravity Model: An Illustration of Structural Estimation as Calibration." Economic Inquiry, 46(4): 511-527.

Behrens, Kristian, Giordano Mion, Yasusada Murata, and Jens Südekum. 2014. "Trade, Wages, And Productivity." International Economic Review, 55: 1305-1348.

Bergstrand, Jeffrey H. 1985. "The Gravity Equation in International Trade: Some Microeconomic Foundations and Empirical Evidence." Review of Economics and Statistics, $67(3): 474-481$.

Bergstrand, Jeffrey H., Mario Larch, and Yoto V. Yotov. 2015. "Economic Integration Agreements, Border Effects, and Distance Elasticities in the Gravity Equation." European Economic Review, 78: 307-327.

Bergstrand, Jeffrey H., Peter H. Egger, and Mario Larch. 2016. "Economic Determinants of the Timing of Preferential Trade Agreement Formations and Enlargements." Econmic Inquiry, 54(1): 315-341.

Brown, Drusilla K., Alan V. Deardorff, and Robert M. Stern. 1992a. "A North American Free Trade Agreement: Analytical Issues and A Computational Assessment." The World Economy, 15(1): 11-30.

Brown, Drusilla K., Alan V. Deardorff, and Robert M. Stern. 1992b. "North American Integration." Economic Journal, 102(415): 1507-1518.

Caliendo, Lorenzo, and Fernando Parro. 2015. "Estimates of the Trade and Welfare Effects of NAFTA." Review of Economic Studies, 82(1): 1-44.

Chaney, Thomas. 2008. "Distorted Gravity: The Intensive and Extensive Margins of International Trade." American Economic Review, 98(4): 1707-1721.

Coe, David T., Arvind Subramanian, Natalia T. Tamirisa, and Rikhil Bhavnani. 2002. "The Missing Globalization Puzzle." IMF Working Paper No. 171.

Costinot, Arnaud, and Andrés Rodríguez-Clare. 2014. "Trade Theory with Numbers: Quantifying the Consequences of Globalization." Chapter 4 in the Handbook of International Economics Vol. 4, eds. Gita Gopinath, Elhanan Helpman, and Kenneth S. Rogoff, Elsevier Ltd., Oxford.

Costinot, Arnaud, Dave Donaldson, and Ivana Komunjer. 2012. "What Goods Do Countries Trade? A Quantitative Exploration of Ricardo's Ideas." Review of Economic Studies, 79(2): 581-608. 
Dawkins, Christina, T.N. Srinivasan, and John Whalley. 2001. "Calibration." In Handbook of Econometrics. Vol. 5, , ed. J.J. Heckman and E.E. Leamer, Chapter 58, 3653-3703. Elsevier.

Deardorff, Alan V. 1998. "Determinants of Bilateral Trade: Does Gravity Work in a Neoclassical World?" In The Regionalization of the World Economy. NBER Chapters, 7-32. National Bureau of Economic Research, Inc.

Deardorff, Alan V., and Robert M. Stern. 1986. The Michigan Model of World Production and Trade: Theory and Applications. Cambridge, MA:Cambridge, MA: MIT Press.

Dekle, Robert, Jonathan Eaton, and Samuel Kortum. 2007. "Unbalanced Trade." American Economic Review: Papers and Proceedings, 97: 351-355.

Dekle, Robert, Jonathan Eaton, and Samuel Kortum. 2008. "Global Rebalancing with Gravity: Measuring the Burden of Adjustment." IMF Staff Papers, 55(3): 511-540.

Dervis, Kemal, Jaime de Melo, and Sherman Robinson. 1982. General Equilibrium Models for Development Policy. Cambridge, MA:Cambridge, MA: MIT Press.

Dixon, Peter B., and B.R. Parmenter. 1996. "Computable General Equilibrium Modelling for Policy Analysis and Forecasting." In Handbook of Computational Economics. Vol. 1 of Handbook of Computational Economics, , ed. H. M. Amman, D. A. Kendrick and J. Rust, Chapter 1, 3-85. Elsevier.

Donaldson, Dave. 2016. "Railroads of the Raj: Estimating the Impact of Transportation Infrastructure." American Economic Review, forthcoming, available for download at http://economics.mit.edu/faculty/ddonald/publications.

Eaton, Jonathan, and Samuel Kortum. 2002. "Technology, Geography and Trade." Econometrica, 70(5): 1741-1779.

Eaton, Jonathan, Samuel Kortum, and Sebastian Sotelo. 2013. "International Trade: Linking Micro and Macro." in: Acemoglu, D., M. Arellano an E. Dekel (eds.), "Advances in Economics and Econometrics - Tenth World Congress", Volume II, Applied Economics, Cambridge: Cambridge University Press, 329-370.

Eckstein, Zvi, Costas Foulides, and Tryphon Kollintzas. 1996. "On the Many Kinds of Growth: A Note." International Economic Review, 37(2): 487-496.

Egger, Peter H., and Mario Larch. 2008. "Interdependent Preferential Trade Agreement Memberships: An Empirical Analysis." Journal of International Economics, 76(2): 384399.

Egger, Peter H., and Mario Larch. 2011. "An Assessment of the Europe Agreements' Effects on Bilateral Trade, GDP, and Welfare." European Economic Review, 55(2): 263279 . 
Egger, Peter H., Mario Larch, and Kevin E. Staub. 2012. "Trade Preferences and Bilateral Trade in Goods and Services: A Structural Approach." CEPR Working Paper No. 9051.

Egger, Peter H., Mario Larch, Kevin E. Staub, and Rainer Winkelmann. 2011. "The Trade Effects of Endogenous Preferential Trade Agreements." American Economic Journal: Economic Policy, 3(3): 113-143.

Fally, Thibault. 2015. "Structural Gravity and Fixed Effects." Journal of International Economics, 97(1): 76-85.

Felbermayr, Gabriel, Benedikt Heid, Mario Larch, and Erdal Yalcin. 2014. "The Role of TTIP in the New EU Trade Policy Strategy: A Quantitative Analysis with Special Emphasis on Austria." Report on behalf of the Federal Ministry of Economy, Family and Youth.

Felbermayr, Gabriel, Benedikt Heid, Mario Larch, and Erdal Yalcin. 2015. "Macroeconomic Potentials of Transatlantic Free Trade: A High Resolution Perspective for Europe and the World." Economic Policy, 83(3): 491-537.

Fernández-Valz, Iván, and Martin Weidner. 2015. "Individual and Time Effects in Nonlinear Panel Models with Large N, T." unpublished manuscript available for download at http://arxiv.org/pdf/1311.7065v3.pdf.

Fieler, Ana Cecília. 2011. "Nonhomotheticity and Bilateral Trade: Evidence and a Quantitative Explanation." Econometrica, 79(4): 1069-1101.

Fox, Alan K. 1999. "Evaluating the Success of a CGE Model of the Canada-U.S. Free Trade Agreement." unpublished manuscript, available for download at http://www-personal. umich.edu/ alanfox/uscfinal_ti.pdf.

Francois, Joseph F., and Kenneth A. Reinert, ed. 1998. Applied Methods for Trade Policy Analysis. Cambridge Books, Cambridge University Press.

Frankel, Jeffrey A., and David Romer. 1999. "Does Trade Cause Growth?" American Economic Review, 89(3): 379-399.

Gilbert, John, and Edward Tower. 2012. Introduction to Numerical Simulation for Trade Theory and Policy. World Scientific Books, World Scientific Publishing Co. Pte. Ltd.

Ginsburgh, Victor, and Michiel Keyzer. 2002. The Structure of Applied General Equilibrium Models. Vol. 1 of MIT Press Books, The MIT Press.

Grossman, Gene M., and Esteban Rossi-Hansberg. 2012. "Task Trade between Similar Countries." Econometrica, 80(2): 593-629.

Head, Keith, and John Ries. 2001. "Increasing Returns Versus National Product Differentiation as an Explanation for the Pattern of U.S.-Canada Trade." American Economic Review, 91(4): 858-876. 
Head, Keith, and Thierry Mayer. 2014. "Gravity Equations: Workhorse, Toolkit, and Cookbook." Chapter 3 in the Handbook of International Economics Vol. 4, eds. Gita Gopinath, Elhanan Helpman, and Kenneth S. Rogoff, Elsevier Ltd., Oxford.

Heid, Benedikt. 2015. "Regional Trade Agreements, Unemployment, and the Informal Sector." CESifo Area Conference on Global Economy.

Heid, Benedikt, and Mario Larch. 2016. "Gravity with Unemployment." Journal of International Economics, 101: 70-85.

Helpman, Elhanan, Marc Melitz, and Yona Rubinstein. 2008. "Trading Partners and Trading Volumes." Quarterly Journal of Economics, 123(2): 441-487.

Hercowitz, Zvi, and Michael Sampson. 1991. "Output Growth, the Real Wage, and Employment Fluctuations." American Economic Review, 81(5): 1215-1237.

Hertel, Thomas. 1997. "Global Trade Analysis: Modeling and Applications." GTAP Books, Cambridge University Press.

Hillberry, Russell H., Michael A. Anderson, Edward J. Balistreri, and Alan K. Fox. 2005. "Taste Parameters as Model Residuals: Assessing the "Fit" of an Armington Trade Model." Review of International Economics, 13(5): 973-984.

Johnson, Robert C., and Guillermo Noguera. 2012. "Accounting for Intermediates: Production Sharing and Trade in Value Added." Journal of International Economics, 86(2): 224-236.

Jones, Ronald W. 1965. "The Structure of Simple General Equilibrium Models." Journal of Political Economy, 73: 557-572.

Kehoe, Timothy J. 2003. "An Evaluation of the Performance of Applied General Equilibrium Models of the Impact of NAFTA." Federal Reserve Bank of Minneapolis Working Paper No. 320, available for download at https://www.minneapolisfed.org/research/sr/sr320.pdf.

Klein, Lawrence R., and Dominick Salvatore. 1995. "Welfare Effects of the North American Free Trade Agreement." Journal of Policy Modeling, 17(2): 163-176.

Kraemer, Kenneth, and Jason Dedrick. 2002. "Dell Computer: Organization of a Global Production Network." unpublished manuscript, available for download at http://crito. uci.edu/papers/2002/dell.pdf

Krueger, Anne O. 1999. "Trade Creation and Trade Diversion Under NAFTA." NBER Working Paper No. 7429.

Krugman, Paul R. 1980. "Scale Economies, Product Differentiation, and the Pattern of Trade." American Economic Review, 70(5): 950-959. 
Krugman, Paul R. 1995. "Increasing Returns, Imperfect Competition and the Positive Theory of International Trade." In Handbook of International Economics. Vol. 3 of Handbook of International Economics, , ed. G. M. Grossman and K. Rogoff, Chapter 24, 12431277. Elsevier.

Krugman, Paul R. 2011. "Calibration And All That (Wonkish)." New York Times Column from October 18th, 2011.

Larch, Mario, and Joschka Wanner. 2014. "Carbon Tariffs: An Analysis of the Trade, Welfare and Emission Effects." CESifo Working Paper No. 4598.

Leamer, Edward E., and James Levinsohn. 1995. "International Trade Theory: The Evidence." Chapter 26 in the Handbook of International Economics Vol. 3, eds. Gene M. Grossman and Kenneth S. Rogoff, Elsevier Ltd., Oxford, 3: 1339-1394.

Lederman, Daniel, William F. Maloney, and Luis Servén. 2005. Lessons from NAFTA for Latin America and the Caribbean. Palo Alto, California and Washington, DC.:Stanford University Press and the World Bank, Latin American Development Forum Series.

Lucas, Robert E., and Edward C. Prescott. 1971. "Investment Under Uncertainty." Econometrica, 39(5): 659-681.

Mathworks. 2013. "Matlab: Release 2013b." 3 Apple Hill Drive, Natick, MA 01760-2098, United States, http://www.mathworks.com/.

McCallum, John. 1995. "National Borders Matter." American Economic Review, 85(3): 615-623.

McCleery, R.K. 1992. "An Intertemporal Linked Macroeconomic CGE Model of the United States and Mexico Focussing on Demographic Change and Factor Flows." Paper 8 in the Addendum of Economy-Wide Modeling of the Economic Implications of a FTA with Mexico and a NAFTA with Canada and Mexico, eds. Joseph F. Francois and Clinton R. Shiells, Report on Investigation No. 332-317 Under Section 332 of the Tariff Act of 1930, USITC Publication 2516, United States International Trade Commission, Washington, DC.

Melitz, Marc J. 2003. "The Impact of Trade on Intra-Industry Reallocations and Aggregate Industry Productivity." Econometrica, 71(6): 1695-1725.

Novy, Dennis. 2013a. "Gravity Redux: Measuring International Trade Costs With Panel Data." Economic Inquiry, 51(1): 101-121.

Novy, Dennis. 2013b. "International Trade without CES: Estimating Translog Gravity." Journal of International Economics, 89(2): 271-282.

Olivero, María Pía, and Yoto V. Yotov. 2012. "Dynamic Gravity: Endogenous Country Size and Asset Accumulation." Canadian Journal of Economics, 45(1): 64-92. 
Ossa, Ralph. 2011. "A 'New Trade' Theory of GATT/WTO Negotiations." Journal of Political Economy, 119(1): 122-152.

Ottaviano, Gianmarco I.P. 2014. "European Integration and the Gains from Trade." CEP Discussion Paper No. 1301, available for download at http://cep.lse.ac.uk/pubs/download/dp1301.pdf.

Piermartini, Roberta, and Yoto V. Yotov. 2015. "Estimating Trade Policy Effects with Structural Gravity." unpublished manuscript.

Ravenstein, Ernest George. 1889. "The Laws of Migration: Part 2." Journal of the Royal Statistical Society, 52(2): 241-305.

Redding, Stephen J. 2016. "Goods Trade, Factor Mobility and Welfare." Journal of International Economics, forthcoming.

Redding, Stephen J., and Anthony J. Venables. 2004. "Economic Geography and International Inequality." Journal of International Economic, 62(1): 53-82.

Rolleigh, Michael M. 2013. "Plant Heterogeneity and Applied General Equilibrium Models of Trade: Lessons from the Canada-US Free Trade Agreement." unpublished manuscript, available for download at http://econ.williams.edu/files/trade_2013.pdf.

Romalis, John. 2007. "NAFTA's and CUSTFA's Impact on International Trade." Review of Economics and Statistics, 89(3): 416-435.

Samuelson, Paul A. 1952. "The Transfer Problem and Transport Costs: The Terms of Trade when Impediments are Absent." Economic Journal, 62(246): 278-304.

Santos Silva, João M.C., and Silvana Tenreyro. 2006. "The Log of Gravity." Review of Economics and Statistics, 88(4): 641-658.

Santos Silva, João M.C., and Silvana Tenreyro. 2010. "On the Existence of the Maximum Likelihood Estimates in Poisson Regression." Economics Letters, 107(2): 310-312.

Santos Silva, João M.C., and Silvana Tenreyro. 2011. "Further Simulation Evidence on the Performance of the Poisson Pseudo-Maximum Likelihood Estimator." Economics Letters, 112(2): 220-222.

Shikher, Serge. 2012. "Predicting the Effects of NAFTA: Now We Can Do It Better!" Journal of International and Global Economic Studies, 5(2): 32-59.

Shoven, John B., and John Whalley. 1984. "Applied General-Equilibrium Models of Taxation and International Trade: An Introduction and Survey." Journal of Economic Literature, 22(3): 1007-51.

Shoven, John B., and John Whalley. 1992. Applying General Equilibrium. Cambridge University Press. 
StataCorp LP. 2013. "Stata Statistical Software: Release 13.1." College Station, Texas 77845 USA, http://www.stata.com/.

Tinbergen, Jan. 1962. Shaping the World Economy: Suggestions for an International Economic Policy. New York:The Twentieth Century Fund.

Trefler, Daniel. 2004. "The Long and Short of the Canada-U.S. Free Trade Agreement." American Economic Review, 94(4): 870-895.

Trefler, Daniel. 2006. "The Long and Short of the Canada-U.S. Free Trade Agreement." STICERD - Economics of Industry Papers 41, Suntory and Toyota International Centres for Economics, availabe for download at http://sticerd.lse.ac.uk/dps/ei/EI41.pdf.

Varian, Hal R. 2007. "An iPod Has Global Value. Ask the (Many) Countries That Make It." The New York Times (June 28, 2007), availabe at http://www.nytimes.com/ 2007/06/28/business/worldbusiness/28scene.html?_r=0.

Yotov, Yoto V. 2012. "A Simple Solution to the Distance Puzzle in International Trade." Economics Letters, 117(3): 794-798.

Zylkin, Thomas. 2014. "Not all Free Trade Agreements have the Same Advantages." School of Economics Working Paper Series. 

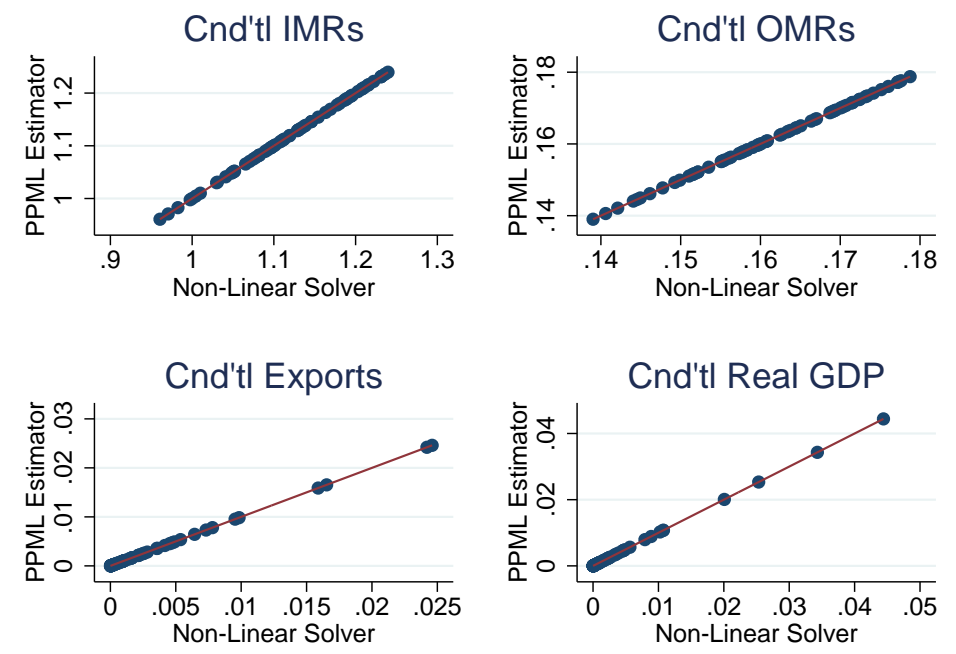

Note: These figures compare the results from Matlab and Stata for (clockwise, starting from the upper left) the IMR, OMR, the real GDP (in 100m dollars), and total exports (in $100 \mathrm{~m}$ dollars) of each country for the Conditional GE effects when abandoning international borders.

Figure 1: Trade Without Borders Conditional GE Results: Matlab versus Stata
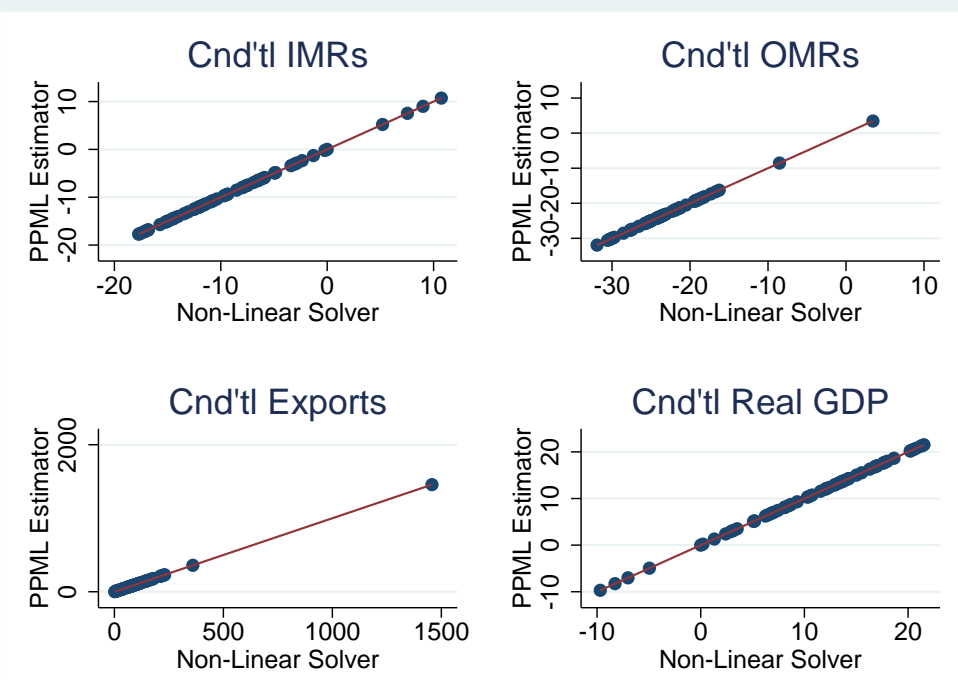

Note: These figures compare the results from Matlab and Stata for (clockwise, starting from the upper left) the changes (in percent) of the IMR, the changes (in percent) of the OMR, welfare effects in percent (calculated as changes in real GDP), and the changes (in percent) of total exports of each country for the Conditional GE effects when abandoning international borders.

Figure 2: Trade Without Borders Conditional GE Indexes: Matlab versus Stata 

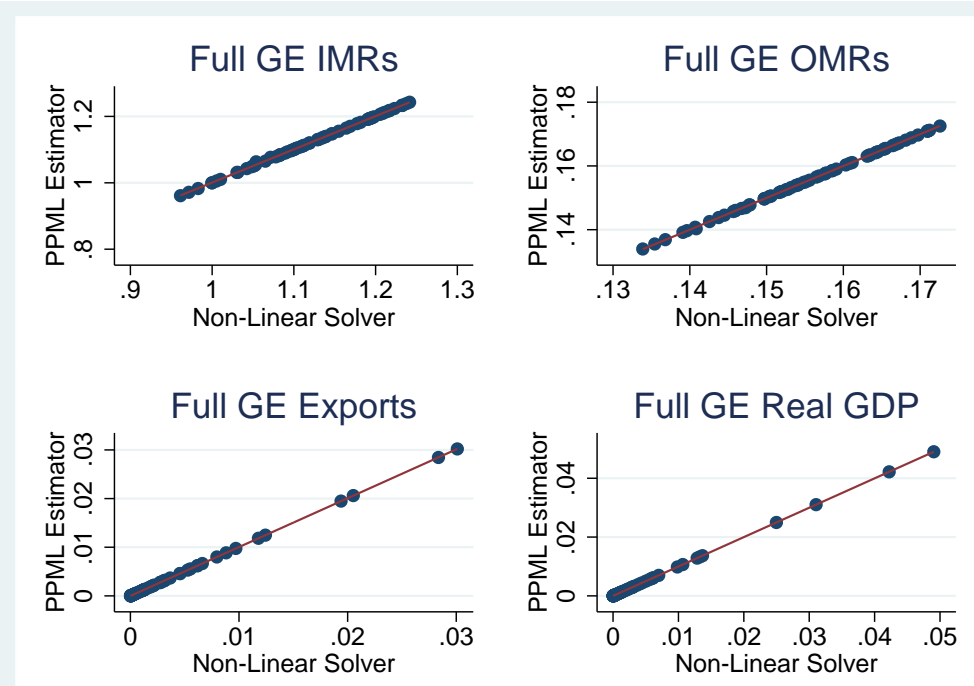

Note: These figures compare the results from Matlab and Stata for (clockwise, starting from the upper left) the IMR, OMR, the real GDP (in 100m dollars), and total exports (in 100m dollars) of each country for the Full Endowment GE effects when abandoning international borders.

Figure 3: Trade Without Borders Full Endowment GE Results: Matlab versus Stata

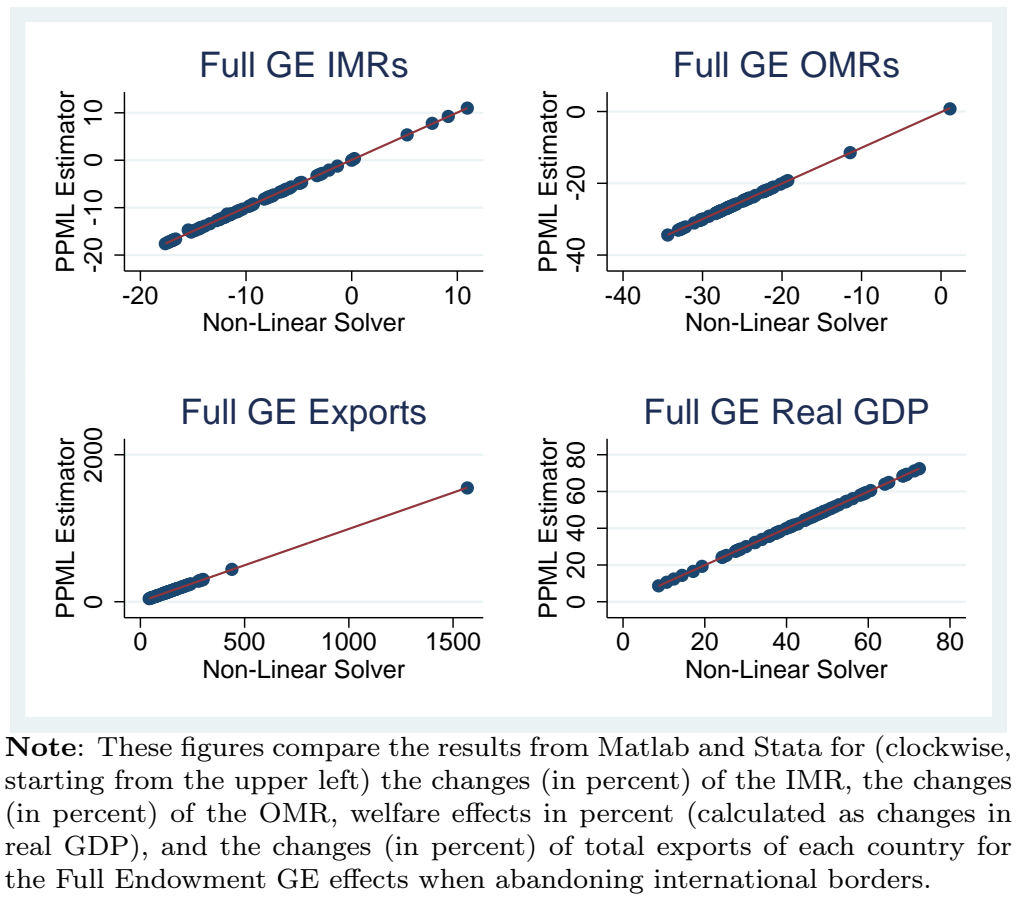

Figure 4: Trade Without Borders Full Endowment GE Indexes: Matlab versus Stata 

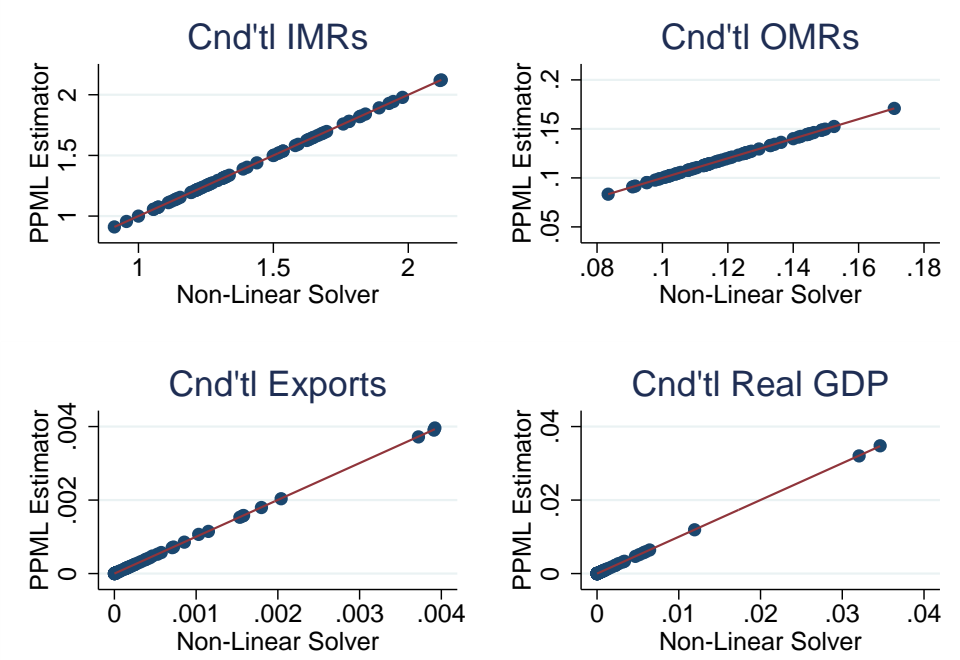

Note: These figures compare the results from Matlab and Stata for (clockwise, starting from the upper left) the IMR, OMR, the real GDP (in 100m dollars), and total exports (in $100 \mathrm{~m}$ dollars) of each country for the Conditional GE effects of NAFTA.

Figure 5: NAFTA Conditional GE Results: Matlab versus Stata

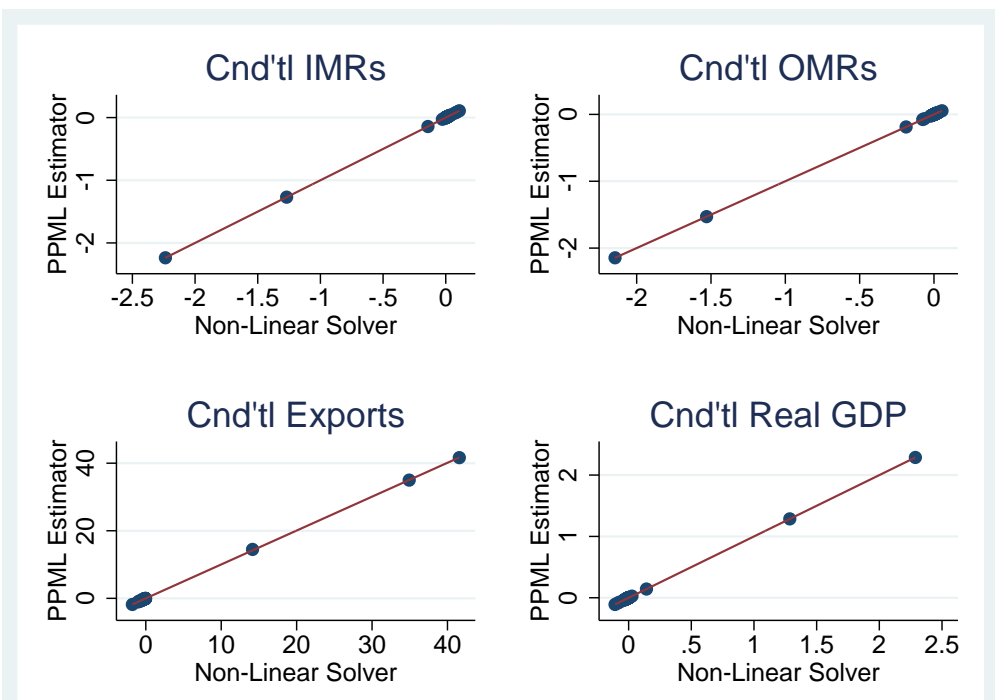

Note: These figures compare the results from Matlab and Stata for (clockwise, starting from the upper left) the changes (in percent) of the IMR, the changes (in percent) of the OMR, welfare effects in percent (calculated as changes in real GDP), and the changes (in percent) of total exports of each country for the Conditional GE effects of NAFTA.

Figure 6: NAFTA Conditional GE Indexes: Matlab versus Stata 


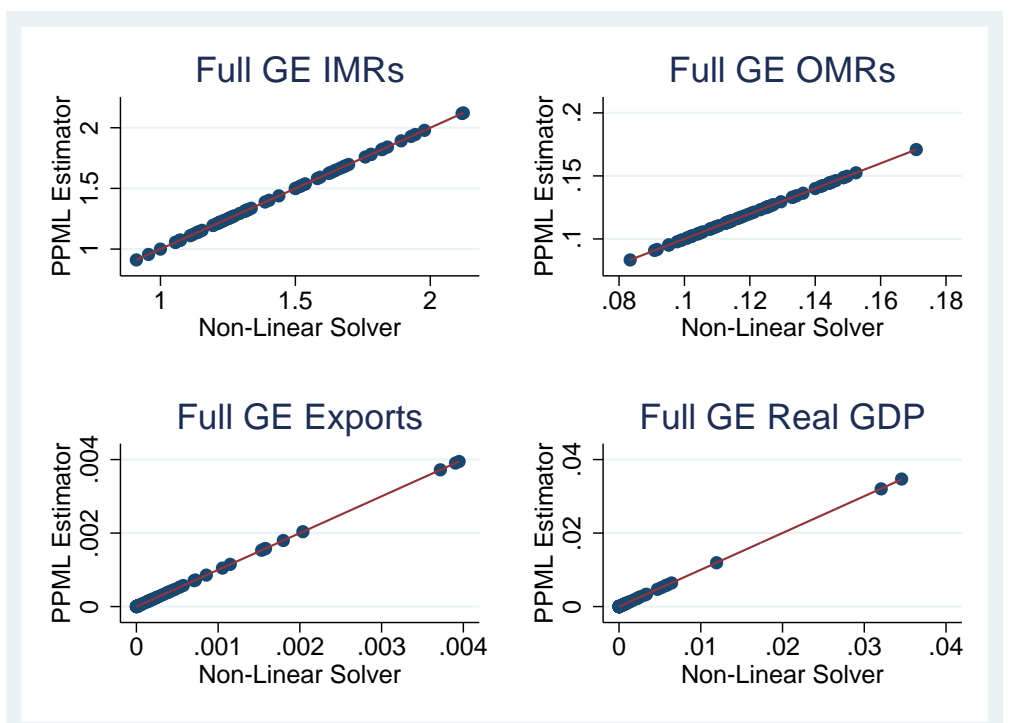

Note: These figures compare the results from Matlab and Stata for (clockwise, starting from the upper left) the IMR, OMR, the real GDP (in $100 \mathrm{~m}$ dollars), and total exports (in 100m dollars) of each country for the Full Endowment GE effects of NAFTA.

Figure 7: NAFTA Full Endowment GE Results: Matlab versus Stata

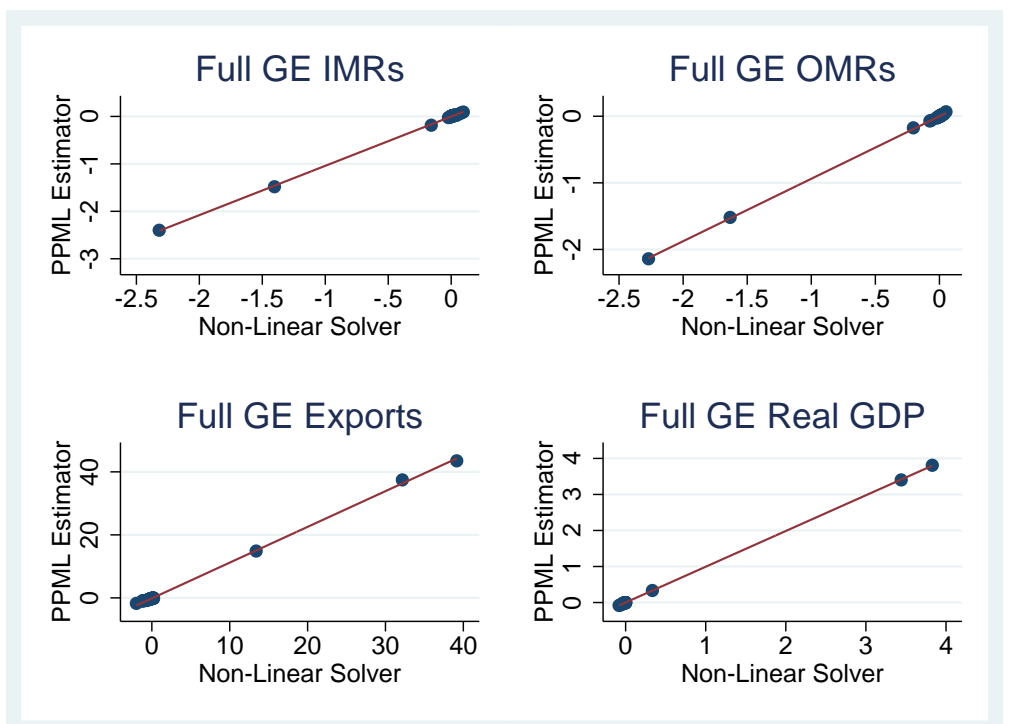

Note: These figures compare the results from Matlab and Stata for (clockwise, starting from the upper left) the changes (in percent) of the IMR, the changes (in percent) of the OMR, welfare effects in percent (calculated as changes in real GDP), and the changes (in percent) of total exports of each country for the Full Endowment GE effects of NAFTA.

Figure 8: NAFTA Full Endowment GE Indexes: Matlab versus Stata 
Table 1: Effects of Abolishing International Borders

\begin{tabular}{|c|c|c|c|c|c|c|}
\hline \multirow{2}{*}{ (1) } & \multirow{3}{*}{$\begin{array}{c}(2) \\
\text { Cond. GE } \\
\% \Delta \text { Exports }\end{array}$} & (3) & (4) & (5) & $(6)$ & (7) \\
\hline & & \multicolumn{5}{|c|}{ Full Endowment GE } \\
\hline Country & & $\% \Delta$ Exports & $\% \Delta$ RGDP & $\% \Delta \mathrm{IMR}$ & $\% \Delta \mathrm{OMR}$ & $\% \Delta p$ \\
\hline ARG & 65.52 & 118.09 & 48.99 & -11.29 & -27.78 & 32.17 \\
\hline AUS & 229.56 & 300.20 & 28.61 & -5.63 & -20.23 & 21.38 \\
\hline AUT & 59.21 & 111.35 & 49.08 & -10.82 & -28.27 & 32.95 \\
\hline BEL & 156.91 & 219.10 & 27.74 & -2.95 & -22.17 & 23.97 \\
\hline BGR & 24.22 & 69.17 & 59.40 & -14.51 & -30.31 & 36.27 \\
\hline $\mathrm{BOL}$ & 13.54 & 58.16 & 68.58 & -17.28 & -32.15 & 39.44 \\
\hline BRA & 172.56 & 233.57 & 25.22 & -2.08 & -21.16 & 22.61 \\
\hline CAN & 80.82 & 137.99 & 54.29 & -14.19 & -27.92 & 32.39 \\
\hline $\mathrm{CHE}$ & 93.00 & 149.11 & 39.79 & -7.52 & -25.89 & 29.28 \\
\hline CHL & 105.17 & 161.46 & 37.20 & -6.71 & -25.02 & 27.99 \\
\hline $\mathrm{CHN}$ & 175.50 & 238.22 & 14.36 & 7.78 & -21.65 & 23.26 \\
\hline CMR & 7.64 & 50.57 & 68.39 & -16.90 & -32.42 & 39.93 \\
\hline $\mathrm{COL}$ & 83.65 & 138.07 & 49.11 & -12.73 & -26.45 & 30.13 \\
\hline CRI & 84.91 & 138.94 & 46.55 & -11.43 & -26.23 & 29.80 \\
\hline CYP & 59.06 & 110.14 & 52.78 & -13.39 & -27.87 & 32.32 \\
\hline DEU & 133.39 & 191.01 & 24.35 & 0.00 & -22.45 & 24.35 \\
\hline DNK & 65.93 & 119.46 & 48.37 & -10.69 & -27.99 & 32.50 \\
\hline $\mathrm{ECU}$ & 65.89 & 118.04 & 54.72 & -14.79 & -27.56 & 31.83 \\
\hline EGY & 61.86 & 113.67 & 51.02 & -12.42 & -27.83 & 32.26 \\
\hline ESP & 149.78 & 209.64 & 32.34 & -6.40 & -22.10 & 23.86 \\
\hline FIN & 77.92 & 131.50 & 41.74 & -7.99 & -26.64 & 30.41 \\
\hline FRA & 118.71 & 177.47 & 35.95 & -6.53 & -24.38 & 27.07 \\
\hline GBR & 214.11 & 280.02 & 24.14 & -3.25 & -19.25 & 20.11 \\
\hline GRC & 112.21 & 168.72 & 41.31 & -10.32 & -24.15 & 26.73 \\
\hline HKG & 1457.10 & 1548.27 & 16.50 & -14.72 & 0.75 & -0.64 \\
\hline HUN & 66.52 & 117.97 & 45.20 & -9.72 & -27.08 & 31.08 \\
\hline IDN & 108.12 & 169.15 & 38.30 & -6.15 & -26.24 & 29.80 \\
\hline IND & 145.98 & 212.46 & 33.92 & -4.83 & -24.65 & 27.45 \\
\hline IRL & 64.47 & 116.54 & 40.95 & -6.26 & -27.75 & 32.12 \\
\hline IRN & 70.79 & 124.58 & 49.74 & -11.99 & -27.53 & 31.79 \\
\hline ISL & 38.93 & 88.12 & 59.22 & -14.81 & -29.93 & 35.64 \\
\hline ISR & 141.12 & 199.55 & 27.94 & -3.02 & -22.25 & 24.08 \\
\hline ITA & 143.88 & 202.82 & 27.43 & -2.77 & -22.12 & 23.90 \\
\hline JOR & 76.27 & 129.97 & 46.81 & -10.95 & -26.85 & 30.74 \\
\hline JPN & 220.80 & 293.39 & 12.38 & 9.24 & -21.28 & 22.76 \\
\hline KEN & 35.23 & 83.92 & 60.52 & -15.15 & -30.27 & 36.21 \\
\hline KOR & 210.18 & 287.50 & 19.28 & 5.35 & -23.39 & 25.65 \\
\hline KWT & 180.09 & 243.53 & 32.15 & -7.33 & -21.06 & 22.47 \\
\hline LKA & 88.36 & 146.07 & 44.40 & -9.26 & -27.05 & 31.04 \\
\hline MAC & 104.96 & 157.29 & 42.36 & -11.34 & -23.78 & 26.21 \\
\hline MAR & 43.00 & 91.93 & 56.12 & -13.89 & -29.19 & 34.43 \\
\hline MEX & 114.55 & 174.62 & 45.84 & -11.52 & -25.72 & 29.03 \\
\hline MLT & 78.09 & 131.52 & 47.93 & -11.97 & -26.51 & 30.22 \\
\hline MMR & 28.55 & 80.30 & 63.97 & -14.33 & -32.73 & 40.47 \\
\hline MUS & 94.50 & 151.85 & 46.40 & -11.33 & -26.25 & 29.82 \\
\hline MWI & 8.23 & 52.10 & 69.18 & -16.90 & -32.80 & 40.60 \\
\hline MYS & 101.62 & 162.91 & 37.65 & -4.85 & -27.01 & 30.98 \\
\hline NER & 1.17 & 42.72 & 71.20 & -17.60 & -33.06 & 41.06 \\
\hline NGA & 109.73 & 167.13 & 40.73 & -9.26 & -24.82 & 27.70 \\
\hline NLD & 120.09 & 180.17 & 35.58 & -5.93 & -24.70 & 27.53 \\
\hline NOR & 59.36 & 110.89 & 50.61 & -11.99 & -28.02 & 32.56 \\
\hline NPL & 6.95 & 53.44 & 72.43 & -16.75 & -34.41 & 43.54 \\
\hline PAN & 74.94 & 127.96 & 57.99 & -17.29 & -26.81 & 30.67 \\
\hline PHL & 80.44 & 139.31 & 44.42 & -7.77 & -28.43 & 33.20 \\
\hline POL & 83.16 & 138.60 & 44.25 & -9.52 & -26.71 & 30.53 \\
\hline PRT & 73.00 & 125.48 & 47.58 & -11.50 & -26.77 & 30.61 \\
\hline QAT & 169.69 & 232.94 & 38.11 & -10.65 & -21.76 & 23.41 \\
\hline $\mathrm{ROM}$ & 52.91 & 102.89 & 51.80 & -12.47 & -28.22 & 32.87 \\
\hline SEN & 24.30 & 70.75 & 64.94 & -16.62 & -31.05 & 37.53 \\
\hline SGP & 230.01 & 303.71 & 8.66 & 10.99 & -19.63 & 20.60 \\
\hline SWE & 76.56 & 129.64 & 40.97 & -7.54 & -26.59 & 30.34 \\
\hline THA & 139.51 & 203.11 & 28.52 & -1.23 & -24.29 & 26.93 \\
\hline
\end{tabular}


Table 1 - Continued from previous page

\begin{tabular}{|c|c|c|c|c|c|c|}
\hline \multirow{3}{*}{$\begin{array}{c}\text { (1) } \\
\text { Country }\end{array}$} & \multirow{3}{*}{$\begin{array}{c}(2) \\
\text { Cond. GE } \\
\% \Delta \text { Exports }\end{array}$} & (3) & (4) & $(5)$ & $(6)$ & (7) \\
\hline & & \multicolumn{5}{|c|}{ Full Endowment GE } \\
\hline & & $\% \Delta$ Exports & $\% \Delta$ RGDP & $\% \Delta \mathrm{IMR}$ & $\% \Delta \mathrm{OMR}$ & $\% \Delta p$ \\
\hline TTO & 93.90 & 149.50 & 40.88 & -8.19 & -25.93 & 29.34 \\
\hline TUN & 31.71 & 79.01 & 58.71 & -14.28 & -30.17 & 36.05 \\
\hline TUR & 113.06 & 169.74 & 37.47 & -7.80 & -24.16 & 26.75 \\
\hline TZA & 8.30 & 52.01 & 69.38 & -17.10 & -32.70 & 40.41 \\
\hline URY & 33.44 & 81.02 & 58.80 & -14.41 & -30.09 & 35.91 \\
\hline USA & 359.98 & 440.67 & 10.61 & 0.35 & -11.46 & 11.00 \\
\hline $\mathrm{ZAF}$ & 164.11 & 226.92 & 30.04 & -4.68 & -22.16 & 23.96 \\
\hline
\end{tabular}

Notes: This table reports results from abolishing international borders. Column (1) lists the country abbreviations. Column (2) reports the percentage changes in total exports of a country for the Conditional GE scenario. The "Cond. GE" scenario takes the direct and indirect trade cost changes into account but holds GDPs constant. Column (3) to (7) report results for the Full Endowment GE scenario that additionally takes general equilibrium income effects into account. Column (3) reports the percentage changes in total exports of a country, column (4) the percentage changes in real GDP (which may be taken as a welfare measure), column (5) reports the percentage changes in the inward multilateral resistances (IMRs), and column (6) the corresponding outward MRs (OMRs). The last column, column (7), reports the changes in producer prices. See text for further details. 
Table 2: Effects of NAFTA

\begin{tabular}{|c|c|c|c|c|c|c|c|}
\hline \multirow{3}{*}{$\begin{array}{c}\text { (1) } \\
\text { Country }\end{array}$} & \multirow{3}{*}{$\begin{array}{c}(2) \\
\text { Partial Effect } \\
\% \Delta \text { Exports }\end{array}$} & \multirow{3}{*}{$\begin{array}{c}(3) \\
\text { Cond. GE } \\
\% \Delta \text { Exports }\end{array}$} & \multirow{2}{*}{\multicolumn{5}{|c|}{$\begin{array}{l}(5) \\
\text { Full Endowment GE }\end{array}$}} \\
\hline & & & & & & & \\
\hline & & & $\% \Delta$ Exports & $\% \Delta$ RGDP & $\% \Delta \mathrm{IMR}$ & $\% \Delta \mathrm{OMR}$ & $\% \Delta p$ \\
\hline ARG & 0.00 & -0.66 & -0.69 & -0.01 & 0.01 & 0.00 & 0.00 \\
\hline AUS & 0.00 & -0.49 & -0.51 & -0.01 & 0.02 & -0.01 & 0.01 \\
\hline AUT & 0.00 & -0.07 & -0.10 & -0.01 & 0.00 & 0.01 & -0.01 \\
\hline BEL & 0.00 & -0.09 & -0.12 & 0.00 & 0.00 & 0.00 & 0.00 \\
\hline BGR & 0.00 & -0.05 & -0.07 & 0.00 & 0.00 & 0.00 & 0.00 \\
\hline BOL & 0.00 & -0.47 & -0.48 & -0.02 & 0.03 & -0.01 & 0.01 \\
\hline BRA & 0.00 & -0.65 & -0.69 & -0.01 & -0.01 & 0.02 & -0.02 \\
\hline CAN & 55.05 & 34.99 & 37.46 & 3.40 & -1.48 & -2.14 & 1.87 \\
\hline $\mathrm{CHE}$ & 0.00 & -0.14 & -0.17 & -0.01 & 0.00 & 0.01 & -0.01 \\
\hline CHL & 0.00 & -0.81 & -0.83 & -0.03 & 0.01 & 0.03 & -0.03 \\
\hline $\mathrm{CHN}$ & 0.00 & -0.34 & -0.38 & -0.01 & -0.01 & 0.03 & -0.02 \\
\hline CMR & 0.00 & -0.13 & -0.16 & -0.01 & 0.01 & 0.00 & 0.00 \\
\hline COL & 0.00 & -1.80 & -1.73 & -0.03 & 0.09 & -0.07 & 0.06 \\
\hline CRI & 0.00 & -1.03 & -1.04 & -0.07 & 0.06 & 0.01 & -0.01 \\
\hline CYP & 0.00 & -0.09 & -0.11 & 0.00 & 0.01 & -0.01 & 0.01 \\
\hline DEU & 0.00 & -0.14 & -0.17 & -0.01 & 0.00 & 0.01 & -0.01 \\
\hline DNK & 0.00 & -0.06 & -0.09 & -0.01 & 0.00 & 0.01 & 0.05 \\
\hline $\mathrm{ECU}$ & 0.00 & -0.93 & -0.89 & -0.02 & 0.08 & -0.06 & 0.01 \\
\hline EGY & 0.00 & -0.31 & -0.33 & -0.01 & 0.02 & -0.02 & -0.01 \\
\hline ESP & 0.00 & -0.13 & -0.15 & -0.01 & 0.00 & 0.01 & -0.01 \\
\hline FIN & 0.00 & -0.09 & -0.11 & -0.01 & 0.00 & 0.01 & 0.00 \\
\hline FRA & 0.00 & -0.13 & -0.15 & -0.01 & 0.00 & 0.01 & 0.00 \\
\hline GBR & 0.00 & -0.23 & -0.25 & -0.01 & 0.01 & 0.01 & 0.00 \\
\hline GRC & 0.00 & -0.08 & -0.11 & 0.00 & 0.01 & 0.00 & -0.01 \\
\hline HKG & 0.00 & -0.20 & -0.23 & -0.02 & 0.01 & 0.01 & 0.00 \\
\hline HUN & 0.00 & -0.04 & -0.07 & 0.00 & 0.00 & 0.01 & -0.01 \\
\hline IDN & 0.00 & -0.19 & -0.24 & -0.01 & 0.00 & 0.01 & 0.00 \\
\hline IND & 0.00 & -0.30 & -0.33 & -0.01 & 0.01 & 0.00 & -0.02 \\
\hline IRL & 0.00 & -0.10 & -0.13 & -0.03 & 0.01 & 0.02 & 0.01 \\
\hline IRN & 0.00 & -0.13 & -0.16 & 0.00 & 0.01 & -0.01 & 0.01 \\
\hline ISL & 0.00 & -0.23 & -0.25 & -0.01 & 0.02 & -0.01 & 0.00 \\
\hline ISR & 0.00 & -0.38 & -0.41 & -0.02 & 0.02 & 0.00 & -0.01 \\
\hline ITA & 0.00 & -0.12 & -0.15 & -0.01 & 0.00 & 0.01 & 0.02 \\
\hline JOR & 0.00 & -0.28 & -0.30 & 0.00 & 0.02 & -0.02 & -0.03 \\
\hline JPN & 0.00 & -0.35 & -0.42 & -0.01 & -0.02 & 0.03 & 0.02 \\
\hline KEN & 0.00 & -0.22 & -0.24 & 0.00 & 0.02 & -0.02 & -0.02 \\
\hline KOR & 0.00 & -0.41 & -0.45 & -0.02 & -0.01 & 0.03 & 0.00 \\
\hline KWT & 0.00 & -0.23 & -0.26 & -0.01 & 0.01 & 0.00 & 0.00 \\
\hline LKA & 0.00 & -0.30 & -0.33 & -0.01 & 0.02 & -0.01 & -0.02 \\
\hline MAC & 0.00 & -0.21 & -0.24 & -0.05 & 0.02 & 0.03 & 0.00 \\
\hline MAR & 0.00 & -0.08 & -0.10 & 0.00 & 0.00 & 0.00 & 1.32 \\
\hline MEX & 56.65 & 41.64 & 43.51 & 3.81 & -2.40 & -1.52 & -0.01 \\
\hline MLT & 0.00 & -0.13 & -0.15 & -0.02 & 0.01 & 0.01 & 0.01 \\
\hline MMR & 0.00 & -0.13 & -0.18 & 0.00 & 0.01 & -0.01 & 0.00 \\
\hline MUS & 0.00 & -0.06 & -0.09 & -0.01 & 0.01 & 0.00 & 0.01 \\
\hline MWI & 0.00 & -0.18 & -0.19 & -0.01 & 0.02 & -0.01 & -0.02 \\
\hline MYS & 0.00 & -0.22 & -0.27 & -0.03 & 0.01 & 0.03 & -0.01 \\
\hline NER & 0.00 & -0.11 & -0.13 & -0.02 & 0.02 & 0.01 & 0.02 \\
\hline NGA & 0.00 & -0.37 & -0.39 & 0.00 & 0.03 & -0.03 & -0.01 \\
\hline NLD & 0.00 & -0.07 & -0.09 & -0.01 & 0.00 & 0.01 & 0.00 \\
\hline NOR & 0.00 & -0.24 & -0.25 & -0.01 & 0.02 & 0.00 & 0.01 \\
\hline NPL & 0.00 & -0.22 & -0.25 & -0.01 & 0.02 & -0.01 & 0.00 \\
\hline PAN & 0.00 & -0.60 & -0.62 & -0.02 & 0.03 & 0.00 & -0.02 \\
\hline PHL & 0.00 & -0.29 & -0.33 & -0.03 & 0.01 & 0.02 & 0.00 \\
\hline POL & 0.00 & -0.05 & -0.07 & 0.00 & 0.00 & 0.00 & 0.00 \\
\hline PRT & 0.00 & -0.06 & -0.08 & 0.00 & 0.00 & 0.00 & -0.01 \\
\hline QAT & 0.00 & -0.19 & -0.22 & -0.01 & 0.01 & 0.01 & 0.00 \\
\hline ROM & 0.00 & -0.08 & -0.10 & 0.00 & 0.00 & 0.00 & 0.01 \\
\hline SEN & 0.00 & -0.08 & -0.10 & 0.00 & 0.01 & -0.01 & -0.02 \\
\hline SGP & 0.00 & -0.15 & -0.19 & -0.03 & 0.01 & 0.02 & -0.01 \\
\hline SWE & 0.00 & -0.11 & -0.13 & -0.01 & 0.00 & 0.01 & -0.01 \\
\hline THA & 0.00 & -0.25 & -0.29 & -0.01 & 0.00 & 0.02 & -0.06 \\
\hline
\end{tabular}


Table 2 - Continued from previous page

\begin{tabular}{|c|c|c|c|c|c|c|c|}
\hline \multirow{3}{*}{$\begin{array}{c}\text { (1) } \\
\text { Country }\end{array}$} & \multirow{3}{*}{$\begin{array}{c}(2) \\
\text { Partial Effect } \\
\% \Delta \text { Exports }\end{array}$} & \multirow{3}{*}{$\begin{array}{c}(3) \\
\text { Cond. GE } \\
\% \Delta \text { Exports }\end{array}$} & \multirow{2}{*}{\multicolumn{5}{|c|}{$\begin{array}{l}(5) \quad(6) \\
\text { Full Endowment GE }\end{array}$}} \\
\hline & & & & & & & \\
\hline & & & $\% \Delta$ Exports & $\% \Delta$ RGDP & $\% \Delta \mathrm{IMR}$ & $\% \Delta \mathrm{OMR}$ & $\% \Delta p$ \\
\hline TTO & 0.00 & -0.86 & -0.88 & -0.08 & 0.02 & 0.07 & 0.00 \\
\hline TUN & 0.00 & -0.04 & -0.07 & 0.00 & 0.00 & 0.00 & 0.00 \\
\hline TUR & 0.00 & -0.14 & -0.16 & 0.00 & 0.00 & 0.00 & 0.01 \\
\hline TZA & 0.00 & -0.16 & -0.17 & -0.01 & 0.02 & -0.01 & -0.01 \\
\hline URY & 0.00 & -0.42 & -0.44 & -0.02 & 0.01 & 0.01 & 0.15 \\
\hline USA & 18.83 & 14.48 & 14.88 & 0.33 & -0.18 & -0.17 & 0.00 \\
\hline ZAF & 0.00 & -0.31 & -0.34 & -0.01 & 0.01 & 0.00 & -0.01 \\
\hline
\end{tabular}

Notes: This table reports results from our NAFTA counterfactual analysis. Column (1) lists the country abbreviations. Column (2) reports the partial equilibrium percentage changes in total exports of a country. Column (3) reports the percentage changes in total exports of a country for the Conditional GE scenario. The "Cond. GE" scenario takes the direct and indirect trade cost changes into account but holds GDPs constant. Column (4) to (8) report results for the Full Endowment GE scenario that additionally takes general equilibrium income effects into account. Column (4) reports the percentage changes in total exports of a country, column (5) the percentage changes in real GDP (which may be taken as a welfare measure), column (6) reports the percentage changes in the inward multilateral resistances (IMRs), and column (7) the corresponding outward MRs (OMRs). The last column, column (8), reports the changes in producer prices. See text for further details. 
Table 3: Parameter Estimates from Anderson, Larch and Yotov (2015b)

\begin{tabular}{cccc}
\hline \hline Recovered From & Parameter & Min. Value & Max. Value \\
\hline \multirow{2}{*}{ Trade } & $\widehat{\eta}_{1}$ & \multicolumn{2}{c}{0.827} \\
& $\widehat{t}_{i j}$ & 1.184 & $(0.135)^{* *}$ \\
& $\widehat{\alpha}$ & 0.495 & 132.7 \\
Income & $\widehat{\sigma}$ & $(0.060)^{* *}$ & 0.582 \\
& & 4.084 & $(0.052)^{* *}$ \\
& $\widehat{\delta}$ & $0.394)^{* *}$ & $(3.701)^{* *}$ \\
\hline Capital & & 0.016 & 0.061 \\
Cons. Discount & $\widehat{\beta}$ & $(0.003)^{* *}$ & \multicolumn{2}{c}{$(0.004)^{* *}$} \\
\hline \hline
\end{tabular}

Notes: This table reports the values for the structural parameters in system (63)-(65) as obtained in Anderson, Larch and Yotov (2016). Panel "Trade" reports the RTA estimate (top row), and the minimum and maximum values for bilateral trade costs (bottom row) from gravity estimations that correspond to Equation (63). Panel "Income" reports the minimum and the maximum values for the capital shares (top row), and for the elasticity of substitution (bottom row), that are obtained from various specifications, including robustness analysis, of Equation 64. Panel "Capital" reports the minimum and the maximum values of capital depreciation rates from various specifications, including robustness analysis, based on Equation 65. Finally, panel "Cons. Discount" reports an estimate of the consumer discount factor that is borrowed from the literature. Robust standard errors, when available, are in parentheses. $+p<0.10$, ${ }^{*} p<.05,{ }^{* *} p<.01$. 


\section{Appendix A: Structural Gravity from the Supply Side}

In the main text, we derived the structural gravity framework from the demand side assuming Armington (1969)-type preferences. In this appendix, we show that an isomorphic structural gravity framework can be derived from the supply side (see for a nice discussion of demandside and supply-side gravity foundations Anderson, 2011). We base this derivation on the most influential supply-side model, the Ricardian model of international trade by Eaton and Kortum (2002) (see for a similar derivation Heid and Larch, 2016).

Consumer preferences are still assumed to be homothetic, globally common/identical across countries, and approximated by a Constant Elasticity of Substitution (CES) utility function:

$$
U_{j}=\left[\int_{0}^{1} c(l)^{\frac{\sigma-1}{\sigma}} d k\right]^{\frac{\sigma}{\sigma-1}},
$$

where $j$ denotes the country and $\sigma$ is the elasticity of substitution among different varieties. Following Eaton and Kortum (2002), we assume here a continuum of goods $l \in[0,1]$, whith consumption of individual goods denoted by $c(l)$. We stick to the assumption that trade of goods from $i$ to $j$ imposes iceberg trade costs $t_{i j}>1$.

In contrast to our baseline framework, countries now differ in the efficiency with which they can produce goods. Let $z_{i}(l)$ denote country $i$ 's efficiency in producing good $l \in[0,1]$. Then, with constant returns to scale the cost of producing a unit of good $l$ in country $i$ is $\mathfrak{c}_{i} / z_{i}(l)$, with $\mathfrak{c}_{i}$ denoting the input costs in country $i$.

Taking iceberg trade costs into account, delivering a unit of good $k$ produced in country $i$ to country $j$ costs:

$$
p_{i j}(l)=\left(\frac{\mathfrak{c}_{i}}{z_{i}(l)}\right) t_{i j}
$$

With perfect competition, $p_{i j}(l)$ is the price consumers in country $j$ would pay if they decide to buy good $l$ from country $i$. As we allow for international trade, consumers are free to choose from which country to buy a good. Therefore, the actually price consumers pay for good $l$ is $p_{j}(l)$, the lowest price across all sources $i$ :

$$
p_{j}(l)=\min \left\{p_{i j}(l) ; i=1, \cdots, N\right\},
$$

where $N$ again denotes the number of countries in the world.

We next have to specify the efficiency for the countries. Following Eaton and Kortum (2002), we assume that efficiency is drawn from a Fréchet distribution: $F_{i}(z)=e^{-T_{i} z^{-\theta}}$, where $T_{i}$ is the location parameter for country $i$ and $\theta$ governs the variation within the distribution, which is assumed to be common to all countries.

Replacing $z$ in $F_{i}(z)$ using Equation $(79)$ leads to $G_{i j}(p)=\operatorname{Pr}\left[P_{i j} \leq p\right]=1-e^{-\left[T_{i}\left(\mathfrak{c}_{i} t_{i j}\right)^{-\theta}\right] p^{\theta}}$. The distribution of prices for which a country $j$ buys is given by $G_{j}(p)=\operatorname{Pr}\left[P_{j} \leq p\right]=$ $1-\prod_{i=1}^{N}\left[1-G_{i j}(p)\right]$ (see the first equation on page 1748 in Eaton and Kortum, 2002) and leads to:

$$
G_{j}(p)=1-e^{-\Phi_{j} p^{\theta}}
$$

where $\Phi_{j}=\sum_{i=1}^{N} T_{i}\left(\mathfrak{c}_{i} t_{i j}\right)^{-\theta}$.

The probability that country $i$ provides good $l$ at the lowest price to country $j$ is given 
by (see Eaton and Kortum, 2002, page 1748):

$$
\pi_{i j}=\frac{T_{i}\left(\mathfrak{c}_{i} t_{i j}\right)^{-\theta}}{\Phi_{j}} .
$$

As we assume a continuum of goods between zero and one, this is also the fraction of goods that country $j$ buys from country $i$. The price of a good that country $j$ actually buys from any country $i$ is also distributed $G_{j}(p)$, and the exact price index is given by $P_{j}=\gamma \Phi_{j}^{-1 / \theta}$ with $\gamma=\left[\Gamma\left(\frac{\theta+1-\sigma}{\theta}\right)\right]^{\frac{1}{1-\sigma}}$ where $\Gamma$ is the Gamma function (see pages 1748-1749 in Eaton and Kortum, 2002).

The fraction of goods that country $j$ buys from country $i, \pi_{i j}$, is also the fraction of its expenditures on goods from country $i, X_{i j}$, due to the fact that the average expenditures per good do not vary by source. Hence,

$$
X_{i j}=\frac{T_{i}\left(\mathfrak{c}_{i} t_{i j}\right)^{-\theta}}{\Phi_{j}} E_{j}=\frac{T_{i}\left(\mathfrak{c}_{i} t_{i j}\right)^{-\theta}}{\sum_{k=1}^{N} T_{k}\left(\mathfrak{c}_{k} t_{k j}\right)^{-\theta}} E_{j},
$$

where $E_{j}$ is country $j$ 's total spending.

We now use the fact that at delivered prices (because part of the shipments melt en route), the value of output in country $i, Y_{i}$, should be equal to the total expenditure on this country's variety in all countries in the world, including $i$ itself. Hence:

$$
Y_{i}=\sum_{j=1}^{N} X_{i j}=T_{i} \mathfrak{c}_{i}^{-\theta} \sum_{j=1}^{N} \frac{t_{i j}^{-\theta}}{\Phi_{j}} E_{j} .
$$

Solving for $T_{i} \mathbf{c}_{i}^{-\theta}$ leads to:

$$
T_{i} \mathbf{c}_{i}^{-\theta}=\frac{Y_{i}}{\sum_{j=1}^{N} \frac{t_{i j}^{-\theta}}{\Phi_{j}} E_{j}} .
$$

Using this expression for $T_{i} \mathfrak{c}_{i}^{-\theta}$ in Equation 83 leads to:

$$
X_{i j}=\frac{t_{i j}^{-\theta}}{\Phi_{j}\left(\sum_{j=1}^{N} \frac{t_{i j}^{-\theta}}{\Phi_{j}} E_{j}\right)} Y_{i} E_{j}
$$

Now replace $\Phi_{j}$ using $P_{j}=\gamma \Phi_{j}^{-\frac{1}{\theta}}$ in both terms of the denominator:

$$
X_{i j}=\frac{t_{i j}^{-\theta}}{\gamma^{\theta} P_{j}^{-\theta}\left(\sum_{j=1}^{N} \frac{t_{i j}^{-\theta}}{\gamma^{\theta} P_{j}^{-\theta}} E_{j}\right)} Y_{i} E_{j} .
$$

Define:

$$
\Pi_{i}=\left(\sum_{j=1}^{N}\left(\frac{t_{i j}}{P_{j}}\right)^{-\theta} \frac{E_{j}}{Y}\right)^{-\frac{1}{\theta}}
$$


where $Y=\sum_{j} Y_{j}$. Note that we can express $P_{j}$ also as follows:

$$
\begin{aligned}
P_{j} & =\left(\gamma^{-\theta} \Phi_{j}\right)^{-\frac{1}{\theta}}=\left(\gamma^{-\theta} \sum_{i=1}^{N} T_{i}\left(\mathfrak{c}_{i} t_{i j}\right)^{-\theta}\right)^{-\frac{1}{\theta}}=\left(\gamma^{-\theta} \sum_{i=1}^{N} \frac{t_{i j}^{-\theta} Y_{i}}{\sum_{l=1}^{N} \frac{t_{i l}^{-\theta}}{\Phi_{l}} E_{l}}\right)^{-\frac{1}{\theta}} \\
& =\left(\sum_{i=1}^{N}\left(\frac{t_{i j}}{\Pi_{i}}\right)^{-\theta} \frac{Y_{i}}{Y}\right)^{-\frac{1}{\theta}},
\end{aligned}
$$

Then we can write:

$$
X_{i j}=\frac{Y_{i} E_{j}}{Y}\left(\frac{t_{i j}}{\Pi_{i} P_{j}}\right)^{-\theta} .
$$

Replacing $-\theta$ by $1-\sigma$ we end up with exactly the same system as the one we presented based on the demand side in Equations (8)-(10).

Hence, the structural gravity system can be derived from the demand and the supply side. They are isomorphic. The only difference is that the elasticity of substitution is replaced by the Fréchet parameter governing the variation within the distribution.

Last, let us discuss the counterfactual analysis using the gravity framework based on the supply side. With the demand-side model, we assumed an endowment economy and could close the model by using the market clearing condition. Assuming an endowment economy is at odds with the supply side in the supply-side framework. However, it is still possible to close the model in a simple way for counterfactual analysis. Specifically, we assume that firms produce a final good with one unit of the single production factor labor, i.e. $\mathfrak{c}_{i}=w_{i}$. We then can re-write Equation (85) as follows:

$$
T_{i} w_{i}^{-\theta}=\frac{Y_{i}}{\sum_{j=1}^{N} \frac{t_{i j}^{-\theta}}{\Phi_{j}} E_{j}}=\frac{\frac{Y_{i}}{Y}}{\sum_{j=1}^{N} \gamma^{-\theta}\left(\frac{t_{i j}}{P_{j}}\right)^{-\theta} \frac{E_{j}}{Y}}=\gamma^{\theta} \frac{Y_{i}}{Y} \Pi_{i}^{\theta} .
$$

We now can solve for wages $w_{i}$ :

$$
w_{i}=\gamma^{-1} T_{i}^{\frac{1}{\theta}}\left(\frac{Y_{i}}{Y}\right)^{-\frac{1}{\theta}} \Pi_{i}^{-1}
$$

This expression replaces the one for $p_{i}$ in Equation (14) in the system derived from the demand side. As labor is the only factor of production, $Y_{i}=w_{i} L_{i}$. This replaces Equation (15) in the system derived from the demand side. Again, we stick to the assumption of exogenous trade imbalances when considering our counterfactuals, i.e. $E_{i}=\phi_{i} Y_{i}$, where $\phi_{i}>1$ shows that country $i$ runs a trade deficit and $\phi_{i}<1$ captures a trade surplus of country $i$. We therefore can write the structural gravity system derived from the supply side 
as follows:

$$
\begin{aligned}
X_{i j} & =\frac{Y_{i} E_{j}}{Y}\left(\frac{t_{i j}}{\Pi_{i} P_{j}}\right)^{-\theta}, \\
P_{j}^{-\theta} & =\sum_{i=1}^{N}\left(\frac{t_{i j}}{\Pi_{i}}\right)^{-\theta} \frac{Y_{i}}{Y}, \\
\Pi_{i}^{-\theta} & =\sum_{j=1}^{N}\left(\frac{t_{i j}}{P_{j}}\right)^{-\theta} \frac{E_{j}}{Y}, \\
w_{i} & =\left(\frac{Y_{i}}{Y}\right)^{-\frac{1}{\theta}} \frac{T_{i}^{\frac{1}{\theta}}}{\gamma \Pi_{i}}, \\
Y_{i} & =w_{i} L_{i}, \\
E_{i} & =\phi_{i} Y_{i} .
\end{aligned}
$$

The change in total output is then given by $Y_{i}^{C F L} / Y_{i}=w_{i}^{C F L} / w_{i}$. Hence,

$$
\frac{Y_{i}^{C F L}}{Y_{i}}=\frac{\gamma T_{i}^{\frac{1}{\theta}}\left(\frac{Y_{i}^{C F L}}{Y^{C F L}}\right)^{-\frac{1}{\theta}}\left(\Pi_{i}^{C F L}\right)^{-1}}{\gamma T_{i}^{\frac{1}{\theta}}\left(\frac{Y_{i}}{Y}\right)^{-\frac{1}{\theta}} \Pi_{i}^{-1}}=\frac{\left(\frac{Y_{i}^{C F L}}{Y^{C F L}}\right)^{-\frac{1}{\theta}}\left(\Pi_{i}^{C F L}\right)^{-1}}{\left(\frac{Y_{i}}{Y}\right)^{-\frac{1}{\theta}} \Pi_{i}^{-1}} .
$$




\section{Appendix B: Structural Gravity with Sectors}

The objectives of this appendix are to demonstrate how the aggregate structural gravity model can be extended to the sectoral level, to compare the aggregate and the sectoral gravity system, to discuss implications of moving to the sectoral level, and to present and compare two sectoral versions of the structural gravity model; one on the demand side and one on the supply side. To derive gravity on the demand side, we follow Larch and Wanner (2014) and Anderson and Yotov (2016), and to obtain a gravity system on the supply side, we follow Eaton and Kortum (2002) (see also Costinot, Donaldson and Komunjer, 2012, Caliendo and Parro, 2015; Donaldson, 2016).

\section{Sectoral Gravity on the Demand Side}

Sectoral gravity on the demand side is obtained by extending the standard assumptions from Anderson (1979) to accommodate sectors. Specifically, we consider a model with many $(K)$ goods, where, within each good's class $k \in K$, varieties are differentiated by place of origin (Armington) as before. Similarly to the aggregate setting from the main analysis, we also assume an endowment economy setting, but this time at the sectoral level:

$$
Y_{i}^{k}=p_{i}^{k} Q_{i}^{k}
$$

Here, $Q_{i}^{k}$ is the endowment of goods in class $k$ in country $i, p_{i}^{k}$ is the corresponding factorygate price, and $Y_{i}^{k}$ is sectoral income in country $i$. Finally, on the demand side, we assume that consumer preferences within each class of goods are assumed to be CES, as in the main analysis, however this time the CES preferences across varieties within each class of goods are nested in a Cobb-Douglas utility function that reflects preference across different goods classes. As a result, for each country, the expenditure in each class of goods, $E_{i}^{k}$, is obtained as a constant share $\alpha^{k}$ of this country's total expenditure $E_{i}$ :

$$
E_{i}^{k}=\alpha^{k} E_{i}=\alpha^{k} \phi_{i} Y_{i}
$$

where, as in our main analysis, the rightmost equality reflects the fact that we allow for nationally varying exogenous trade imbalances $\phi_{i} \neq 1$. Solving the consumer optimization problem and imposing market clearing at delivered prices for each sector obtains the demand- 
side structural gravity system:

$$
\begin{aligned}
X_{i j}^{k} & =\frac{Y_{i}^{k} E_{j}^{k}}{Y^{k}}\left(\frac{t_{i j}^{k}}{\Pi_{i}^{k} P_{j}^{k}}\right)^{1-\sigma_{k}}, \\
\left(\Pi_{i}^{k}\right)^{1-\sigma_{k}} & =\sum_{j}\left(\frac{t_{i j}^{k}}{P_{j}^{k}}\right)^{1-\sigma_{k}} \frac{E_{j}^{k}}{Y^{k}}, \\
\left(P_{j}^{k}\right)^{1-\sigma_{k}} & =\sum_{i}\left(\frac{t_{i j}^{k}}{\Pi_{i}^{k}}\right)^{1-\sigma_{k}} \frac{Y_{i}^{k}}{Y^{k}}, \\
p_{i}^{k} & =\left(\frac{Y_{i}^{k}}{Y^{k}}\right)^{\frac{1}{1-\sigma}} \frac{1}{\beta_{i}^{k} \Pi_{i}^{k}}, \\
E_{i}^{k} & =\alpha^{k} \phi_{i} Y_{i}, \\
Y_{i} & =\sum_{k} Y_{i}^{k}=\sum_{k} p_{i}^{k} Q_{i}^{k}, \\
Y^{k} & =\sum_{i} Y_{i}^{k}=\sum_{i} p_{i}^{k} Q_{i}^{k} .
\end{aligned}
$$

System (88)- 94 is remarkably similar to the aggregate structural gravity system (11)-(15). In fact, from an expositional perspective, the only difference between the two gravity systems is the addition of super- and subscript ' $k$ ' in the sectoral system (88)-(91), the addition of the expenditure share $\alpha^{k}$ in the sectoral system in Equation (92), and the addition of the adding up expression for the total value of output in a country (Equation (93)) as well as for the total value of output in a sector in the world (Equation (94)). One nice implication of this result is the so-called 'separability' property of structural gravity, i.e. the gravity system holds separately for each sector. Two important implications of the sectoral gravity system from an estimation perspective are that (i) it implies that the gravity equation can be estimated for each sector using exactly the same estimation techniques and best practice estimation approaches that apply to aggregate data (see Piermartini and Yotov, 2015, for details and discussion on gravity estimations); and (ii) if gravity is estimated with data pooled across sectors, then the exporter and the importer fixed effects that are used to account for the multilateral resistances should also vary by sector, i.e. they should be exporter-sector and importer-sector fixed effects.

The most important difference between system (88)-94) and the aggregate gravity system (11)-(15) is that the latter captures intersectoral linkages that arise on the demand side, i.e. due to the substitutability of goods across goods classes. The intuition is that in the sectoral setting consumers substitute not only varieties within each class of goods, but they also substitute goods from different classes with each other. The main implication of this result is that a change in trade costs between any given pair of countries in the world or in any given sector may potentially affect prices in all other sectors and in all other countries in the world. These links are captured by the market clearing conditions and, to see them more clearly, we use the definitions of income, expenditure, and the multilateral resistances to 
rewrite the system of market clearing conditions (91) as:

$$
\frac{p_{i}^{k} Q_{i}^{k}}{\sum_{i} p_{i}^{k} Q_{i}^{k}}=\sum_{j} \frac{\left(\beta_{i}^{k} p_{i}^{k} t_{i j}^{k}\right)^{1-\sigma_{k}}}{\sum_{i}\left(\beta_{i}^{k} p_{i}^{k} t_{i j}^{k}\right)^{1-\sigma_{k}}} \times \frac{\alpha^{k} \phi_{j} \sum_{k} p_{j}^{k} Q_{j}^{k}}{\sum_{i} p_{i}^{k} Q_{i}^{k}} . \quad \forall i, k
$$

System (95) consists of $N \times K$ equations in $N \times K$ unknown $p_{i}^{k}$ s. However, similar to the aggregate gravity system, the sectoral gravity system can only be solved subject to a normalization for each sector because the system is homogeneous of degree zero in the vector of factory-gate prices. Anderson and Yotov (2016) propose and impose a natural normalization of holding world real resources constant:

$$
\sum_{i, k} p_{i}^{k} Q_{i}^{k}=\sum_{i, k} p_{i}^{k 0} Q_{i}^{k}=\sum_{i, k} Y_{i}^{k 0} \quad \forall i, k .
$$

Subject to this normalization, system (95) would deliver a unique vector of changes in factorygate prices in response to a given change in sectoral bilateral trade costs. Importantly, it is clear from system (95) that a change in any possible sector-pair trade costs $t_{i j}^{k}$ will result in changes in factory-gate price changes in all countries and all sectors in the world.

\section{Sectoral Gravity from the Supply Side}

In Appendix A, we derived the structural gravity framework at the aggregate level from the supply side. We now show how to extend the aggregate structural gravity system from the supply side to the sectoral level, as for example suggested by Eaton and Kortum $(2002)$ and others following.

For each sector $k$, consumer preferences are still assumed to be homothetic, globally common/identical across countries, and approximated by a Constant Elasticity of Substitution (CES) utility function:

$$
U_{j}^{k}=\left[\int_{0}^{1} c^{k}(l)^{\frac{\sigma_{k}-1}{\sigma_{k}}} d l\right]^{\frac{\sigma_{k}}{\sigma_{k}-1}}
$$

where $j$ denotes the country and $\sigma_{k}$ is the sector-specific elasticity of substitution among different varieties $l \in[0,1]$ of sector $k$. As for the sectoral demand-side derivation, we also assume here that goods from different sectors are combined by a Cobb-Douglas utility function that reflects preference across different goods classes. As a result, for each country, the expenditure in each class of goods, $E_{i}^{k}$, is obtained as a constant share $\alpha^{k}$ of this country's total expenditure $E_{i}$ :

$$
E_{i}^{k}=\alpha_{k} E_{i}=\alpha_{k} \phi_{i} Y_{i}
$$

Now it holds in each sector that with constant returns to scale the cost of producing a unit of good $l$ in sector $k$ in country $i$ is $\mathfrak{c}_{i}^{k} / z_{i}^{k}(l)$, with $\mathfrak{c}_{i}^{k}$ denoting the input costs in sector $k$ in country $i$. Taking iceberg trade costs into account, delivering a unit of good $l$ of sector $k$ 
produced in country $i$ to country $j$ costs:

$$
p_{i j}^{k}(l)=\left(\frac{\mathfrak{c}_{i}^{k}}{z_{i}^{k}(l)}\right) t_{i j}^{k}
$$

Keeping all other assumptions on the supply side for each sector $k$, similar steps to derive the lowest price across all sources, the distribution of prices, and exact price index, leads to the following expression for the fraction of its expenditures on goods in sector $k$ from country $i, X_{i j}^{k}$ :

$$
X_{i j}^{k}=\frac{T_{i}^{k}\left(\mathfrak{c}_{i}^{k} t_{i j}^{k}\right)^{-\theta_{k}}}{\Phi_{j}^{k}} E_{j}^{k}=\frac{T_{i}^{k}\left(\mathfrak{c}_{i}^{k} t_{i j}^{k}\right)^{-\theta_{k}}}{\sum_{l=1}^{N} T_{l}^{k}\left(\mathfrak{c}_{l}^{k} t_{l j}^{k}\right)^{-\theta_{k}}} E_{j}^{k} .
$$

Using market clearance, the expressions for the multilateral resistance terms can be derived at the sectoral level. As in the aggregate case, we close the sectoral supply-side model in a simple way for counterfactual analysis. Assume that there is a single factor of production, labor, where one unit of labor can produce one unit of output in each sector $k$. Hence, $\mathfrak{c}_{i}^{k}=w_{i}^{k}$. We can then express the market-clearing condition as follows:

$$
\begin{aligned}
T_{i}^{k}\left(w_{i}^{k}\right)^{-\theta_{k}} & =\frac{Y_{i}^{k}}{\sum_{j=1}^{N} \frac{\left(t_{i j}^{k}\right)^{-\theta_{k}}}{\Phi_{j}^{k}} E_{j}^{k}}=\frac{\frac{Y_{i}^{k}}{Y^{k}}}{\sum_{j=1}^{N}\left(\gamma^{k}\right)^{-\theta_{k}}\left(\frac{t_{i j}^{k}}{P_{j}^{k}}\right)^{-\theta_{k}} \frac{E_{j}^{k}}{Y^{k}}} \\
& =\left(\gamma^{k}\right)^{\theta_{k}} \frac{Y_{i}^{k}}{Y^{k}}\left(\Pi_{i}^{k}\right)^{\theta_{k}} .
\end{aligned}
$$

The sectoral gravity system derived from the supply side can then be written as:

$$
\begin{aligned}
X_{i j}^{k} & =\frac{Y_{i}^{k} E_{j}^{k}}{Y^{k}}\left(\frac{t_{i j}^{k}}{\prod_{i}^{k} P_{j}^{k}}\right)^{-\theta_{k}}, \\
\left(\Pi_{i}\right)^{-\theta_{k}} & =\sum_{j=1}^{N}\left(\frac{t_{i j}^{k}}{P_{j}^{k}}\right)^{-\theta_{k}} \frac{E_{j}^{k}}{Y^{k}}, \\
\left(P_{j}^{k}\right)^{-\theta_{k}} & =\sum_{i=1}^{N}\left(\frac{t_{i j}^{k}}{\Pi_{i}^{k}}\right)^{-\theta_{k}} \frac{Y_{i}^{k}}{Y^{k}}, \\
w_{i}^{k} & =\left(\frac{Y_{i}^{k}}{Y^{k}}\right)^{-\frac{1}{\theta_{k}}} \frac{\left(T_{i}^{k}\right)^{\frac{1}{\theta_{k}}}}{\gamma^{k} \Pi_{i}^{k}} \\
E_{i}^{k} & =\alpha_{k} \phi_{i} Y_{i}, \\
Y_{i} & =\sum_{k} Y_{i}^{k}=\sum_{k} w_{i}^{k} L_{i}^{k}, \\
Y^{k} & =\sum_{i} Y_{i}^{k}=\sum_{i} w_{i}^{k} L_{i}^{k} .
\end{aligned}
$$

Hence, the system described in Appendix A for the aggregate model readily extends to 
the sectoral level. It also compares directly with the demand-side sectoral gravity system given by Equations (88)-(94), with the only notable change of replacing $1-\sigma_{k}$ by $-\theta_{k}$.

In the aggregate case, we used Equation 105 to solve for wages. However, here we have for each sector $k$ one such condition. In contrast to the aggregate model, we do not only have one total labor supply $L_{i}$, but also have to determine sectoral labor allocations. In order to close the model, we follow Eaton and Kortum (2002) and distinguish two cases: one case where labor is sectoral and international immobile, and one where labor is mobile across sectors but not across countries.

\section{Immobile Labor}

Let us start with the case of immobile labor. This case is close to the assumption of sectoral given endowments made before for our demand-side sectoral model as sectoral labor allocations $L_{i}^{k}$ are exogenous. We can use Equation (101) together with the fact that the value of output in sector $k$ of country $i$ can be written as $Y_{i}^{k}=w_{i}^{k} L_{i}^{k}$ to obtain an expression for $w_{i}^{k}$ :

$$
\frac{w_{i}^{k} L_{i}^{k}}{\sum_{i} w_{i}^{k} L_{i}^{k}}=\frac{T_{i}^{k}\left(w_{i}^{k}\right)^{-\theta_{k}}}{\left(\gamma^{k}\right)^{\theta_{k}}\left(\Pi_{i}^{k}\right)^{\theta_{k}}} .
$$

Next we replace $\Pi_{i}^{k}$ by its definition and $P_{j}^{k}$ by the expression

$$
\begin{aligned}
\left(\left(\gamma^{k}\right)^{-\theta_{k}} \sum_{i=1}^{N} T_{i}^{k}\left(w_{i}^{k} t_{i j}^{k}\right)^{-\theta_{k}}\right)^{-\frac{1}{\theta_{k}}}: & \\
\frac{w_{i}^{k} L_{i}^{k}}{\sum_{i} w_{i}^{k} L_{i}^{k}} & =\frac{T_{i}^{k}\left(w_{i}^{k}\right)^{-\theta_{k}}}{\left(\gamma^{k}\right)^{\theta_{k}}}\left(\sum_{j=1}^{N} \frac{\left(t_{i j}^{k}\right)^{-\theta_{k}}}{\left(\gamma^{k}\right)^{-\theta_{k}} \sum_{i=1}^{N} T_{i}^{k}\left(w_{i}^{k} t_{i j}^{k}\right)^{-\theta_{k}}} \times \frac{\alpha^{k} \phi_{j} \sum_{k} w_{j}^{k} L_{j}^{k}}{\sum_{i} w_{i}^{k} L_{i}^{k}}\right) \\
& =\left(\sum_{j=1}^{N} \frac{T_{i}^{k}\left(w_{i}^{k} t_{i j}^{k}\right)^{-\theta_{k}}}{\sum_{i=1}^{N} T_{i}^{k}\left(w_{i}^{k} t_{i j}^{k}\right)^{-\theta_{k}}} \times \frac{\alpha^{k} \phi_{j} \sum_{k} w_{j}^{k} L_{j}^{k}}{\sum_{i} w_{i}^{k} L_{i}^{k}}\right)
\end{aligned}
$$

These $N \times K$ market-clearing conditions solve for the $N \times K$ sectoral wages $w_{i}^{k}$. Note that this equation resembles Equation (95) from the demand-side. As there, we also have to chose a numeraire for each sector here. The results under this scenario will be identical to the results from the endowment, demand-side model.

\section{Mobile Labor}

Let us now consider the case where labor is perfectly mobile across sectors, implying a common wage across sectors in a country, $w_{i}$, and endogenous sectoral labor allocations $L_{i}^{k}$. Taking the same steps as before, we can again derive Equation (110). As in the case of mobile labor only the total labor endowment in a country is given, the adding up constraint $L_{i}=\sum_{k} L_{i}^{k}$ implies that $K-1$ sectoral labor allocations in each country have to be solved for using (110). For the remaining sector, we can use the equation to solve for wages $w_{i}$. Note that this equation resembles Equation (95) from the demand-side. As there, we also have to chose a numeraire for each sector here. Note, however, that the counterfactual results here 
will differ from those in the endowment setting. 


\section{Appendix C: The Structural Gravity System in Changes}

Our system given by Equations (11)- 15 can also be written in changes using the exact hat algebra (see Dekle, Eaton and Kortum, 2007, 2008). Let baseline and counterfactual values be denoted with a superscript $b$ and $c$, respectively. The change for variable $X$ is defined as $\widehat{X}=X^{C F L} / X^{B L N}$. Let us start with the trade flow equation as given in Equation (11). As this is a multiplicative equation, we merely divide the counterfactual values by the baseline values to obtain the following expression for trade flow changes:

$$
\widehat{X}_{i j}=\frac{\widehat{Y}_{i} \widehat{E}_{j}}{\widehat{Y}}\left(\frac{\widehat{t}_{i j}}{\widehat{\Pi}_{i} \widehat{P}_{j}}\right)^{1-\sigma}
$$

Note that typically $\widehat{t}_{i j}$ defines the counterfactual scenario of interest. For example, if one wants to evaluate the trade and welfare effects of NAFTA, we would set the RTA dummy for the NAFTA countries to zero, defining $t_{i j}^{C F L}$. Hence, $\widehat{t}_{i j}$ is exogenously given.

We next derive expressions for $\widehat{\Pi}_{i}$ and $\widehat{P}_{j}$. We can use Equation 12 to derive an equation for $\widehat{\Pi}_{i}$ :

$$
\left(\Pi_{i}^{B L N}\right)^{1-\sigma} \widehat{\Pi}_{i}^{1-\sigma}=\sum_{j=1}^{N}\left(\frac{t_{i j}^{B L N} \widehat{t}_{i j}}{P_{j}^{B L N} \widehat{P}_{j}}\right)^{1-\sigma} \frac{E_{j}^{B L N} \widehat{E}_{j}}{Y^{B L N} \widehat{Y}},
$$

where we used the fact that $\widehat{X} X^{B L N}=X^{C F L}$.

Similarly, use Equation (13) to describe the change in $P_{j}$ :

$$
\left(P_{j}^{B L N}\right)^{1-\sigma} \widehat{P}_{j}^{1-\sigma}=\sum_{i=1}^{N}\left(\frac{t_{i j}^{B L N} \widehat{t}_{i j}}{\Pi_{i}^{B L N} \widehat{\Pi}_{i}}\right)^{1-\sigma} \frac{Y_{i}^{B L N} \widehat{Y}_{i}}{Y^{B L N} \widehat{Y}}
$$

Use Equation (14) to derive an expression for the changes of prices:

$$
\widehat{p}_{i}=\frac{\left(\widehat{Y}_{i} / \widehat{Y}\right)^{\frac{1}{1-\sigma}}}{\widehat{\Pi}_{i}}
$$

where,

$$
\widehat{Y}=\frac{\sum_{i=1}^{N} Y_{i}^{C F L}}{\sum_{i=1}^{N} Y_{i}^{B L N}} \Rightarrow Y^{B L N} \widehat{Y}=\sum_{i=1}^{N} Y_{i}^{B L N} \widehat{Y}_{i} .
$$

As endowments stay constant, we can use Equation to to express the change in total nominal output for country $i$ as:

$$
\widehat{Y}_{i}=\widehat{p}_{i}=\frac{\left(\widehat{Y}_{i} / \widehat{Y}\right)^{\frac{1}{1-\sigma}}}{\widehat{\Pi}_{i}}
$$

Note further that total nominal output changes and total spending changes are linked as follows, $\widehat{E}_{i}=\widehat{\phi}_{i} \widehat{Y}_{i}$, where $\widehat{\phi}_{i}$ are the exogenous changes in the trade imbalances of country $i$. 
Hence, the structural gravity system in changes is given by the following set of equations:

$$
\begin{aligned}
\widehat{X}_{i j} & =\frac{\widehat{Y}_{i} \widehat{E}_{j}}{\widehat{Y}}\left(\frac{\widehat{t}_{i j}}{\widehat{\Pi}_{i} \widehat{P}_{j}}\right)^{1-\sigma}, \\
\left(\Pi_{i}^{B L N}\right)^{1-\sigma} \widehat{\Pi}_{i}^{1-\sigma} & =\sum_{j=1}^{N}\left(\frac{t_{i j}^{B L N} \widehat{t}_{i j}}{P_{j}^{B L N} \widehat{P}_{j}}\right)^{1-\sigma} \frac{E_{j}^{B L N} \widehat{E}_{j}}{Y^{B L N} \widehat{Y}}, \\
\left(P_{j}^{B L N}\right)^{1-\sigma} \widehat{P}_{j}^{1-\sigma} & =\sum_{i=1}^{N}\left(\frac{t_{i j}^{B L N} \widehat{t}_{i j}}{\Pi_{i}^{B L N} \widehat{\Pi}_{i}}\right)^{1-\sigma} \frac{Y_{i}^{B L N} \widehat{Y}_{i}}{Y^{B L N} \widehat{Y}}, \\
\widehat{p}_{i} & =\frac{\left(\widehat{Y}_{i} / \widehat{Y}^{\frac{1}{1-\sigma}}\right.}{\widehat{\Pi}_{i}}, \\
Y^{B L N} \widehat{Y}^{1-} & =\sum_{i=1}^{N} Y_{i}^{B L N} \widehat{Y}_{i} \\
\widehat{Y}_{i} & =\widehat{p}_{i} \\
\widehat{E}_{i} & =\widehat{\phi}_{i} \widehat{Y}_{i} .
\end{aligned}
$$

This system needs only data on total nominal output $\left(Y_{i}^{B L N}\right)$, total spending $\left(E_{i}^{B L N}\right)$ and trade costs $\left(t_{i j}^{B L N}\right)$ in the baseline, and a value for the elasticity of substitution $\sigma$. Specifically, information about $\beta_{i}$ is not needed. With given nominal output, expenditures, and trade costs, we can solve for the Baseline $\Pi_{i}^{B L N}$ 's and $P_{j}^{B L N}$ 's. Hence, we are left with seven equations in the seven unknown changes $\widehat{X}_{i j}, \widehat{\Pi}_{i}, \widehat{P}_{j}, \widehat{p}_{i}, \widehat{Y}, \widehat{Y}_{i}$, and $\widehat{E}_{i}$. 